\author{
Universidade de São Paulo \\ Escola de Engenharia de São Carlos \\ Departamento de Engenharia Elétrica
}

Programa de Pós-Graduação em Engenharia Elétrica

Paulo Victor Lameira de Souza

\title{
Um método grafo-algébrico para projeto de ilhamento controlado em Sistemas Elétricos de Potência
}





\title{
Paulo Victor Lameira de Souza
}

\section{Um método grafo-algébrico para projeto de ilhamento controlado em Sistemas Elétricos de Potência}

\author{
Dissertação de Mestrado $^{1}$ apresentada ao \\ Programa de Engenharia Elétrica da Escola \\ de Engenharia de São Carlos como parte \\ dos requisitos para a obtenção do título de \\ Mestre em Ciências.
}

Área de concentração: Sistemas Elétricos de Potência

ORIENTADOR: Prof. Dr. Luís Fernando Costa Alberto Alberto

São Carlos

2014

${ }^{1}$ Trata-se da versão corrigida da dissertação. A versão original se encontra disponível na EESC/USP que aloja o Programa de Pós-Graduação de Engenharia Elétrica. 
AUTORIZO A REPRODUÇÃO TOTAL OU PARCIAL DESTE TRABALHO, POR QUALQUER MEIO CONVENCIONAL OU ELETRÔNICO, PARA FINS DE ESTUDO E PESQUISA, DESDE QUE CITADA A FONTE.

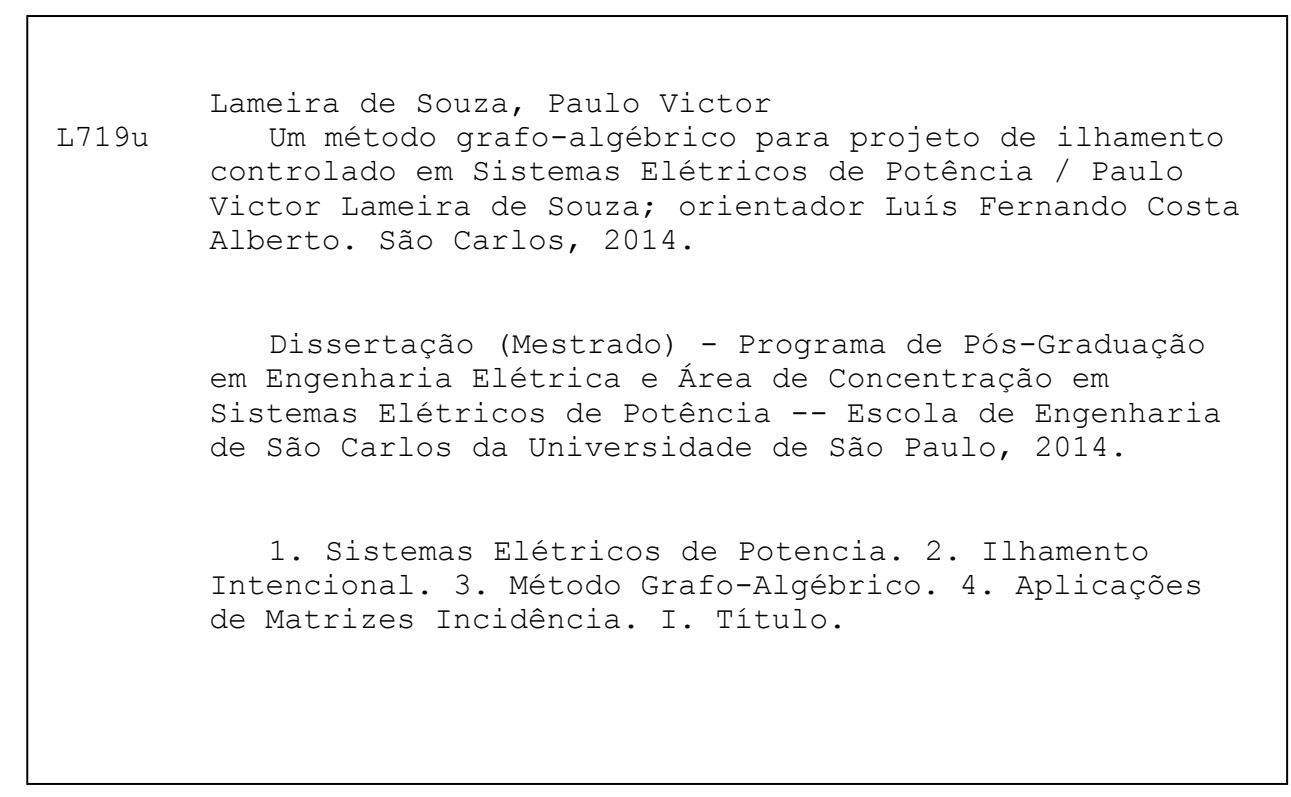




\section{FOLHA DE JULGAMENTO}

Candidato: Engenheiro PAULO VICTOR LAMEIRA DE SOUZA.

Título da dissertação: "Um método grafo-algébrico para projeto de ilhamento controlado em sistemas elétricos de potência".

Data da defesa: 09/05/2014

\section{Comissão Julgadora:}

Resultado:

Prof. Associado Luís Fernando Costa Alberto (Orientador) APROVAD (Escola de Engenharia de São Carlos/EESC)

Prof. Dr. Arturo Suman Bretas

(Universidade Federal do Rio Grande do SUI/UFRGS)

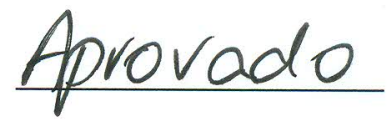

Prof. Associado Alexandre Cláudio Botazzo Delbem (Instituto de Ciências Matemáticas e Computação/ICMC)

Coordenador do Programa de Pós-Graduação em Engenharia Elétrica e Presidente da Comissão de Pós-Graduação:

Prof. Titular Denis Vinicius Coury 


\section{Sumário}

Resumo vii

$\begin{array}{ll}\text { Abstract ix } & \text { ix }\end{array}$

Lista de Figuras $\quad$ xi

Lista de Tabelas $\quad$ xv

Lista de Símbolos $\quad$ xvii

1 Introdução 1

1.1 Sistema Interligadd . . . . . . . . . . . . . . . . . . . . . 1

1.2 lhamento em Sistema Elétrico de Potência . . . . . . . . . . . . . . . . . . 3

1.3 Objetivo do Trabalho . . . . . . . . . . . . . . . . . . . . . . . . . . . 6

1.4 Organização do Trabalho . . . . . . . . . . . . . . . . . . . . . . . . 6

$\begin{array}{llll}2 & \text { Métodos para a Detecção de Ilhamento } & 7\end{array}$

2.1 Introdução . . . . . . . . . . . . . . . . . . . . . . . . . . . . . . . . . . 7

2.2 Coerência de Geradores . . . . . . . . . . . . . . . . . . . . . . . . . . . . . . . . 8

22.1 Coerência Lenta . . . . . . . . . . . . . . . . . . . . 10

2.3 Determinação dos limites físicos das ilhas . . . . . . . . . . . . . . . . . 11

3 Fundamentos Teóricos dos Métodos Grafo-Algébricos 15

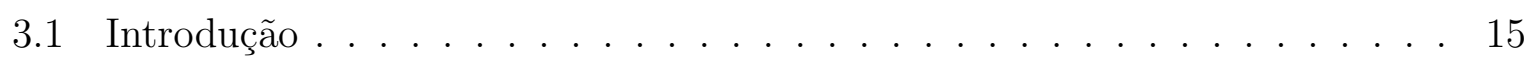

32 Teoria de Grafos . . . . . . . . . . . . . . . . . . . . 15

4 Método Grafo-Algébrico para a Detecção e Identificação de Ilhamento $\begin{array}{ll}\text { Não Intencional } & 29\end{array}$

4.1 Introduçäo . . . . . . . . . . . . . . . . . . . . . . . . . . . . . . . . . . . . . . . . 29 
iv

4.2 Método para a detecção de ilhamento em um SEP . . . . . . . . . . . . . . 30

4.3 Método para identificação ilhas em um SEP . . . . . . . . . . . . . . . . 37

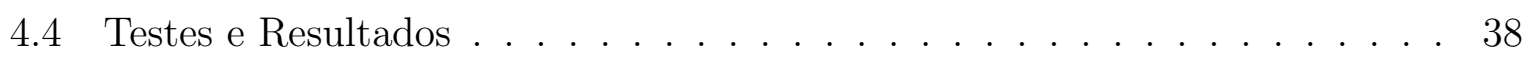

5 Método Grafo-Algébrico para o Planejamento Otimo de Ilhamento In$\begin{array}{ll}\text { tencionall } & 51\end{array}$

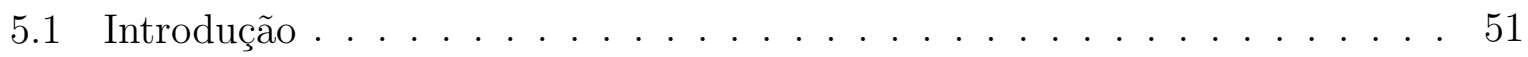

5.2 Método para o projeto de ilhamento intencional . . . . . . . . . . . . 52

$5.2 .1 \quad$ Etapa de Adequação . . . . . . . . . . . . . . . . . . . . . 53

5.2 .2 Etapa Iterativa $\ldots \ldots \ldots$. . . . . . . . . . . . . . . . 57

5.2 .3 Segunda Etapa $\ldots \ldots \ldots$. . . . . . . . . . . . . . . . . . 62

5.2 .4 Terceira Etapa $\ldots \ldots \ldots$. . . . . . . . . . . . . . . . 65

5.2 .5 Aplicação para o mínimo número prático de interrupções . . . . . . 65

5.2 .6 Aplicação para o mínimo fluxo interrompido . . . . . . . . . . . . . 67

5.3 Testes e Discussöes $\ldots \ldots \ldots$. . . . . . . . . . . . . . . . . . . 68

5.3.1 Mínimo número prático de interrupcões de sistema de 9 barras . . . 68

5.3 .2 Thamento controlado de uma sistema de 16 barras e 18 ramos . . . 70

5.3 .3 Whamento controlado sobre o Sistema Sul Reduzido . . . . . . . . . 73

6 Conclusões e Perspectivas Futuras $\quad 87$

6.1 Introduçáo . . . . . . . . . . . . . . . . . . . . . . . . . . . . . 87

62 Conclusoes Parciais . . . . . . . . . . . . . . . . . . . . . . . 87

6.3 Perspectivas Futuras $\ldots \ldots \ldots$

\begin{tabular}{lr}
\hline Referências Bibliográficas & 89
\end{tabular}

$\begin{array}{ll}A \text { Dados dos Sistemas-Teste } & 95\end{array}$ 
Dedicatória

Dedico aos meus pais, Paulo Cesar e Mirly, as meus irmãos Clayton, Fernanda e Henriqueta, a minha sobrinha Julia. 
Agradeço primeiramente a Deus por ter me iluminado e me dado força durante todo o meu caminho.

Ao Professor Luís Fernando Costa Alberto por sua orientação.

Ao Breno, Fabão, Fernando(Goiás), Renan e Rodolpho pelo privilegio de ter morado com essas figuras.

Ao Edson Aparecido Rozas Theodoro por seus conselhos, pela amizade e incentivo. À todos os colegas do Laboratório de Análise Computacional de Sistemas Elétricos de Potência (LACOSEP).

À todos os professores que permitiram um grande salto em conhecimento.

À Escola de Engenharia de São Carlos da Universidade de São Paulo pela oportunidade de realizar o curso de mestrado.

À Coordenação de Aperfeiçoamento de Pessoal de Nível Superior (CAPES), pelo incentivo Financeiro. 


\section{Resumo}

SOUZA, P. V. L. Um método grafo-algébrico para projeto de ilhamento controlado em Sistemas Elétricos de Potência. Dissertação (Mestrado), Escola de Engenharia de São Carlos, Universidade de São Paulo, São Carlos, 2014.

Neste trabalho, um novo método grafo-algébrico para o projeto de ilhamento intencional é proposto. O ilhamento intencional é um dos últimos recursos utilizados pelos operadores para evitar um colapso total do sistema elétrico. Ele objetiva dividir um sistema elétrico em dois ou mais subsistemas estáveis quando não é possível garantir a estabilidade do sistema interligado.

O método desenvolvido é uma extensão de um método grafo-algébrico, baseado na fatoração da matriz incidência ramo-nó e que foi desenvolvido para a identificação de ilhamento não intencional, para o problema de projeto de ilhamento intencional. A aplicação da fatoração da matriz incidência ramo-nó no problema de projeto de ilhamento é contribuição inédita deste trabalho. O método proposto identifica os conjuntos de corte, compostos por linhas de transmissão/transformadores (ramos), aptos a dividir um sistema elétrico de potência conexo em dois ou mais subsistemas (ilhas), sob a condição de um número mínimo, previamente estabelecido, de ramos interrompidos ou uma interrupção mínima de fluxo de potência ativa.

A identificação dos conjuntos de cortes é realizada por meio de uma fatoração ordenada da matriz incidência nó-ramo e por um processo de regularização de cortes. O método foi testado com resultados promissores em alguns sistemas elétricos de pequeno e médio porte. Apresentou boas características que sugerem que o mesmo seja adequado para aplicações em tempo real. O método fornece a informação das barras que formam cada ilha, adaptase facilmente a mudanças na topologia e pode ser facilmente implementado com rotinas já existentes nos programas de computador comumente utilizados para análise de sistemas elétricos de potência. Trabalhos futuros são necessários para testar a metodologia em sistemas de maior porte, para avaliar a eficiência computacional do método e comparar com a eficiência de outros métodos relatados na literatura.

Sistemas Elétricos de Potencia, Ilhamento Intencional, Método Grafo-Algébrico, Aplicações da Matriz de Incidência.. 


\section{Abstract}

SOUZA, P. V. L. A graph-algebraic method for the design of controlled islanding in Electric Power Systems. Dissertation (M. S. Degree) - Escola de Engenharia de São Carlos, Universidade de São Paulo, São Carlos, 2014.

In this work, a new graph-algebraic method for the design of intentional islanding is proposed. Intentional islanding is one of the last resources used by the Power Electrical System Operators to avoid a total collapse of the electrical system. It aims to divide a power system into two or more stable subsystems when it is not possible to guarantee the stability of the interconnected system.

The developed method is an extension of a graph-algebraic method, which is based on a factorization of the branch-node incidence matrix and which was developed to identify unintended islanding, to the problem of intended. The unprecedented contribution of this work is the application of the factorization of the incidence branch-node matrix in the design of islanding control. The proposed method identifies the cutsets, composed of transmission lines / transformers (branches), able to divide a connected Electrical Power System in two or more subsystems (islands), under the constraint of a minimum number of interrupted branches or minimal interruption of power flow.

The identification of cutsets are made through an ordered factorization of the incidence branch node matrix and a regularization process of cutsets. The method has been tested with promising results in some electrical systems of small and medium size. It has shown good characteristics which suggests that it is suitable for real-time applications. The method automatically provides the set of buses that form each island, it easily adapts to changes in topology and can be easily implemented with routines that are already developed in existing computer programs commonly used for analysis of electric power systems. Further work is needed to test the methodology in larger systems to evaluate the computational efficiency of the method and compare with the efficiency of other methods reported in the literature.

Electric Power Systems, Intentional Islanding, Algebraic-Graph Methods, Incidence Matrices.. 



\section{Lista de Figuras}

$2.1 \quad$ SEP IEEE 118-bus. Fonte: (PEIRAVI; ILDARABADI, 2009) . . . . . . . . . . . . . . 12

$2.2 \quad$ Grafo equivalente ao SEP IEEE 118-bus. Fonte: (NAJAFI, 2009] $\ldots \ldots \ldots$. . . . . . . 13

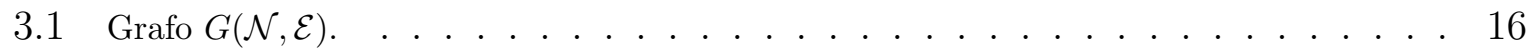

3.2 Representação de um grafo pela matriz incidência $H$. . . . . . . . . . . . . . 17

B.3 Ramo Crítico . . . . . . . . . . . . . . . . . . . 18

3.4 Grafo Induzido $G\left(\overline{\mathcal{N}},\left.\mathcal{E}\right|_{\overline{\mathcal{N}}}\right)$ a partir $\operatorname{de} G(\mathcal{N}, \mathcal{E}) . \ldots \ldots \ldots$

3.5 Exemplo de Corte, Conjunto de Corte e Fronteira. . . . . . . . . . . . . . . . . . . 19

इ.6 Custo do Corte . . . . . . . . . . . . . . . . . . . 20

3.7 Corte não Regular. . . . . . . . . . . . . . . . . . . . . . . . . 20

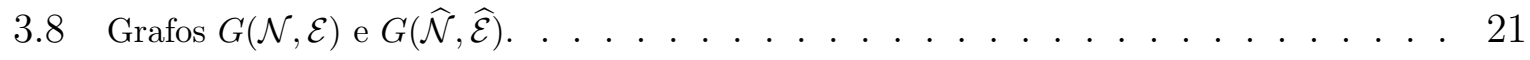

$3.9 \quad$ Grafos $G(\mathcal{N}, \mathcal{E})$ e equivalente agregado $G_{X}(\mathcal{N}=X \cup A, \mathcal{E})$. . . . . . . . . . . . 22

3.10 Grafos $G(\mathcal{N}, \mathcal{E})$ e equivalente agregado $G_{X}(\mathcal{N}=X \cup A, \mathcal{E})$. . . . . . . . . . . . 23

3.11 Agregação de nós pela soma de linhas da matriz nó-ramo $H$. . . . . . . . . . . . 24

4.1 Processo de identificação de nós conexos $\ldots \ldots$. . . . . . . . . . . . . . 37

$4.2 \quad$ Fluxograma do algoritmo de identificação de ilhas. . . . . . . . . . . . . . . . . . 39

$4.3 \quad$ SEP composto de 3 barras e 4 ramos. . . . . . . . . . . . . . . . . . . 40

4.4 SEP composto de 13 barras e 16 ramos. . . . . . . . . . . . . . . . . . . . . . . 40 
xii

4.5 SEP composto de 13 barras e 16 ramos. . . . . . . . . . . . . . . . . . . . . . . . 42

$4.6 \quad$ SEP composto de 13 barras e 16 ramos $\ldots \ldots \ldots$. . . . . . . . . . . . . . . . . . . . 43

4.7 Grafo equivalente ao SEP IEEE 118-bus. Fonte: (NAJAFI, 2009)] . . . . . . . . . . . 44

4.8 Grafo equivalente ao SEP IEEE 118-barra. Fonte: (NAJAFI, 2009) . . . . . . . . . . . 45

5.1 Fluxograma do Algoritmo de determinação de cutsets para o ilhamento controlado. . . 54

5.2 Caso 1 para simplificação $\ldots \ldots \ldots \ldots$. . . . . . . . . . . . . 55

5.3 Caso 2 para simplificação $\ldots \ldots \ldots$. . . . . . . . . . . . . . 56

5.4 Caso 3 para simplificação. $\ldots \ldots \ldots \ldots$. . . . . . . . . . . . . . 57

5.5 Fatoração Triangular Inferior Ordenada $\ldots \ldots \ldots$. . . . . . . . . . . . . . . . . . 59

5.6 Sistema de potência 4 -barras $/ 4$-linhas.$\ldots \ldots$. . . . . . . . . . 60

5.7 Sistema de potência 7 -barras $/ 8$-linhas $\ldots \ldots \ldots$. . . . . . . . . 63

5.8 Corte $\left\{L_{2}, L_{4}, L_{5}, L_{7}\right\}$ aplicado ao Sistema de potência 7-barras $/ 8$-linhas. . . . . . . 65

5.9 Sistema de potência com 9 barras $/ 10$ linhas. . . . . . . . . . . . . 68

5.10 Sistema de potência com 16 barras e 19 linhas $\ldots$. . . . . . . . . . . . 70

5.11 Sistema de potência com 16 barras e 19 linhas após a primeira simplificação. . . . . . 71

5.12 Agregação de nós geradores Sistema de potência com 16 barras e 19 linhas. . . . . . . 72

5.13 Sistema de potência com 16 barras e 19 linhas simplificada e com nós agregados. . . . . 72

5.14 Sistema Elétrico Brasileiro Sul Reduzido. Fonte: (THEODORO et al., 2012) . . . . 74

5.15 Variação do angulo e velocidade dos rotores. . . . . . . . . . . . . . . . . . . 75

5.16 Variação do angulo e velocidade dos rotores. . . . . . . . . . . . . . . . . . 76

5.17 variação do angulo e velocidade dos rotores. . . . . . . . . . . . . . . . . . . . . 78

5.18 variação do angulo e velocidade dos rotores . . . . . . . . . . . . . . . . . . . . . . 79

5.19 Variação do angulo e velocidade dos rotores . . . . . . . . . . . . . . . . . . 80

5.20 variação do angulo e velocidade dos rotores . . . . . . . . . . . . . . . . . . . . 80 
5.21 Variação do angulo e velocidade dos rotores. . . . . . . . . . . . . . . . . . . . . . 82

5.22 Variação do angulo e velocidade dos rotores. . . . . . . . . . . . . . . . . . 82

5.23 Variação do angulo e velocidade dos rotores. . . . . . . . . . . . . . . . . . 83

5.24 Variação do angulo e velocidade dos rotores. . . . . . . . . . . . . . . . . . 84 


\section{Lista de Tabelas}

4.1 Ramos críticos do sistema ieee 118 barras e analise de ilhamento . . . . . . . . . . . 48

4.2 Ilhas formadas no SEP IEEE 118 barra pela retirado das ligações entre os barramentos |barra33 - barra37|, |barra19 - barra34|, |barra30 - barra38|, barra24 - barra70|,

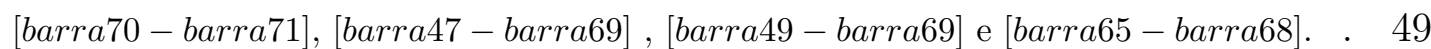

$5.1 \quad$ Lista de Contingências. . . . . . . . . . . . . . . . . . . . . . . . . . . . 74

r. Dados de barra Pré-Falta f . . . . . . . . . . . . . . . . . . . . . 95

7.2 Dados de Linha . . . . . . . . . . . . . . . . . . . . . . . . . 96 


\title{
Lista de Símbolos
}

\author{
$\mathcal{N} \quad$ Conjunto de nós \\ $\mathcal{E} \quad$ Conjunto de arestas \\ H Matriz Incidência Nó-Ramo \\ $h_{i j} \quad$ Elemento localizado na linha $i$ e coluna $j$ da Matriz Incidência Nó-Ramo \\ $\left.\mathcal{E}\right|_{\mathcal{N}} \quad$ O conjunto de todas as arestas de $\mathcal{E}$ que conectam os nós de $\overline{\mathcal{N}}$ \\ $P=\left\{X, X^{\prime}\right\} \quad$ Partição de um conjunto de nós \\ $C\left(\left\{X, X^{\prime}\right\}\right) \quad$ conjunto de todas as arestas que são incidentes a um nó de $X$ e a um nó \\ de $X^{\prime}$ \\ $J\left(C\left(\left\{X, X^{\prime}\right\}\right)\right) \quad$ Custo do conjunto de corte \\ $\hat{A}=A \backslash\{a\} \quad$ Conjunto $\hat{A}$ contem todos os elementos de $A$, com a exceção do elemento
} a. 


\section{Capítulo 1}

\section{Introdução}

\subsection{Sistema Interligado}

Até a primeira metade do século XX, grande parte da energia elétrica era produzida por meio de geradores de pequeno porte, localizados próximos às cargas, sem que houvesse conexão entre redes. Existiam sistemas e empresas isoladas (ilhados), sendo que a transmissão a longa distância era feita ponto a ponto, ou seja, da usina para o centro de consumo (MONTICELLI, 20(03). Com o passar do tempo, estes sistemas, antes desconectados, passaram a se interligar, resultando em uma rede elétrica única, com milhares de quilômetros de extensão. Portanto a geração de energia elétrica passou de distribuída para centralizada.

O processo de interligação do Sistema Elétrico de Potencia (SEP), em conjunto com os avanços tecnológicos, possibilitou que os geradores com maior capacidade de produção de energia fossem desenvolvidos, permitindo a instalação desses em regiões mais viáveis, tanto do ponto de vista econômico quanto operacional. Consequentemente, a geração não era mais necessariamente próxima das cargas, uma vez que apesar de distante geograficamente, a energia produzida poderia ser transmitida aos consumidores por meio do sistema interligado.

Assim a interligação dos SEPs resultou em diversas vantagens econômicas e operacionais, as quais estão presentes até hoje. Entre esses benefícios, tem-se a cooperação 
mútua entre os sistemas para o suprimento de energia, bem como o aumento da reserva energética do sistema como um todo após a interligação (KUNDUR, 1994).

No Brasil, por suas proporções continentais, é possível que, enquanto o Nordeste enfrente períodos chuvosos, o Sul e o Sudeste passem por fortes secas. Portanto, para aproveitar essa característica do país, o governo optou pelo Sistema Interligado Nacional, em que usinas hidrelétricas e termoelétricas são conectadas a grandes redes de transmissão (MONTTCELLI, 2003). O sistema interligado traz economia para o setor como um todo e permite que a matriz energética brasileira seja principalmente hidráulica. Além disso, locais que não são atendidos por hidrelétricas podem receber a energia mais limpa e mais barata de outras localidades. Assim, o acionamento de termoelétricas fica restrito a períodos em que essa energia fica mais barata ou que há risco de faltar água nos reservatórios das hidrelétricas.

Por outro lado, a interligação permite que panes no sistema se espalhem rapidamente de uma localidade afetando uma grande porção do Sistema Elétrico de Potência(SEP). Esse efeito é conhecido como "efeito dominó" ou "falhas em cascata" e consiste em uma sequência de eventos, tais como a abertura de linhas, que ocorrem devido a distúrbios na rede e da função local de relés de proteção (AGHAMOHAMMADI; SHAHMOHAMMADI, [2(12).

Além disso, pelo tamanho físico do SEP interligado, o modelo de um sistema de energia apresenta alta complexidade dado o número de variáveis necessárias para a sua representação adequada. Mesmo para estudos mais simples, considerando-se operações em regime estacionário, podem ser necessárias milhares de equações algébricas para a sua modelagem. Então, temos as seguintes desvantagens do sistema interligado:

- Maior complexidade de operação e planejamento;

- Problemas locais podem se transformar em problemas globais, como por exemplo, problemas de estabilidade e blecaute;

- Maiores níveis de corrente de curto-circuito

Portanto no sistema interligado, observa-se a globalização de problemas locais, isto é, transformação de um problema local em um problema geral. 
De acordo com (BALU et al, [1992), um SEP nunca será absolutamente seguro, ou seja, livre de riscos de interrupção do fornecimentos de energia. Na prática, segurança passou a significar a capacidade de um sistema suportar, sem consequências graves, qualquer perturbação presente em uma lista pré-selecionada de prováveis distúrbios ("contingências"). Desta forma, segurança torna-se um rótulo, baseado num procedimento de classificação. Mais apropriadamente, pode-se pensar em segurança como o nível de risco de um sistema continuar operando normalmente, em um instante qualquer.

De uma perspectiva de controle, o objetivo da operação do sistema de potência é manter o sistema elétrico operando, sem sobrecargas de equipamentos, e atendendo a todos os consumidores em qualquer condição de operação. Para tal objetivo, é necessário que os níveis de tensão, frequência, fluxo de potência nas interligações, carregamento de linhas e equipamentos, sejam mantidos dentro de faixas, ou limites de segurança, previamente estabelecidas. A partir desta perspectiva, a segurança pode ser definida como a probabilidade do ponto de operação do sistema permanecer em uma região do espaço de estados viável, dadas as probabilidades de mudanças no sistema (contingências) e seu ambiente (condições meteorológicas, demanda dos consumidores, etc.). Então temos que quanto mais seguro for o SEP, maior será a capacidade desse SEP evitar blecautes.

\subsection{Ilhamento em Sistema Elétrico de Potência}

A demanda por energia elétrica vem crescendo a um ritmo mais acelerado que a capacidade do Sistema Elétrico de Potência de suprir essa demanda. Isto tem levado os sistemas interligados de energia a operarem muito próximo aos seus limites de operação de segurança, o que os torna mais vulneráveis a qualquer perturbação.

Em 14 de agosto de 2003, o SEP norte americano sofreu um Blackout em consequência de oscilações assíncronas no sistema e de erros na atuação de reles. Quando oscilações assíncronas ocorrem por um longo período, é provável que o sistema irá experimentar abertura em cascata de geradores, ocasionando desequilíbrio entre geração e carga e em seguida um blecaute. Para esses casos, se o sistema sofresse um processo de ilhamento controlado, a queda do sistema poderia ser evitada (LIU; LIU, 2006). 
Outros estudos históricos a cerca de blecautes (ARCHER; DAVIES, 20102), ([TAYLOR; ERICKSON, 1997), (THADEN, 1999) e (AHMED et al., 2003) apontam que a maioria deles surgiu como fruto de operações incorretas de relés locais, provocando o surgimentos de ilhas com excessivo desequilíbrio de potência. Apontam também que se o processo de ilhamento controlado fosse executado a tempo, muitos blecautes teriam sido evitados.

O processo de ilhamento no SEP é definido como a cisão de um sistema interligado, formando subsistemas disjuntos, podendo ser um ilhamento intencional ou não intencional.O ilhamento não intencional é divisão passiva de um SEP interligado em $n$ partições. No SEP, um grande distúrbio pode desencadear a perda de sincronismo entre os grupos de geradores. Essa perda de sincronismo pode desencadear operações errôneas de disjuntores no sistema de transmissão, o que resulta em um ilhamento não intencional.

Frequentemente o ilhamento não intencional produz ilhas eletricamente instáveis, ou seja, com desequilíbrio entre a geração e a carga da ilha gerada, o que pode levar ao colapso do SEP (por exemplo, algumas ilhas são compostas principalmente por geradores e, outras principalmente por cargas, portanto o desligamento da maior parte do SEP é quase inevitável).

Já o ilhamento intencional é uma ação corretiva, frente a um grande distúrbio na rede, quando a integridade do SEP é ameaçada (YOU; VITTAL; WANG, 20104), (SUN; ZHENG; LU, [2(0):3).Essa ação consiste em particionar a rede elétrica interligada em subsistemas menores (ilhas) estáveis pelo desligamento de linhas adequadamente selecionadas. O ilhamento intencional pode evitar um blecaute e manter o suprimento de energia, embora a rede de energia seja separada em ilhas assíncronas.

O processo de ilhamento intencional do SEP é considerada uma ação corretiva final contra um perturbação grave. Caso o SEP não seja reparado a tempo, poderão ocorrer falhas catastróficas no sistema (YOU; VITTAL; WANG, 20104).

Se a rede elétrica apresenta grave instabilidade e se o sistema de controle emergencial falha na tentativa de restabelecer a normalidade do sistema, uma estratégia de ilhamento poderá ser executada a fim de dividir a rede elétrica interligada em várias ilhas estáveis, ao desconectar linhas de transmissão selecionados. A execução de um ilhamento intencional eficiente, que satisfaça todas as restrições dinâmicas e atinja a estabilidade nas ilhas 
geradas é uma tarefa desafiadora. É necessário um grande esforço para determinar uma estratégia de divisão com as seguintes características: velocidade de execução e ação adequada para cada cenário.

A primeira característica está relacionada com o curto período de tempo disponível para a aplicação do ilhamento em tempo real sem que o ponto de operação do SEP fique muito distante do ponto de operação adequado e a segunda característica é necessária para garantir a operação estável das ilhas geradas (WANG; VIT"TAL, 2004).

De acordo com (AGHAMOHAMMADI; SHAHMOHAMMADI, 2012), na aplicação da estratégia de ilhamento controlado, três tarefas devem ser realizadas sequencialmente.

1. Reconhecer quando a aplicação do ilhamento intencional é inevitável para manter a integridade de rede, caso contrário o sistema será separado em ilhas descontroladas.

2. Identificar as ilhas adequadas para o ilhamento intencional da rede, de tal forma que cada ilha seja capaz de preservar o seu equilíbrio entre geração e carga, e as ilhas sejam estáveis.

3. Implementar o ilhamento controlado, de modo que não haja qualquer consequência dinâmica e transitória, de modo a garantir a coerência entre geradores interligados, evitando grande oscilação e instabilidade nas ilhas.

Neste trabalho, uma contribuição na segunda etapa do processo de projeto de ilhamento intencional é apresentada. Um método grafo-algébrico para a determinação de um conjunto de corte minimal prático para o ilhamento intencional é proposto. Este método é baseado na fatoração triangular inferior ordenada da matriz incidência nó-ramo de maneira a identificar os conjuntos de corte (linhas / equipamentos de transmissão) através de combinações lineares das linhas da matriz incidência nó-ramo. As principais características deste método são: (i) simples implementação, (ii) velocidade de computação e (iii) simples identificação dos conjuntos de corte. 


\subsection{Objetivo do Trabalho}

O presente trabalho tem por objetivo estudar um método grafo-algébrico para analise de ilhamento não intencional. Em particular, investiga-se a aplicação do mesmo, na segunda etapa do projeto de ilhamento intencional, ou seja, na identificação dos conjuntos de corte (Linhas / equipamentos de transmissão) a serem desligados a fim de gerar ilhas com melhor balanço entre geração e carga. Um método rápido grafo-algébrico para a determinação de um conjunto de corte minimal prático para o ilhamento intencional é proposto, ou seja, um conjunto de corte que traga o menor impacto sobre a rede, seja em número de componentes de transmissão desligados ou na carga desligada.

\subsection{Organização do Trabalho}

Este trabalho está estruturado em 6 capítulos. No capítulo 2, apresenta-se uma revisão bibliográfica crítica sobre os Métodos de Detecção de Ilhamento. No capitulo 3, é feita uma revisão dos conceitos de grafos. No capítulo 4, uma metodologia grafo-algébrica para a detecção de ilhamentos não intencional é discutida. No capítulo 5, uma metodologia grafoalgébrica para o planejamento ótimo de ilhamento intencional é discutida. No capítulo 6, são apresentados conclusões e perspectivas futuras de pesquisa. 


\section{Capítulo 2}

\section{Métodos para a Detecção de}

\section{Ilhamento}

\subsection{Introdução}

O objetivo deste capítulo é avaliar as principais vantagens e desvantagens das diferentes metodologias aplicadas ao ilhamento intencional encontradas na literatura.

Dentre os métodos existentes para a determinação de ilhamentos, a maioria deles é realizada em duas etapas. Na primeira etapa, técnicas de agrupamento de geradores e/ou barras são utilizadas. Nesta etapa, subconjuntos de barras a serem mantidas em uma mesma ilha são determinadas. Usualmente análises de coerência lenta (YOU; VIT"TAL; WANG, 20104), (WANG; VIT"TAD, 20104), (VIT"TAL; HEYD'T, 200.9) são empregadas para determinação destes conjuntos.

A segunda etapa do projeto de ilhamento intencional consiste em determinar, o conjunto de equipamentos a serem eliminados a fim de particionar a rede, ou seja, os limites físicos de cada ilha, ou fronteira. Essa tarefa tem como entrada os subconjuntos de barras que devem estar em uma mesma partição, como determinado na primeira etapa. Usualmente, a teoria de grafo é empregada nesta etapa e o problema de ilhamento é modelado como um problema de otimização combinatorial, no qual se procura por cortes minimais, cujo objetivo pode ser minimizar o número de linhas a serem desconectadas, minimizar 
o fluxo de potência a ser interrompido e portanto minimizar o impacto na rede (WANG: VITTAD, 20(04), minimizar o número de transações do mercado de energia que são interrompidas com o ilhamento (VIT'TAL; HEYDT, 2009) ou ainda minimizar o corte de cargas em cada área.

\subsection{Coerência de Geradores}

Na ocorrência de uma contingencia sobre um SEP multi-máquinas, este é dito transitoriamente estável quando a diferença das velocidades e ângulos de fase de todas as suas máquinas permanecem limitadas indefinidamente após a eliminação de um defeito na rede. Caso isso não ocorra, esse sistema será reconhecido como transitoriamente instável. Durante a ocorrência de perturbações em sistemas multi-máquinas é possível que algumas máquinas apresentem respostas semelhantes de modo a oscilar em conjunto, formando grupos de geradores coerentes.

Um par de geradores $(i, j)$ é dito coerente se satisfaz a seguinte condição:

$$
\left\|\theta_{i}(t)-\theta_{j}(t)\right\| \leq L
$$

para todo $t>t_{o}$. Onde $\theta_{i}(t)$ e $\theta_{j}(t)$ são os ângulos do rotor dos geradores $i$ e $j$.

Quando o SEP está sujeito a uma perturbação grave de modo que os sistemas de controle convencionais são incapazes de garantir a estabilidade do sistema, a execução de técnicas de proteção de emergência, como ilhamento controlado, tornam-se viáveis, onde a definição dos grupos geradores coerentes é uma parte essencial para a execução dessas técnicas(YYU; VITTAL; WANG, 201(14)). Isso se justifica no fato da estabilidade das ilhas criadas após a falta dependerem da coerência dos geradores no interior das mesmas, o que ressalta a importância de se detectar corretamente os geradores coerentes.

A vantagem do ilhamento intencional baseado em coerência de geradores está na consideração das características dinâmicas do sistema de potência. Em geral, admite-se que os grupos de geradores coerentes são quase independentes do tamanho da perturbação e que os grupos coerentes são independentes do nível de detalhamento dos modelos das 
máquinas (YOU; VITTAL; WANG, 20(1)4). Isso possibilita que modelos simplificados de geradores sejam utilizados e também que um número menor de cenários de estudos sejam requeridos para a análise de um SEP frente a uma contingência, poupando esforço computacional. Em contra partida, os grupos de geradores coerentes podem se modificar com a mudança do ponto de operação e topologia do sistema.

Devido à importância da detecção de coerência para problemas de análise de estabilidade transitória e estudos de controle, várias técnicas foram introduzidas para determinar os grupos de geradores coerentes em sistemas interligados de energia. Algumas dessas técnicas utilizam a análise de modelos dinâmicos lineares do SEP no domínio do tempo (SOUZA; SILVA, 1992), outras são baseadas em grupos de controle (JIN; SIDHU; SUN, 2005), a análise de Fourier também é empregada para a determinação de grupos de geradores coerentes (JONSSON; BEGOVIC; DAALDER, 2004) (HIYAMA, 1981), métodos de subespaço de Krylov (CHANIOTIS; PAI, 2010.5), (A.IAFI, 2010.9) para a redução de modelos de sistemas de potência também são utilizados, métodos que utilizam a fase das oscilações dos geradores para determinar coerência usando a transformação de HilbertHuang (SENROY), 2008) e Coerência Lenta (WANG; VIT"TAD, 2004) (VIT"TAL; HEYDT), [20(1) também foram propostos na literatura.

Nestes métodos, duas hipóteses são feitas:

1. Os grupos coerentes de geradores são independentes do tamanho da perturbação, de modo que o modelo linearizado pode ser usado para determinar a coerência.

2. Os grupos coerentes são independentes do nível de detalhamento utilizado na modelagem da unidade geradora, de modo que um modelo de gerador clássico pode ser considerado.

A primeira hipótese é baseada na observação de que o comportamento de coerência de um gerador não é significativamente alterado com o tempo de compensação de uma falha específica. A segundo hipótese se baseia no fato de que o nível de detalhamento do modelo do gerador não modifica radicalmente as características básicas de rede, tais como os modos de oscilação entre as áreas (YOU; VIT"TAL; WANG, 2004). 


\subsubsection{Coerência Lenta}

A coerência lenta é uma aplicação do método "two-time-scale" em Sistemas de Potência. O método assume que as variáveis de estado de um sistema de $n$-ésima ordem podem ser divididas em $r$ estados lentos $y$, e $(n-r)$ estados rápidos $z$, no qual os $r$ estados mais lentos são associados com os $r$ grupos de geradores coerentes. A determinação dos grupos coerentes é possível usando a eliminação Gaussiana sobre a matriz de autovalores do sistema, após a seleção dos $r$ modos mais lentos. O método "two-time-scale"pode ser aplicado em modelos linearizados e não linearizados.

Em ( linearizados, a existência de acoplamentos fracos entre os $r$ grupos de geradores formados. Esses fracos acoplamentos justificam a análise de ilhamento baseada em coerência lenta. A coerência lenta é uma evidência física de fraco acoplamento na rede. O modelo eletro-mecânico linearizado dos geradores é suficiente para a determinação dos grupo de geradores coerentes (YOU; VITTAL; WANG, 2004).

(YOU; VIT"TAL; WANG, 2004) afirma que as dinâmicas rápidas se propagam muito rapidamente dentro de cada área coerente, pelas ligações fortes entre os geradores. Usualmente, estas dinâmicas são estáveis e são rapidamente amortecidas dentro de cada área. No entanto, as dinâmicas lentas são percebidas como oscilações entre grupos coerentes de geradores.

Em muitos sistemas de grande escala, sempre há a existência de geradores que possuem forte interação, ao mesmo tempo que existem grupos com pouca interação entre si. As dinâmicas lentas, embora possuam origem em ligações mais fracas entre grupos de geradores, podem provocar flutuações excessivas de fluxo de potência entre área e em um curto intervalo de tempo podes levar um sistema elétrico de potência ao colapso. Quando uma grande perturbação acontece, em algumas situações, é imperativo que as conexões fracas sejam desligadas antes que interações lentas se tornem significativas e conduzam o sistema a um colapso.

Os métodos de agrupamento de geradores baseados em coerência lenta possuem as seguintes vantagens: 
1. Coerência lenta entre os grupos de geradores não varia significativamente com a mudança da condição inicial e da perturbação.

2. As ligações fracas sobre duas escalas de tempo formam uma inerente descrição para as caracterizar as oscilações em sistemas de potência de grande porte: As oscilações rápidas dentro de um grupo de máquinas e as oscilações lentas entre os grupos via linhas de interligação fracas.

3. O método de coerência lenta também preserva as características do agrupamento baseado em coerência. É independente do tamanho da perturbação e do detalhamento do modelo do gerador.

\subsection{Determinação dos limites físicos das ilhas}

Após a definição dos geradores coerentes, é iniciada a etapa de determinação de uma estratégia de ilhamento, que pode ser definida como o conjunto de linhas de transmissão a serem retiradas de operação para a formação das ilhas.

Temos que cada grupo de geradores deve operar em ilhas distintas. Quando um sistema de potência é particionado em vários subsistemas menores (ilhas), um pequeno desequilíbrio entre a carga e a geração pode causar uma grande variação de frequência e dificultar a restauração do sistema ([NA.JAF], [2001). Portanto, é necessário que o desequilíbrio de potência dentro das ilhas seja minimizado, para que os subsistemas gerados sejam estáveis. Alem disso, é importante que todos os equipamentos de transmissão dentro das ilhas estejam operando dentro de seus limites de operação e segurança.

Portanto a estratégia de ilhamento deve obedecer os seguintes critérios:

- Sincronização de Geradores (SG): Os grupos de geradores assíncronos devem estar em ilhas distintas.

- Equilíbrio entre Geração e Consumo (EGC): Em cada ilha, a geração de energia elétrica deve ser igual ao consumo. 
- Limites de Transmissão (LT): Os limites de capacidade das linhas de transmissão e outros equipamento devem ser respeitados.

Para a determinação da estratégia de ilhamento, muito autores empregam a teoria de grafo nesta etapa, pelo fato do SEP poder ser modelado como um grafo. Portanto, o ilhamento pode ser tratado como um problema de enumeração das arestas que podem desconectar conjuntos de nós, gerando grafos desconexos a partir de um grafo conexo. Esse é um dos problemas mais fundamentais da teoria de grafos. Na figura [2.] e [2.2] são mostrados o SEP IEEE 118-bus e seu grafo equivalente.

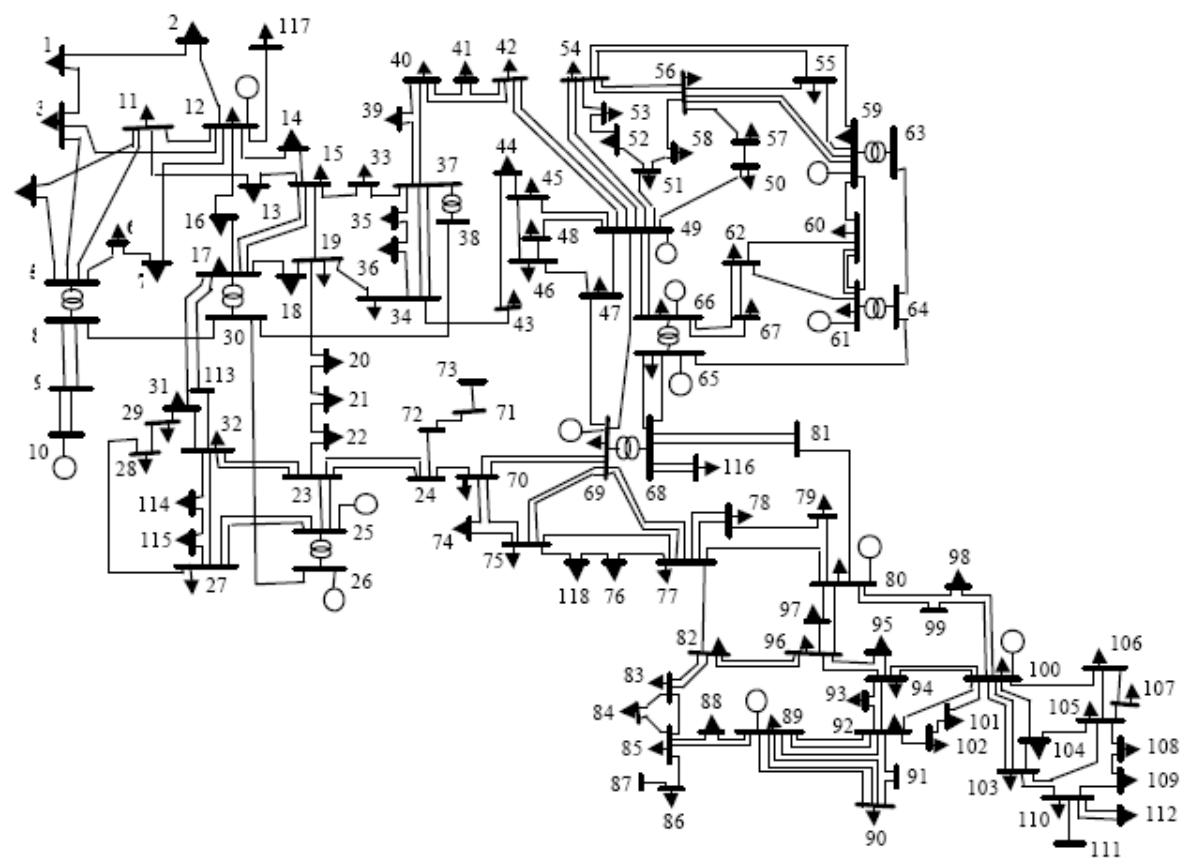

Figura 2.1: SEP IEEE 118-bus. Fonte: (PEIRAVI; ILDARABADI, 20109)

A identificação de cortes no processo de ilhamento pode ser tratada como um problema de otimização combinatorial, no qual se procura por cortes minimais, cujos objetivos podem ser:

- Minimizar o número de linhas a serem desconectadas;

- Minimizar o fluxo de potência a ser interrompido e o impacto sobre a rede (WANG: VIT"TAL, 2004); 


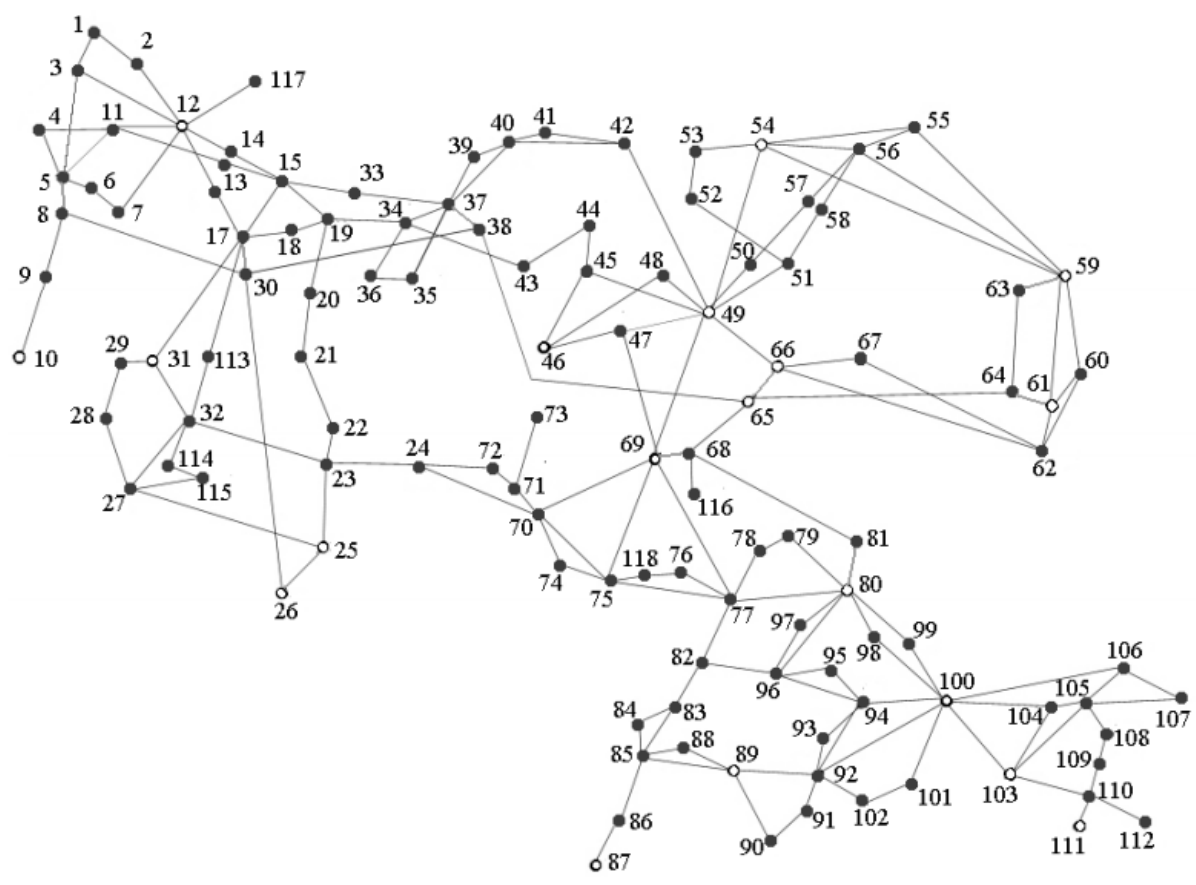

Figura 2.2: Grafo equivalente ao SEP IEEE 118-bus. Fonte: ([NA.IAFI, 2000.9)

- Reduzir o número de transações do mercado de energia que são interrompidas com o ilhamento (VIT"TAL; HEYDT), 2009);

- Otimizar o despacho de energia nessa operação, a fim de maximizar as áreas atendidas pela rede mesmo após o ilhamento.

Em (ZHAO) et al, 20103), (SUN; ZHENG; LU, 20106) e (SUN; ZHENG; LU, 20105), um algoritmo baseado em Diagrama Ordenado de Decisão Binária (OBDD, do inglês Ordered Binary Decision Diagram) é usado para determinar a estratégia de ilhamento. O OBDD, proposto em (BRYANT, 1986), é uma representação de um grafo por uma expressão booleana. Nesses trabalhos, os autores representam o SEP por meio de um grafo $G(V, E, W)$, de modo que $V=\left\{v_{1}, \ldots, v_{n}\right\}$ é o conjunto de nós, onde $v_{i}$ representa uma barramento do sistema de potência, e $E$ é um conjunto de arestas, de modo que $\left\{e_{i j}\right\}$ representa uma linha de transmissão que conecta os barramentos $i$ e $j$, e $W=\left\{w_{1}, \ldots, W_{n}\right\}$ é o conjunto dos pesos de cada nó, que representa a injeção de potência no nó $i$.

Este método, usado para determinar o cenário de ilhamento mais adequado à rede sobre analise, é constituído por 3 fases. Na Fase 1, é construído um grafo simplificado a 
partir do grafo original; na Fase 2, utiliza-se um algoritmo de busca baseado em OBDD para encontrar todas as estratégias de ilhamento que satisfazem SG e EGC; e na fase 3 o critério LT é verificado calculando-se o fluxo de potência para todas as estratégias de ilhamento encontradas. O OBDD é uma técnica muito eficiente para resolver problemas complicados de álgebra booleana, sendo essa uma vantagem dos métodos baseados nessa técnica (SUN; ZHENG; LU, 2(106).

Em (WANG; VIT"TAL, 2004) e ([NA.TAFT, 200.9) o SEP é modelado como um grafo, com diferentes pesos em cada ramo, portanto, na metodologia apresentada nesses trabalhos, a busca é focada nos ramos. Em (WANG; VITTAL, 20104), afirma-se que a busca focada nas arestas é ineficiente, porque existem mais arestas que nós na rede. Porém, a maioria dos sistemas de potência, a nível de transmissão, é esparso, não existindo muita diferença em termos de números de nós e ramos (WANG; VIT"TAL, 2004).

A vantagem deste método é que o problema de ilhamento pode ser decomposto em dois estágios: No primeiro estágio, encontram-se os conjuntos de corte que desconectam os conjuntos de geradores; no segundo estágio verifica-se o fluxo a ser interrompido para cada conjunto de corte para se obter o conjunto de corte ótimo. Outra vantagem está no fato de que no segundo estágio podem ser aplicados critérios adicionais para formular o procedimento de otimização sobre diferentes condições.

A determinação da estratégia de ilhamento é feita através de algoritmos de busca em Teoria de Grafos, tais como busca em largura(em inglês Breadth-first search - BFS) e busca em profundidade(Depth-first search - DFS). Em (YOU; VIT"TAL; WANG, 20144) são feitas buscas exaustivas por todas as possibilidades de estratégia de ilhamento, utilizado o algoritmo apresentado em (TSAI, [2000).

Algoritmos de pesquisa heurística também são usados para determinar a estratégia de ilhamento. Em (AGHAMOHAMMADI; SHAHMOHAMMADI, 2012) é usado um algoritmo de pesquisa de formigas, que busca e melhor partição, levando-se em conta fatores como: conectividade dos subsistemas criados, estabilidade dinâmica, níveis de tensão e frequência, SG, EGC e LT. Em (LODHA; BHATIA, ए998) é usado um algoritmo de pesquisa TABU para determinar o corte minimal. 


\section{Capítulo 3}

\section{Fundamentos Teóricos dos Métodos Grafo-Algébricos}

\subsection{Introdução}

Nesta capítulo são apresentados os fundamentos teóricos necessários para o desenvolvimento do novo método grafo-algébrico para análise de ilhamento apresentado nos capítulos posteriores desse trabalho.

\subsection{Teoria de Grafos}

É possível representar a topologia de um SEP por meio de grafos, de modo que barramentos são associados aos nós (ou vértices) e os equipamentos de transmissão são associados às arestas (ou ramos) de um grafo. O método apresentado nesse trabalho faz uso desta característica, porém para um entendimento mais claro do desenvolvimento do método proposto, algumas definições sobre teoria de grafo são necessárias.

Definição 3.2.1 (Grafo): Um grafo $G(\mathcal{N}, \mathcal{E})$ é composto pelos conjuntos $\mathcal{N}$ e $\mathcal{E}$, no qual um elemento $n$ do conjunto $\mathcal{N}$ chama-se nó, e um elemento $e=\left(n_{i}, n_{j}\right)$ do conjunto $\mathcal{E}$ chama-se aresta. Na fig (足) é mostrado um grafo com 5 nó e 7 arestas. 


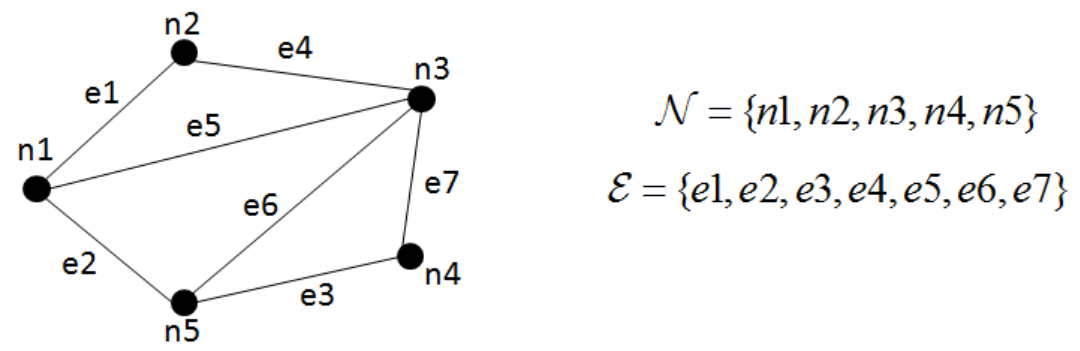

Figura 3.1: Grafo $G(\mathcal{N}, \mathcal{E})$.

Definição 3.2.2 : A pseudo-orientação das arestas que conectam os nós i e $j$ em um grafo é uma escolha arbitrária no qual um dos nós é definido como ponto inicial e o outro como ponto final.

Umas das formas de representação de grafos é através da matriz incidência nó-ramo $H$. Nessa representação, a matriz $H$ armazena a topologia do grafo, onde os elementos não nulos representam a conexão entre os nós e arestas. Embora a representação não orientada possa ser usada em conjunto com a álgebra $\mathbb{Z}_{2}$ (THEOD)()R() et aL, [2012), utilizaremos uma pseudo-orientação para os ramos para poder utilizar a álgebra real nas operações com as matrizes incidência ([THEODORO; BENEDITO; ALBERTO, 20U).

Definição 3.2.3 (Matriz H): Considerando a pseudo-orientação das arestas, a matriz incidência, denotada por $H$, é uma matriz $\boldsymbol{n} \times \boldsymbol{m}$ que descreve a topologia do sistema de potência de acordo com a regra a seguir:

$$
h_{i j}= \begin{cases}1(-1) & \text { se o ramo " } j " \text { é conectado } \\ & \text { ao ramo " } i " \text { no ponto inicial } \\ & (\text { final }) ; \\ 0 & \text { caso contrário. }\end{cases}
$$

onde $i=1, \ldots, \boldsymbol{n}$ e $j=1, \ldots, \boldsymbol{m}$, sendo $\boldsymbol{n}$ e $\boldsymbol{m}$ respectivamente o número de barras e de ramos que compõem o SEP.

Na fig (3.2) é mostrado um exemplo da representação de um grafo pela matriz incidência $H$. 


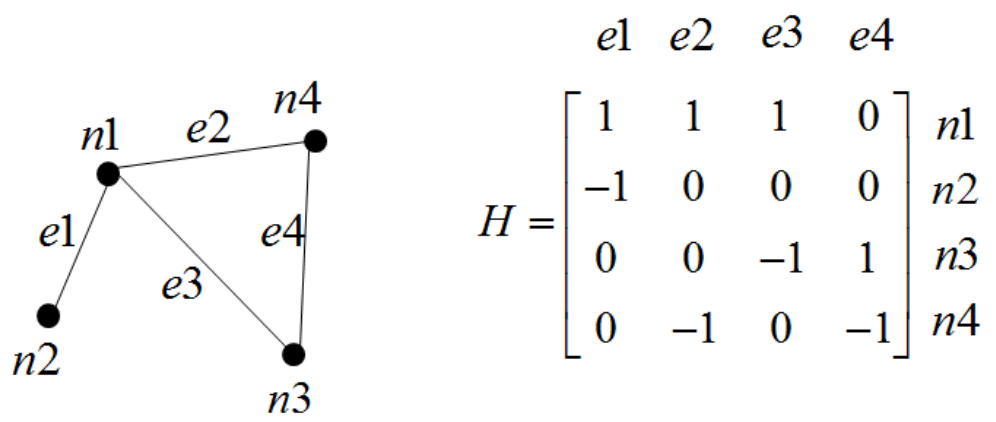

Figura 3.2: Representação de um grafo pela matriz incidência $H$.

Nessa representação, cada linha da matriz $H$ está relacionada a um barramento e suas conexões com os ramos, que são representados pelas colunas. Cada coluna da matriz incidência $H$ é associada com um único equipamento de transmissão (ramo) e possui exatamente dois elementos não nulos associados com o barramento conectado (nó) no sistema de potência. Em (THEODORO; BENEDITO; ALBERTO, 20T]), prova-se que o posto da matriz incidência nó-ramo $H_{n \times m}$ de um grafo conexo é $n-1$.

Definição 3.2.4 (Caminho): Seja uma sequência de arestas $\left\{e_{1}, \ldots, e_{i}\right\}$ de um grafo $G$, onde $e_{k} \neq e_{j}$, para todo $k \neq j$. Se existe uma sequêrncia de nós $\left\{n_{1}, \ldots, n_{i}\right\}, n_{k} \neq n_{j}$, para todo $k \neq j$, tal que $e_{k}=\left[n_{k-1}, n_{k}\right]$, então a sequência $\left\{e_{1}, \ldots, e_{i}\right\}$ é dita ser um caminho.

Definição 3.2.5 (Grafo conexo): Um grafo é conexo se para todo par de nós há ao menos um caminho composto por arestas que os conectam. Caso contrário o grafo é dito desconexo. A fig (… mostra um exemplo de grafo conexo e grafo desconexo.

Definição 3.2.6 (Ramo Crítico): Seja o grafo $G(\mathcal{N}, \mathcal{E})$ um grafo conexo. Se existe um ramo $e_{i} \in \mathcal{E}$, tal que o grafo $G(\mathcal{N}, \widehat{\mathcal{E}})$, onde $\widehat{\mathcal{E}}=\mathcal{E} \backslash\left\{e_{i}\right\}$ é um grafo desconexo, o ramo $e_{i}$ é dito ramo crítico. Na fig (马.马) é mostrado um grafo conexo com seu ramo crítico, e o grafo desconexo gerado pela retirada do ramo crítico.

Definição 3.2.7 (Subgrafo): Um grafo $\bar{G}(\overline{\mathcal{N}}, \overline{\mathcal{E}})$ composto por subconjuntos $\overline{\mathcal{N}} \subset \mathcal{N}$ e $\overline{\mathcal{E}}$ $\subset \mathcal{E}$ de um grafo $G(\mathcal{N}, \mathcal{E})$ é denominado um subgrafo de $G(\mathcal{N}, \mathcal{E})$.

Estaremos interessados em um tipo particular de subgrafo, o chamado grafo induzido. Considere um grafo $G(\mathcal{N}, \mathcal{E})$ e $\overline{\mathcal{N}} \subset \mathcal{N}$. O conjunto de todas as arestas de $\mathcal{E}$ que conectam os nós de $\overline{\mathcal{N}}$ entre si é denotado por $\left.\mathcal{E}\right|_{\overline{\mathcal{N}}}$. 


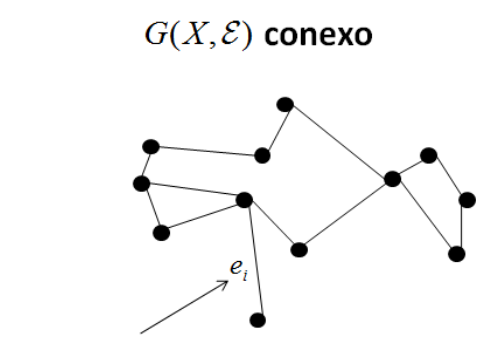

$G(X, \hat{\mathcal{E}})$ não conexo

Ramo Critico

Figura 3.3: Ramo Crítico.

Definição 3.2.8 (Grafo Induzido): O subgrafo $G\left(\overline{\mathcal{N}},\left.\mathcal{E}\right|_{\overline{\mathcal{N}}}\right)=\left.G\right|_{\mathcal{N}}$ do grafo $G(\mathcal{N}, \mathcal{E})$ é chamado grafo induzido de $\overline{\mathcal{N}}$. Na fig (3.4) temos um exemplo de um subgrafo $G\left(\overline{\mathcal{N}},\left.\mathcal{E}\right|_{\overline{\mathcal{N}}}\right)=$ $\left.G\right|_{\mathcal{N}}$ de $G(\mathcal{N}, \mathcal{E})$ induzido de $\overline{\mathcal{N}}$.

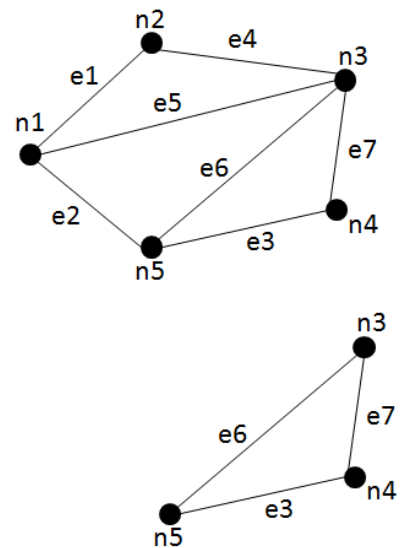

$$
\begin{gathered}
\mathcal{N}=\{n 1, n 2, n 3, n 4, n 5\} \\
\mathcal{E}=\{e 1, e 2, e 3, e 4, e 5, e 6, e 7\}
\end{gathered}
$$

Figura 3.4: Grafo Induzido $G\left(\overline{\mathcal{N}},\left.\mathcal{E}\right|_{\overline{\mathcal{N}}}\right)$ a partir de $G(\mathcal{N}, \mathcal{E})$.

Definição 3.2.9 (Corte): Dado um grafo $G(\mathcal{N}, \mathcal{E})$, um corte é uma partição $P=\left\{X, X^{\prime}\right\}$ de $\mathcal{N}$ em dois subconjuntos disjuntos não vazios, no qual $X \cup X^{\prime}=\mathcal{N} . N a$ fig (苯) é mostrado um exemplo de corte.

O projeto de ilhamento é essencialmente a busca por um corte apropriado de um grafo. A implementação de um corte consiste na eliminação de um conjunto de arestas do grafo em questão. O conjunto de corte indica quais arestas devem ser eliminadas para a implementação de um corte.

Definição 3.2.10 (Conjunto de corte): Um conjunto de corte $C(P)$ ou $C\left(\left\{X, X^{\prime}\right\}\right)$ é o 
conjunto de todas as arestas que são incidentes a um nó de $X$ e a um nó de $X^{\prime}$. Na fig (官.5) é mostrado um exemplo de conjunto de corte.

Definição 3.2.11 (Fronteira do conjunto de corte): Um nó $k \in \mathcal{N}$ pertence à fronteira do conjunto de corte $C$, se existir uma aresta $l \in C$ incidente a este nó. Na fig (马.5) é mostrado um exemplo de fronteira.

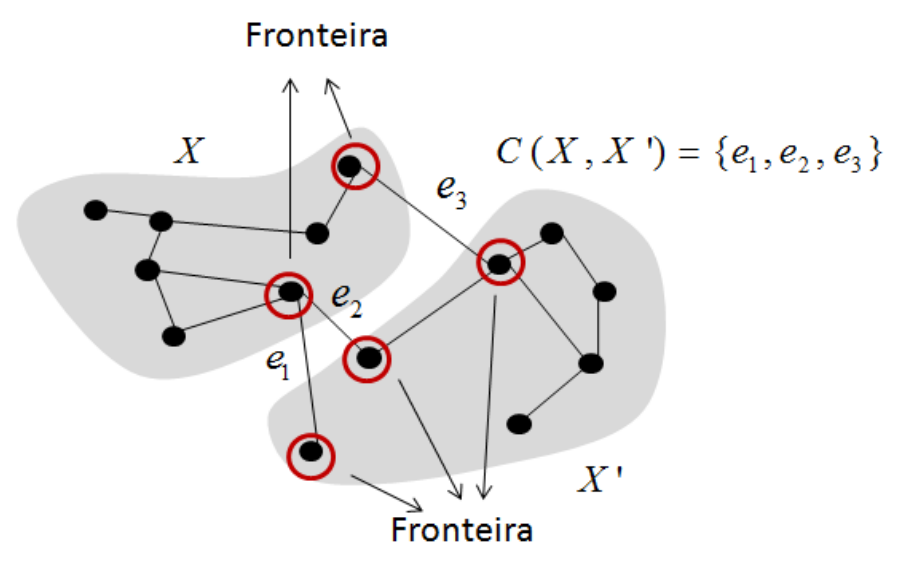

Figura 3.5: Exemplo de Corte, Conjunto de Corte e Fronteira.

Associando a cada aresta um valor ou custo, obtemos um grafo valorado e podemos determinar o custo da implementação de um determinado corte. Seja $w\left(a_{r}\right)=w(i, j)$ o peso associado a uma aresta $a_{r}=(i, j)$.

Definição 3.2.12 (Custo do conjunto de corte): Seja o grafo $G(\mathcal{N}, \mathcal{E})$. O custo $J$ do conjunto de corte $C\left(\left\{X, X^{\prime}\right\}\right)$ é dado pela equação abaixo:

$$
J\left(C\left(\left\{X, X^{\prime}\right\}\right)\right)=\sum_{(i, j) \in C\left(\left\{X, X^{\prime}\right\}\right)} w(i, j)
$$

ou seja, pelo somatório dos pesos das arestas $a_{r} \in C\left(\left\{X, X^{\prime}\right\}\right)$.

Considera e fig (通). Note que o custo do conjunto de corte $C\left(\left\{X, X^{\prime}\right\}\right)=\left\{e_{1}, e_{2}, e_{3}\right\}$ é dado por $J\left(C\left(\left\{X, X^{\prime}\right\}\right)\right)=w\left(e_{1}\right)+w\left(e_{2}\right)+w\left(e_{3}\right)$.

Neste trabalho estaremos interessados em tipos particulares de cortes. Considere a seguinte definição de corte regular relativo aos subconjuntos de nós $U$ e $U^{\prime}$. 


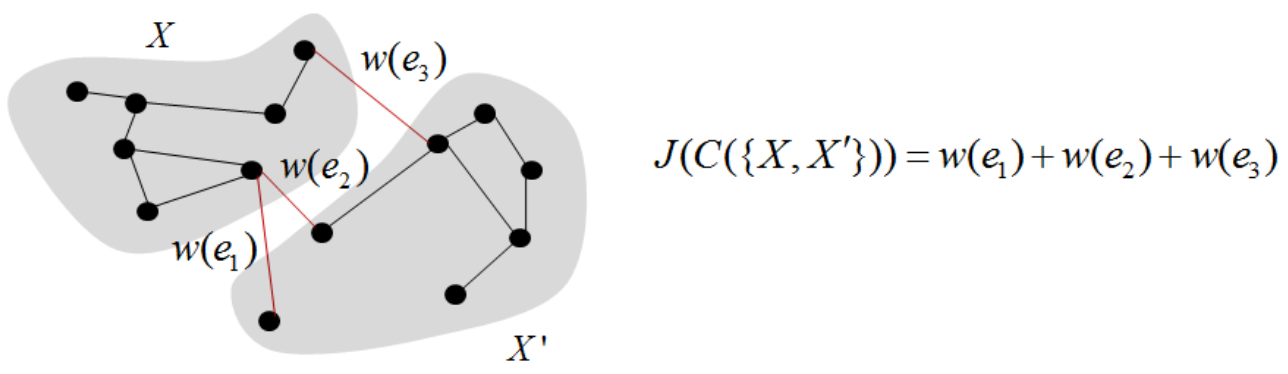

Figura 3.6: Custo do Corte.

Definição 3.2.13 (Corte regular relativo a $U$ e $U^{\prime}$ ) Dado um grafo $G(\mathcal{N}, \mathcal{E})$, um corte $C\left(\left\{X, X^{\prime}\right\}\right)$ é um corte regular relativo aos subconjuntos $U$ e $U^{\prime}$ de $\mathcal{N}$ se $U \subset X, U^{\prime} \subset X^{\prime}$

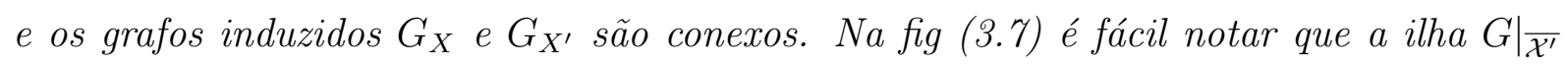
gerada pelo conjunto de corte $C\left(\left\{X, X^{\prime}\right\}\right)$ é desconexa. Portanto o conjunto de corte $C\left(\left\{X, X^{\prime}\right\}\right)$ não é regular.

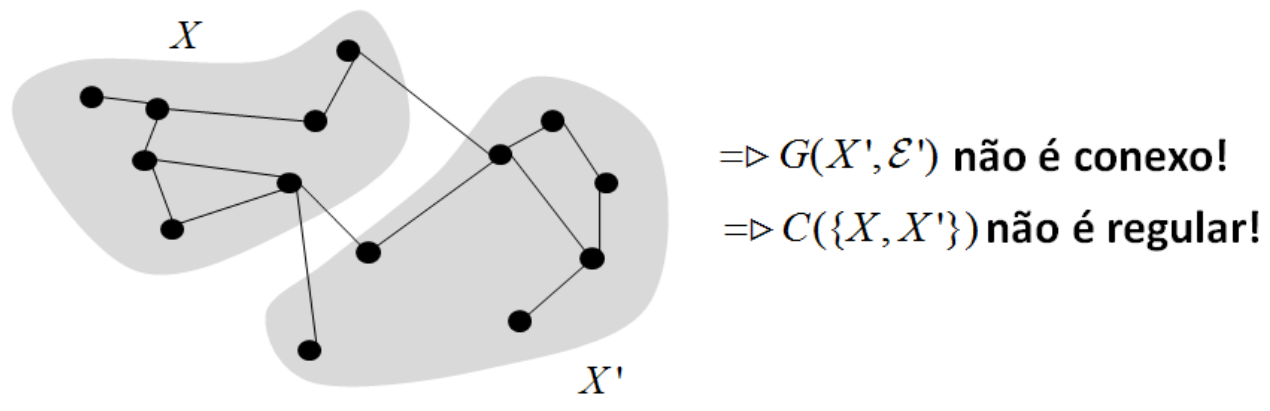

Figura 3.7: Corte não Regular.

O conjunto de todos os cortes regulares relativos a U e U' será denotado por $\Omega\left(\left\{U, U^{\prime}\right\}\right)$.

Definição 3.2.14 (Conjunto de corte vizinho): Temos que o conjunto de corte $C\left(\left\{\hat{X}, \hat{X}^{\prime}\right\}\right)$ é um conjunto de corte vizinho a um corte $C(P)=C\left(\left\{X, X^{\prime}\right\}\right)$ se existir um nó $k$ pertencente à fronteira do conjunto de corte $C(P)$ tal que $\hat{X}=X \cup k$ e $\hat{X}^{\prime}=X^{\prime} \backslash\{k\}$ ou $\hat{X}^{\prime}=X^{\prime} \cup k$ e $\hat{X}=X \backslash\{k\}$.

Para exemplificar a definição (3.2.14), considere a fig (3.8).

Note que $\hat{X}^{\prime}=X^{\prime} \cup k$ e $\hat{X}=X \backslash\{k\}$, portanto o conjunto de corte $C\left(\left\{\hat{X}, \hat{X}^{\prime}\right\}\right)$ é um conjunto de corte vizinho a um corte $C(P)=C\left(\left\{X, X^{\prime}\right\}\right)$.

Denotaremos por $\Delta\left(\left\{X, X^{\prime}\right\}\right)$ o conjunto formado por todos os conjuntos de corte vizinhos a um corte $C\left(\left\{X, X^{\prime}\right\}\right)$. 

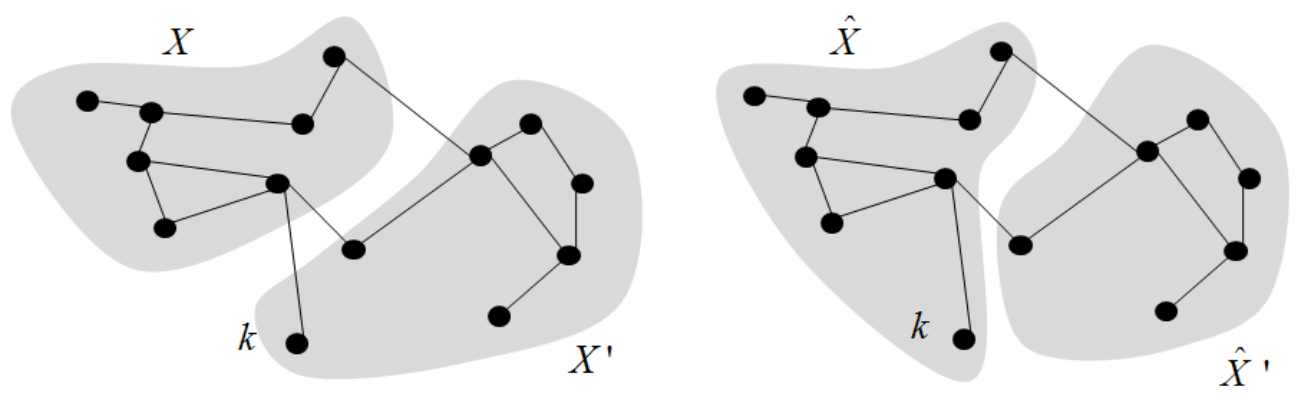

Figura 3.8: Grafos $G(\mathcal{N}, \mathcal{E})$ e $G(\widehat{\mathcal{N}}, \widehat{\mathcal{E}})$.

Observação 3.2.1 : Num grafo $G(\mathcal{N}, \mathcal{E})$ onde temos a partição $P=\{k, X\}$, sendo o nó $k \in \mathcal{N}$ e $X=\mathcal{N} \backslash\{k\}$, é possível mostrar que as arestas associadas a elementos não nulos da linha da matriz $H$ que representa o nó $k$ formam o conjunto de corte $C(P)$ (THEODORO et ald, [2010).

Definição 3.2.15 (Conjunto de corte minimal local): Dado um grafo $G(\mathcal{N}, \mathcal{E})$ e dois subconjuntos de vértices $U$ e $U^{\prime}$ disjuntos pertencentes a $\mathcal{N}$, um corte regular $C\left\{X, X^{\prime}\right\}$ relativo a $U$ e $U^{\prime}$ é um corte minimal local relativo a $U$ e $U^{\prime}$ se possui o menor custo dentre os cortes vizinhos e regulares relativos a $U$ e $U^{\prime}$ e portanto, satisfaz o seguinte problema de otimização:

$$
\begin{gathered}
\min _{C_{j}} J\left(C_{j}\left(X_{j}, X_{j}^{\prime}\right)\right. \\
\text { s. } a C_{j} \in \Delta\left(X, X^{\prime}\right) \cap\left(\left\{U, U^{\prime}\right\}\right)
\end{gathered}
$$

Definição 3.2.16 (Conjunto de corte minimal global): Dado um grafo $G(\mathcal{N}, \mathcal{E})$ e dois subconjuntos de vértices $U$ e $U^{\prime}$ disjuntos pertencentes a $\mathcal{N}$, um corte regular $C\left(\left\{X, X^{\prime}\right\}\right)$ relativo a $U$ e $U^{\prime}$ é um corte minimal global se possui o menor custo dentre os cortes regulares relativos a U e U' e portanto é solução do seguinte problema de otimização:

$$
\begin{gathered}
\left.\min _{\{} C_{j}\right\} J\left(C_{j}\left(\left\{X_{j}, X_{j}^{\prime}\right\}\right)\right. \\
\text { s. } a C_{j} \in \Omega\left(\left\{U, U^{\prime}\right\}\right)
\end{gathered}
$$


A busca pelo corte minimal global é um problema de otimização combinatorial com alto custo computacional, especialmente em problemas de grande dimensão como é o caso dos sistemas elétricos de potência. Neste trabalho, para minimizar o esforço computacional procuraremos por cortes que são mínimos locais e que atendam requisitos práticos. Para isto considere o conceito de conjunto de corte vizinho.

Definição 3.2.17 (Grafo Agregado): Dado um corte $P=\left\{X, X^{\prime}\right\}$ de um grafo $G(\mathcal{N}, \mathcal{E})$, o grafo agregado $G_{X^{\prime}}$ é composto pelos nós $X^{\prime}$ e pelo nó fictício $A$, tal que todas as arestas de $\left.\mathcal{E}\right|_{X^{\prime}}$ são arestas de $G_{X^{\prime}}$ e além disso, a aresta $e=(A, i), i \in X^{\prime}$ pertence ao conjunto de arestas de $G_{X^{\prime}}$ se existe uma aresta $(i, j)$ ou $(j, i)$ que pertence ao conjunto $C\left(\left\{X, X^{\prime}\right\}\right)$. Então o grafo resultante $G_{X^{\prime}}(\tilde{\mathcal{N}}, \tilde{\mathcal{E}})$, com $\tilde{\mathcal{N}}=X^{\prime} \cup A$ e $\tilde{\mathcal{E}} \subset \mathcal{E}$, é um grafo agregado de $G(\mathcal{N}, \mathcal{E})$ onde os nós do conjunto $X$ foram representados por um único nó equivalente $A$, que é denominado nó agregado. A fig (马.g) exemplifica esse processo.
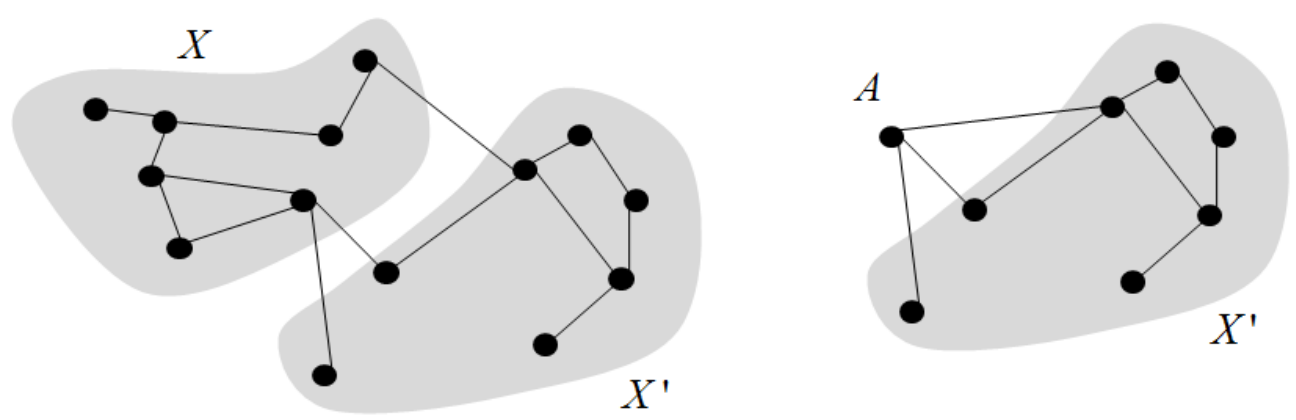

Figura 3.9: $\operatorname{Grafos} G(\mathcal{N}, \mathcal{E})$ e equivalente agregado $G_{X}(\tilde{\mathcal{N}}=X \cup A, \tilde{\mathcal{E}})$.

Observação 3.2.2 : Se o nó A é a agregação do conjunto de nós $X^{\prime}$, podemos concluir que as arestas $\left.\mathcal{E}\right|_{X^{\prime}}$ não são representadas na matriz incidência nó-ramo $H_{X}$ do grafo agregado $G_{X}$. Pelo fato da matriz incidência $H$, representativa do grafo não agregado $G(\mathcal{N}, \mathcal{E})$, ser esparsa de modo que cada coluna possui apenas 2 elementos não nulos de módulos iguais e sinais opostos, o vetor de $H_{X}$ que representa o nó agregado $k$ é igual a soma dos vetores de $H$ associadas a $X$, como é mostrado nas figuras (‥J) e (T.T0). Portanto é possível gerar $H_{X}$ a partir de $H$.

Lemma 3.2.18 Considere um grafo $G(\mathcal{N}, \mathcal{E})$, e sua matriz nó-ramo $H$ associada. O grafo $G$ é uma reunião disjunta de $p, p>1$ subgrafos conexos se e somente se o posto de $H$ for igual a $n-p$. 


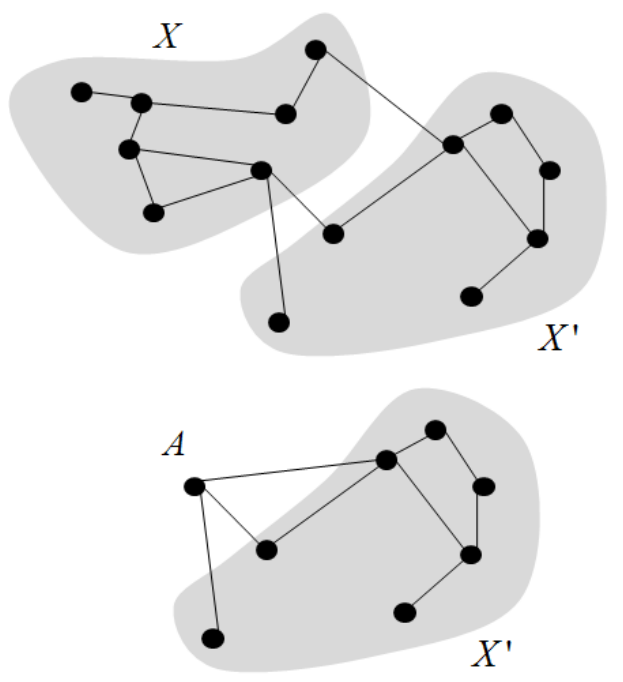

$$
\begin{aligned}
& H=\left[\begin{array}{ccccc}
h_{(1,1)} & h_{(1,2)} & h_{(1,3)} & \ldots & h_{(1, n)} \\
\vdots & \vdots & \vdots & \ldots & \vdots \\
h_{(j, 1)} & h_{(j, 2)} & h_{(j, 3)} & \ddots & h_{(j, n)} \\
h_{(j+1,1)} & h_{(j+1,2)} & h_{(j+1,3)} & & h_{(j+1, n)} \\
\vdots & \vdots & \vdots & \ldots & \vdots \\
h_{m 1} & h_{m 2} & h_{m 3} & \ldots & h_{m n}
\end{array}\right]{ }^{\prime} \\
& \left.H=\left[\begin{array}{ccccc}
a_{(1,1)} & a_{(1,2)} & a_{(1,3)} & \ldots & a_{(1, n)} \\
h_{(j+1,1)} & h_{(j+1,2)} & h_{(j+1,3)} & \ldots & h_{(j+1, n)} \\
\vdots & \vdots & \vdots & \ldots & \vdots \\
h_{m 1} & h_{m 2} & h_{m 3} & \ldots & h_{m n}
\end{array}\right]\right\} X^{\prime}
\end{aligned}
$$

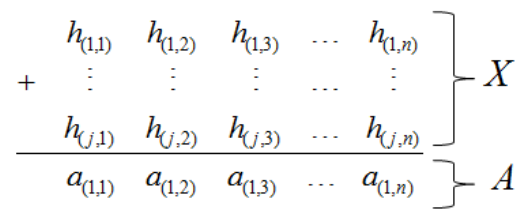

Figura 3.10: Grafos $G(\mathcal{N}, \mathcal{E})$ e equivalente agregado $G_{X}(\tilde{\mathcal{N}}=X \cup A, \tilde{\mathcal{E}})$.

Prova 3.2.1 Suponha que o grafo $G$ seja desconexo, ou seja, composto pela reunião disjunta de $p$ subgrafos conexos $\left\{G_{1}\left(\mathcal{N}_{1}, \mathcal{E}_{1}\right), G_{2}\left(\mathcal{N}_{2}, \mathcal{E}_{2}\right), \ldots, G_{p}\left(\mathcal{N}_{p}, \mathcal{E}_{p}\right)\right\}$. Temos que $n_{i}$ e e $e_{i}$ $i=1,2, \ldots, p$, correspondem ao número de elementos de $\mathcal{N}_{i}$ e $\mathcal{E}_{i}$, respectivamente. Então a matriz incidência nó-ramo $H$ pode ser organizada da seguinte forma: as linhas e colunas de $H$ são permutadas de modo que as $n_{1}$ primeiras linhas e as $e_{1}$ primeiras colunas são correspondentes aos nós e arestas do grafo $G_{1}$. Seguindo esse ordenamento para as linhas e colunas restantes da matriz $H$, sempre agrupando as linhas e colunas relacionadas aos nós e ramos do mesmo grafo $G_{k}, k=2, \ldots, p$ teremos que matriz $H$ assume a seguinte forma:

$$
H=\left[\begin{array}{llll}
{\left[H_{1}\right]_{\left[n_{1} X e_{1}\right]}} & & & \\
& {\left[H_{2}\right]_{\left[n_{2} X e_{2}\right]}} & & \\
& & \ddots & \\
& & & {\left[H_{p}\right]_{\left[n_{p} X e_{p}\right]}}
\end{array}\right]
$$

sendo $H_{i}$ a matriz incidência nó-ramo associada ao subgrafo $G_{i}\left(\mathcal{N}_{i}, \mathcal{E}_{i}\right), i=1, . ., p$. Como o posto do grafo conexo $G_{i}$ conexo é $n_{i}-1$ (THEODORO; BENEDITO; ALBERTO, [(111), então a partir da estrutura de $H$ podemos afirmar que:

$$
\operatorname{posto}(H)=\sum_{i=1}^{p} \operatorname{posto}\left(H_{i}\right)=\sum_{i=1}^{p}\left(n_{i}-1\right)=n-p .
$$




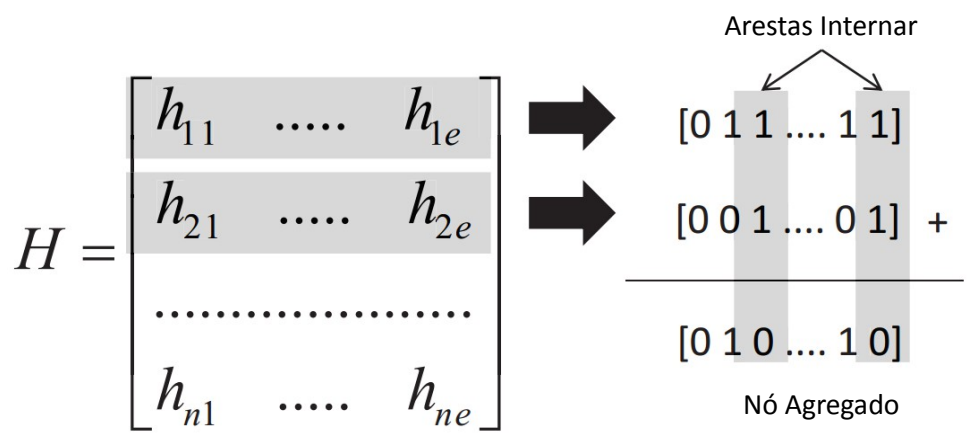

Figura 3.11: Agregação de nós pela soma de linhas da matriz nó-ramo $H$.

Suponha que o posto de $H$ seja igual $n-p$, então se $p>1$, o grafo é uma reunião disjunta de subgrafos (THEODORO; BENEDITO; ALBERTO, 2011). Além disso, existem exatamente $p$ diferentes combinações lineares de linhas de $H$ que resultam na linha nula. Assim, recordando que cada coluna de $H$ tem exatamente duas entradas diferentes de zero, por meio da mudança de linhas e colunas da matriz $H$, é possível organizar esta matriz como se segue:

$$
H=\left[\begin{array}{llll}
{\left[H_{1}\right]_{\left[n_{1} X e_{1}\right]}} & & & \\
& {\left[H_{2}\right]_{\left[n_{2} X e_{2}\right]}} & & \\
& & \ddots & \\
& & & {\left[H_{p}\right]_{\left[n_{p} X e_{p}\right]}}
\end{array}\right]
$$

sendo posto $\left(H_{i}\right)=n_{i}-1, i=1, \ldots, p$. Assim, como matrizes $H_{i}, i=1, \ldots, p$, tem exatamente dois elementos diferentes de zero em suas colunas, cada uma dessas matrizes pode ser admitida como a de uma matriz incidência nó-ramo associado a um subgrafo $G_{i}\left(\mathcal{N}_{i}, \mathcal{E}_{i}\right) i=1, \ldots, p$. Uma vez que o posto de $H_{i}$ é igual a $n_{i}-1$, temos que cada subgrafo $G_{i}$ é conexo, e o resultado está provado.

Teorema 3.2.19 Considere um grafo $G(\mathcal{N}, \mathcal{E})$ e $H$ a matriz nó-ramo associada a $G$. Um conjunto de arestas $C=\left\{l_{1}, l_{2}, \ldots, l_{k}\right\} \subset \mathcal{E}$ é um conjunto de corte do grafo $G$ se $e$ somente for representado por uma combinação linear das linhas de $H$.

Prova 3.2.2 $(\Rightarrow)$ Supomos que o conjunto de conte $C$ divide o grafo $G(\mathcal{N}, \mathcal{E})$ em $p$ subgrafo conexos. Sabemos que em $H$, cada linha está relacionada a um nó de $G$, e cada coluna a uma aresta. Por definição a soma de linhas $l_{i}$ e $l_{j}$ de $H$ (na álgebra $\mathbb{Z}_{2}$ ), 
onde $i \neq j$ e $i, j=1,2, \ldots, p$, relacionadas aos nós $n_{i}$ e $n_{j} \mathcal{N}$ respectivamente, originam a linha correspondente ao nó resultante da agregação dos nós $n_{i}$ e $n_{j}$, como mostrado na fig ("5.11). A linha resultante tem todas os elementos não nulos das linhas somadas, excluindo possivelmente os elementos que foram anulados pela soma na álgebra $\mathbb{Z}_{2}$ (o que indica que esses elementos são associados com as barras internas ao nó agregado).

Portanto, se na operação de agregação dos nós (soma das linhas $l_{i}$ e $l_{j}$ de $H$, sendo $i \neq j$ e $i, j=1,2, \ldots, p)$ são preservados todos os elementos não nulos, então as arestas relacionadas as esses elementos não nulos são suficientes para dividir o grafo em duas parte desconexas, ou seja, é um conjunto de conte C. Além disso, se houver pelo menos uma aresta que conecta os nós relacionados com esta linha, por definição estes nós estão no mesmo subgrafo definido pelo conjunto de conte $C$.

E iniciando a primeira interação a partir de um nó qualquer $i \in \mathcal{N}$. Na linha $l_{i}$ associada ao nó $i$ deve ser identificado um elemento não nulo na coluna $k$ de $H$, que não esteja relacionada a uma aresta contida no conjunto de corte $C$.

Ao identificar esse elemento, deve-se procurar outra linha, que chamaremos $l_{j}$, que contenha um elemento não nulo na coluna $k$. Isso significa que os nós representados pelas linhas $l_{j}$ e $l_{i}$ são conectados por uma aresta que é representada pela coluna $k$ em $H$. Ao somar as linhas $l_{i}$ e $l_{j}$ usando a álgebra $\mathbb{Z}_{2}$, será gerado uma linha que representa a agregação de nós $i$ e $j \in \mathcal{N}$ no mesmo subgrafo definido pelo conjunto de corte $C$. Este processo é repetido até que não haja linhas de $H$, no qual a soma de nós agregados resulte na eliminação de elementos não nulos que não estejam relacionados com arestas contidas em C. Este processo termina com a agregação de todos os nós do subgrafos definido pelo conjunto de corte $C$, e todos os elemento diferentes de zero na linha de nós agregados estão relacionados as arestas do conjunto $C_{1} \subset C$.

Se todas as arestas de $C$ não forem identificadas, o processo descrito anteriormente deve ser iniciado a partir de outro nó que não tenha sido explorado, assegurando que nessa nova interação outro subgrafo definido por $C$ é investigado. Então, seguindo o processo anteriormente descrito, uma nova linha representante da agregação dos nós de outro subgrafo é gerada, identificando pelos elementos não nulos dessa nova linha as arestas do conjunto $C_{2} \subset C$. Esse processo é executado até que $C_{1} \cup C_{2} \cup \ldots \cup C_{p}$ gera $C$, sendo $p$ 
o número de subgrafos gerados por C. Assim, qualquer conjunto de corte pode ser identificado por meio de combinações lineares (utilizando álgebra $\mathbb{Z}_{2}$ ) das linhas da matriz $H$.

$(\Leftarrow)$ Do Teorema 1 (pág. 172 - (THEODORO;BENEDITO; ALBERTO, 2011)), temos que posto $(H)=n-1$, portanto por definição qualquer matriz $H *=M^{-1} . H . M$, onde $M$ possui inversa, é similar a $H$ e posto $\left(H^{*}\right)=\operatorname{posto}(H)=n-1$. Em particular qualquer matriz resultante de combinações lineares (somas de elementos em álgebra $\mathbb{Z}_{2}$ ) entre as linhas de $H$ tem posto igual a $n-1$.

Lembrando que qualquer soma (usando álgebra $\mathbb{Z}_{2}$ ) de linhas de $H$ origina linhas que estão relacionadas com os nós agregados.

Portanto, a matriz resultante $H^{*}$ possui linhas associadas com nós e nós agregados em um grafo gerado a partir do gráfico $G$. Consequentemente, se qualquer conjunto de arestas $C_{k}$, relacionada com os elementos não nulos da k-ésima linha da matriz $H^{*}$, é feita a partir do grafo $G$, então há pelo menos um soma de $L, L<n$, linhas de $H$ que resulta em uma linha nula. Então, por definição o posto $\left(H_{C_{k}}^{*}\right)=n-\bar{p}<n-1$ de mesma forma que posto $\left(H_{C_{k}}\right)=n-\bar{p}<n-1$, onde a termo $\left(C_{k}\right)$ indica que o conjunto de arestas $C_{k}$ foram eliminadas do grafo original.

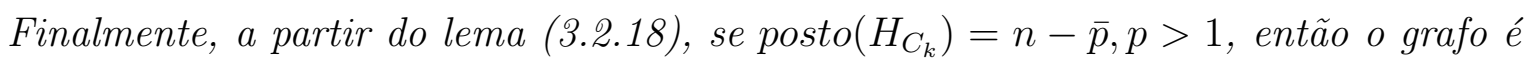
uma reunião disjunta de $\bar{p}$ subgrafos, e o conjunto de arestas $C_{k}$ é um conjunto de corte do grafo $G$ e o resultado é provado.

O resultado anterior é geral no sentido de demonstrar que qualquer combinação linear de linhas da matriz $H$ produz conjuntos de corte. Em particular, o próximo resultado mostra que a fatoração da matriz $H$ produz conjuntos de cortes.

Corolário 3.2.20 (Fatoração Triangular): Considere o grafo $G(\mathcal{N}, \mathcal{E})$, e sua matriz incidência nó-ramo $H$ associada. Seja $H_{f}$ o resultado da fatoração triangular da matriz $H$, então o conjunto de ramos associados aos elementos não nulos de cada linha de $H_{f}$ compõem um conjunto de corte do grafo $G$.

Prova 3.2.3 A partir do teorema 2 (pág. 173 - (THEODORO; BENEDITO; ALBERTO, 
2(111)), é sempre possivel fazer uma fatoração triangular sobre a matriz nó-ramo $H$ associada com o gráfico $G$ a fim de obter $H_{f}$ na forma:

$$
H_{f}=\left[\begin{array}{c|c}
{[I]_{[(n-1) \times(n-1)]}} & {[R]_{[(n-1) \times q]\}}} \\
\hline[0]_{[1 \times(n-1)]} & {[0]_{[1 \times q]}}
\end{array}\right]
$$

sendo $q=[e-(n-1)], I$ a matriz identidade e $R$ a matriz de redundância das arestas. Portanto, aplicando o teorema (3.2.19), por definição temos que os conjuntos de arestas relacionadas com os elementos não nulos de cada linha de $H_{f}$ compõem conjuntos de corte para o grafo $G$, e o resultado é provado.

Como resultado do teorema (3.2.1. ), do corolário (\$.2.201) e de acordo com a observação (3.2. D), temos que dado um grafo $G(\mathcal{N}, \mathcal{E})$ e uma partição $P=\left\{X, X^{\prime}\right\}$, é possível facilmente identificar o conjunto de corte $C\left(\left\{X, X^{\prime}\right\}\right)$ a partir da matriz incidência nóramo. Somando as linhas da matriz H relacionadas aos ramos de X', obtém-se uma nova linha que represente o nó agregado $K$ composto pelos elementos de $X^{\prime}$. O conjunto de corte $C\left(\left\{X, X^{\prime}\right\}\right)$ será formado pelas arestas associadas aos elementos não nulos da linha que representa o nó agregado $K$. Em particular, cada passo da etapa "forward" da fatoração triangular gera um nó agregado e um novo conjunto de corte. 



\section{Capítulo 4}

\section{Método Grafo-Algébrico para a Detecção e Identificação de}

\section{Ilhamento Não Intencional}

\subsection{Introdução}

Como já mencionado anteriormente, a separação física da rede elétrica devido a um distúrbio, pode ser causada por operações errôneas de disjuntores no sistema de transmissão. A identificação desta separação ou ilhamento é uma tarefa importante para a análise de segurança e controle do SEP (GULER; GROSS, 2007), (KOLLURI et al, $20(0) 9)$.

A separação em duas ou mais ilhas requer a implementação de diferentes estratégias para garantir a segurança do sistema. Em estudos de análise de segurança estática "offline", a interrupção de linhas que levam a formação de ilhas é considerada como caso extremo, podendo exigir grandes esforços de controle corretivo. Para aplicações em tempo real ou off-line, uma rápida detecção e identificação de formação de ilhas e a identificação dos fatores causais são necessários para tratar as complicações acima mencionadas(GULER; GROSS, 2007).

Neste capítulo, apresenta-se um método para detecção de ilhamento não intencional 
em sistemas elétricos de potência, proposto em (THE()D()R() et aL, [2012) e um método de identificação das ilhas. O método de detecção de ilhamento não intencional apresentado nesse capítulo é baseado na fatoração triangular da matriz incidência nó-ramo $H$, de forma a localizar os ramos (linhas de transmissão/transformadores) cuja retirada do SEP causaria o ilhamento de uma ou mais barras do mesmo. Já o método de identificação de ilhas é baseado na fatoração ordenada da matriz incidência nó-ramos $H$, de forma a agregar todos os nós que pertencem a um mesmo grafo conexo. Uma grande vantagem deste método de identificação de ilhamento é a capacidade de identificar todos os possíveis ilhamentos, ou ramos críticos, com uma única fatoração da matriz incidência ramo-nó.

\subsection{Método para a detecção de ilhamento em um SEP}

Uma das formas de descrever a topologia da rede de transmissão de um determinado SEP é através da matriz incidência nó-ramo $H$. A matriz $H$, apresentada na definição [2.3, é uma matriz esparsa, onde os elementos não nulos descrevem as interconexões entre as barras do sistema através dos ramos do mesmo.

Podemos observar que cada coluna da matriz incidência nó-ramo $H$ possui exatamente 2 elementos não nulos. Tal fato será amplamente explorado nas demonstrações dos resultados propostos neste trabalho.

Com a matriz incidência nó-ramo $H$ (definição 3.2 .3$)$, é possível realizar análises topológicas sobre a rede, tais como análise de redundância e análise de ilhamento. Tal análise pode ser realizada a partir da fatoração triangular, via eliminação de Gauss (escalonamento) ou algoritmos LDU, da matriz incidência $H$, explicitando assim a dependência linear existente entre os diversos ramos do sistema, de forma a concluir quando a perda de um determinado caminho formado por equipamentos de transmissão pode ser compensada pela existência de um outro caminho dentro do SEP. A fatoração realiza uma transformação no espaço das barras do SEP, de forma a explicitar a relação de redundância entre os ramos do sistema (THE(O)()RO et al, 2012). 
A identificação de todos os ramos críticos é possibilitada pela análise da matriz incidência nó-ramo fatorada $H_{F}$. Como apenas uma fatoração é necessária para obter $H_{F}$ a partir de $H$, essa analise é realizada sem grande esforço computacional.

Com a finalidade de embasar teoricamente o método proposto, as principais definições e resultados utilizados serão enunciados e demonstrados a seguir.

\section{Definição 4.2.1 (Conexidade de um SEP (THEODORO et al., 2012)) Um SEP} é conexo se somente se para todo par de barras deste SEP, há ao menos um caminho composto por ramos (linhas de transmissão/transformadores) que os conectam.

Se modelamos o SEP como um grafo, de modo que os barramentos são análogos aos nós e os ramos são análogos aos equipamentos de transmissão (linhas de transmissão / transformadores), temos que, se um SEP é conexo, o grafo que o representa também o será, de modo que as definição 4.2 .1$]$ e 3.2 .5 são análogas.

\section{Teorema 4.2.2 (Máximo Posto da Matriz H (THEODORO et al, 2012)) Considere} um SEP composto por $\boldsymbol{n}$ barras e $\boldsymbol{m} \geq(\boldsymbol{n}$-1) ramos. Se este sistema é conexo, então, o posto da matriz incidência nó-ramo, $\rho(H)$, é no máximo igual a $\boldsymbol{n}$-1.

Prova 4.2.1 Uma vez que cada vetor coluna da matriz incidência $H$ contém exatamente dois elementos diferentes de zero, um positivo e outro negativo e iguais em módulos, o resultado da soma de todos os $n$ vetores de linha que compõem a matriz incidência $H$ é nula, ou seja, são linearmente dependentes. Deste modo, tem-se que:

$$
\rho(H)<\boldsymbol{n} \Longrightarrow \rho(H) \leq \boldsymbol{n}-1
$$

e o resultado está demonstrado.

Teorema 4.2.3 (Conexidade da Matriz H (THEODORO et al, 2012)) Considere um SEP composto por $n$ barras e $m \geq(n-1)$ ramos. As seguintes afirmações são equivalentes: (i) o sistema é conexo, (ii) para qualquer $L<n$, a soma de quaisquer $L$ vetores linha da matriz incidência $H$ é um vetor não nulo e (iii) o posto $\rho(H)=n-1$. 
A prova desse teorema pode ser encontrada em (THE()D()RO et al., 2012), no corpo módulo-2.

Prova 4.2.2 $(i) \Rightarrow$ (ii) Suponha que possamos dispor as linhas de $H$ de modo que, para $L<n$, onde $L \in \mathbb{N}^{*}$, a soma dos primeiros $L$ vetores-linha da matriz incidência $H$ seja um vetor nulo. Tal fato só é verdade se cada coluna da matriz $H_{L}$, formada pelo agrupamento dos primeiros $L$ vetores linha de $H$, contiver um número par de elementos não nulos, ou seja, dois ou nenhum. Então, pode-se permutar as colunas de $H$, de modo que as $k$ primeiras colunas contenham dois elementos não nulos, um igual a 1 e outro igual a -1 , entre os primeiros $L$ elementos, e consequentemente as $m-k$ colunas restantes contenham os L primeiros elementos nulos. Assim,

$$
H=\left[\begin{array}{c|c}
{\left[H_{(L)}\right]_{(L \times k)}} & {[0]_{[L \times(m-k)]\}}} \\
\hline[0]_{[(n-L) \times k]} & {\left[H_{(n-L)}\right]_{[(n-L) \times(m-k)]}}
\end{array}\right]
$$

o que resulta em duas partições distintas da matriz incidência $H$, ou seja, os primeiros $k$ ramos do SEP são conectados a somente $L$ primeiros barramentos, enquanto os últimos $m-k$ ramos são conectados aos $n-L$ últimos barramentos do sistema. Portanto o sistema é a união de dois subsistemas disjuntos, o que contradiz a hipótese inicial (i).

$($ ii $) \Rightarrow(i)$ Suponha que o sistema seja composto por dois subsistemas disjuntos, um composto por $L<n$ barramentos e $k$ ramos, e outro composto por $n-L$ barramentos e $m-k$ ramos. Portanto é possível permutar as linhas e colunas da matriz incidência $H$ do sis-

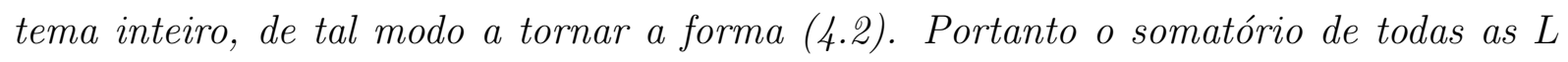
linhas de $H$ é nula, e o resultado segue.

$($ ii $) \Rightarrow($ iii) Suponha que $\rho(H)<n-1$, então existe $L<n$ vetores linhas de $H$ que a soma dessas linhas é um vetor nulo, o que contradiz a hipótese inicial.

(iii) $\Rightarrow($ ii $)$ Suponha que, para $L<n$, existem $L$ vetores linhas de $H$ tal que a soma desses vetores é um vetor nulo, então o posto $\rho(H) \leq n-2$ e o resultado foi prova.

O teorema anterior mostrou que o posto de $H$ é um indicador para a formação de ilhamento. Porém, verificar o posto da matriz $H$ para um sistema de potência de grande dimensão é inviável. 
Os teoremas a seguir irão mostrar que a fatoração da matriz incidência nó-ramo $H_{F}$ fornece informações sobre o nível de redundância dos ramos que compõem o sistema, e torna explícito todos os possíveis casos de ilhamento. O teorema abaixo é uma releitura do teorema utilizado no trabalho de (LONDON; ALBERTO; BRE"TAS, 2007).

Teorema 4.2.4 (Matriz $H_{F}$ (THEODORO et al., 2012)) Considere um SEP composto por $\boldsymbol{n}$ barras e $\boldsymbol{m} \geq(\boldsymbol{n}$-1) ramos. Se este sistema é conexo, existe uma matriz $C$ inversivel, tal que $H_{F}=C^{-1} H$, onde $H$ é a matriz incidência nó-ramo do SEP sob análise, e a matriz incidência nó-ramo fatorada $H_{F}$ possui a seguinte forma:

$$
H_{F}=\left[\begin{array}{c|c}
{[I]_{[(n-1) \times(n-1)]}} & {[R]_{\{(n-1) \times q\}}} \\
\hline[0]_{[1 \times(n-1)]} & {[0]_{\{1 \times q\}},}
\end{array}\right]
$$

onde $q=[\boldsymbol{m}-(\boldsymbol{n}-1)], \underline{I}$ representa a matriz identidade e $\underline{R}$ a matriz de redundância dos ramos.

Prova 4.2.3 Seja o SEP conexo, prova-se, utilizando os teoremas (4.2.2) e (4.2.3), que $H$ tem posto $\rho(H)=(\boldsymbol{n}-1)$ (SAVULFSCU, 1980), de forma que esta matriz possa ser rearranjada, com possíveis permutações de colunas, da seguinte maneira:

$$
H=\left[\begin{array}{c|c}
{[A]_{[(n-1) \times(n-1)]}} & {[D]_{[(n-1) \times q]}} \\
\hline\left[h_{A}\right]_{[1 \times(n-1)]} & {\left[h_{D}\right]_{(1 \times q)},}
\end{array}\right]
$$

onde $q=[\boldsymbol{m}-(\boldsymbol{n}-1)]$ e $\underline{A}$ é uma matriz inversível.

Logo, sendo $\rho(H)=(\boldsymbol{n}-1)$, podemos escrever as qúltimas colunas de $H$ como uma combinação linear das (n-1) primeiras:

$$
\begin{aligned}
{[D]_{[(n-1) \times q]} } & =[A]_{[(n-1) \times(n-1)]}[R]_{[(n-1) \times q]} \\
{\left[h_{D}\right]_{(1 \times q)} } & =\left[h_{A}\right]_{[1 \times(n-1)]}[R]_{[(n-1) \times q]} .
\end{aligned}
$$


De (4.5) e (4.6), pode-se reescrever $H$ da seguinte maneira:

$$
H=\left[\begin{array}{c|c}
{[A]} & {[A][R]} \\
\hline\left[h_{A}\right] & {\left[h_{A}\right][R] .}
\end{array}\right]
$$

Com isso, admitindo a existência de uma matriz $C$ inversível, tem-se que:

$$
H_{F}=\underline{C}^{-1} \cdot H \text {. }
$$

Definindo, então, a matriz de mudança de base $C$ como sendo:

$$
C=\left[\begin{array}{c|c}
{[A]} & {[0]} \\
\hline\left[h_{A}\right] & 1
\end{array}\right]
$$

Desde que $\underline{A}$ seja inversível, pode-se calcular $\underline{C}^{-1}$ :

$$
C^{-1}=\left[\begin{array}{c|c}
{[A]^{-1}} & {[0]} \\
\hline-\left[h_{A}\right][A]^{-1} & 1
\end{array}\right]
$$

Substituindo (4.10) em (4.8), obtém-se:

$$
H_{F}=\left[\begin{array}{c|c}
{[I]} & {[R]} \\
\hline[0] & {[0]}
\end{array}\right]
$$

e o teorema está demonstrado.

As linhas de $H_{F}$ são combinações lineares das linhas da matriz $H$, obtidas pela fatoração triangular da matriz $H$. É possível notar que as combinações lineares das linhas de $H$ preservam a identidade dos ramos, isto é, a informação acerca de cada ramo do sistema é preservada em cada coluna de matriz de $H_{F}$.

Observação 4.2.1 A matriz fatorada de $H$ irá assumir a forma $H_{F}$ (4.⿹丁口), se o sistema de potência for conexo. Porém não é difícil provar que, para $m \geq(n-1)$, se o sistema é composto por $\mathcal{K}$ componentes simplesmente conexas, então a submatriz $[I]$, em 4.3 
tem $(\mathcal{K}-1)$ pivôs nulos em sua diagonal. Portanto, é possivel identificar quantas ilhas compõem o sistema de potência pela fatoração triangular da matriz incidência nó-ramo $H$.

O próximo resultado indica como realizar a identificação de um ramo crítico para o SEP baseado na estrutura da matriz incidência nó-ramo fatorada, $H_{F}$.

Teorema 4.2.5 (Ramos Críticos (THEODORO et al., 2012)) Considere um SEP composto por $\boldsymbol{n}$ barras e $\boldsymbol{m} \geq\left(\boldsymbol{n}\right.$-1) ramos conexo e seja $H_{F}$ a "matriz incidência nó-ramo fatorada" na forma (4.3). Se o k-ésimo vetor linha que compõe a matriz $H_{F}$, com $k<\boldsymbol{n}$, possui apenas um elemento diferente de zero, então o respectivo ramo, associado a este elemento, é um ramo crítico.

Prova 4.2.4 A demonstração deste resultado é imediata uma vez que sendo o SEP conexo, o posto da matriz incidência $H$ é igual a (n-1), dos teoremas (4.2.2) e (4.2.3), e sendo a matriz $H_{F}$ obtida através de combinações lineares dos vetores-linha de $H$ tem-se que: $\rho\left(H_{F}\right)=\rho(H)=\boldsymbol{n}-1$.

Logo, se existe $k<\boldsymbol{n}$, tal que o $k$-ésimo vetor-linha de $H_{F}$ possui apenas um elemento não nulo, e o respectivo ramo associado a este elemento for retirado do sistema, segue-se que: $\rho\left(H_{F}^{(k)}\right)=n-2=\rho\left(H^{(k)}\right)$, onde o sobrescrito $(k)$ indica que a coluna, respectiva ao elemento não nulo do k-ésimo vetor-linha, foi eliminada da matriz incidência original $H$. Ou seja, é possível demonstrar que existe um número $L ; \boldsymbol{n}$, tal que a soma de $L$ vetoreslinha de $H^{(k)}$ é um vetor nulo, e portanto segue, do teorema (4.2.3), que o sistema é uma reunião de dois subsistemas disjuntos, e o resultado está demonstrado.

Baseado no teorema (4.2.5) e admitindo o SEP inicialmente conexo, a análise de ilhamento para o mesmo pode ser realizada do seguinte modo:

1. Constrói-se a matriz incidência nó-ramo $H$, conforme a definição ([.2.3);

2. Obtém-se a matriz $H_{F}$, a partir da fatoração triangular da matriz incidência $H$;

3. Percorrem-se as linhas da matriz $H_{F}$ de modo a determinar as que possuem um único elemento não nulo; 
4. As colunas onde se posicionam os elementos não nulos anteriores indicam os ramos cuja eliminação causa o ilhamento do SEP;

Entre as vantagens do método apresentado, podem ser destacadas:

- Facilidade de implementação: a maioria dos softwares utilizados para análise de SEPs, fazem uso de rotinas de fatoração, seja na resolução de fluxo de potência / estimador de estados / cálculo de curto circuito etc, as quais podem facilmente ser aproveitadas na fatoração da matriz incidência $H$, tornando, então, muito pequeno o esforço necessário para a implementação do método aqui proposto;

- Identificação de todos os possíveis casos de ilhamento: dada a topologia do SEP, apenas uma fatoração é necessária para determinar todos os possíveis casos de ilhamento considerando a perda de um único equipamento (critério N-1);

- Eficiência computação: embora o método exija a construção da matriz incidência $H$, a mesma é esparsa e portanto as técnicas de esparsidade para armazenamento e fatoração (TINNEY; BRANDWAJN; CHAN, 1985) podem ser facilmente aplicadas, proporcionando um método mais eficiente;

- Adaptabilidade em tempo-real: sempre que uma alteração topológica ocorre no SEP, a análise de ilhamento deve ser refeita para determinar as vulnerabilidades do sistema, porém a matriz incidência fatorada $H_{F}$ pode ser atualizada, através de técnicas de refatoração parcial (ZHANG; TINNEY, 1995), de forma a possibilitar sua utilização em tempo-real.

A extensão do método proposto para a perda simultânea de $k$ equipamentos pode ser facilmente desenvolvida através da análise de redundância dos ramos do SEP, obtida a partir da atualização (refatoração parcial) da matriz $H_{F}$, bem como a determinação das barras componentes de cada ilha resultante. 


\subsection{Método para identificação ilhas em um SEP}

O método descrito nessa seção tem o propósito de determinar quais os barramentos que compõem cada ilha formada, caso haja a queda de um elemento de transmissão, ou mesmo determinar se um SEP esta ilhado ou não.

O principio básico deste método é agregar somente os nós que possuem interconexão, em cada componente conexa do grafo, até que não haja mais nós conexos para serem agregados. Deste modo, serão formados nós agregado que representam as componentes conexas existentes no grafo.
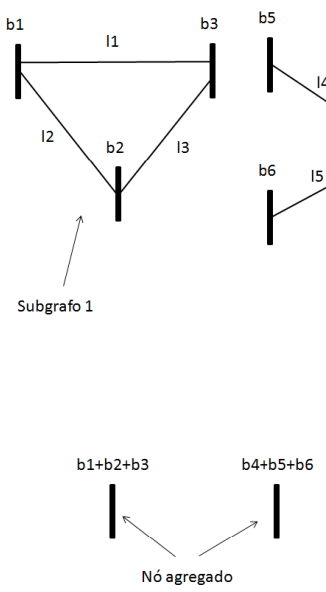

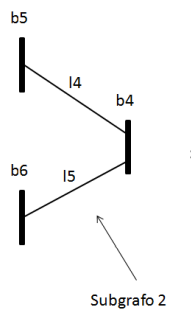

Subgrafo 2

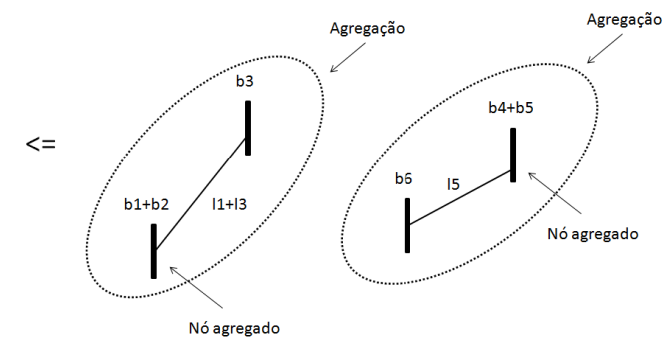

Figura 4.1: Processo de identificação de nós conexos.

Esse processo é ilustrado na fig (4.]). Note que ao final do processo de agregação de nós conexos, foi possível identificar todos os nós que compõem cada componente conexa de um grafo.

Sabemos que o posto da matriz incidência nó-ramo de um grafo $G$ formado pela reunião disjunta de $p$ subgrafos conexos, $p>1$ é igual a $n-p$, como foi mostrado no lema ([3.2.18). Portanto a matriz incidência nó-ramo $H$ pode ser rearranjada da seguinte forma: 


$$
H=\left[\begin{array}{cccc}
{\left[H_{1}\right]_{\left[n_{1} \times e_{1}\right]}} & 0_{\left[n_{1} \times e_{1}\right]} & \ldots & 0_{\left[n_{1} \times e_{1}\right]} \\
0_{\left[n_{2} \times e_{2}\right]} & {\left[H_{2}\right]_{\left[n_{2} \times e_{2}\right]}} & \ldots & 0_{\left[n_{2} \times e_{2}\right]} \\
\vdots & \vdots & \ddots & \vdots \\
0_{\left[n_{p} \times e_{p}\right]} & 0_{\left[n_{p} \times e_{p}\right]} & \ldots & {\left[H_{p}\right]_{\left[n_{p} \times e_{p}\right]}}
\end{array}\right]
$$

Cada matriz $H_{i}, i=1,2, \ldots, p$ pode ser interpretada como a matriz nó-ramo relacionada com uma componente conexa do grafo $G$. Sabemos que a matriz incidência $H_{i}, i=$ $1,2, \ldots, p$ é esparsa, de modo que cada coluna possui apenas 2 elementos não nulos de módulos iguais e sinais opostos.

De acordo com a definição (‥17) e a observação (इ22), sabemos que a soma de linhas de $H$ é equivalente a operação de agregação de nós. Podemos inferir que o vetor linha que representa o nó agregado $k$, na matriz incidência nó-ramo $H_{X}$ de um grafo agregado $G_{X}$, onde o nó agregado é constituído por $X^{\prime}$, sendo $X^{\prime}$ todos os nós de uma componente conexa do grafo original $G$, é nulo, pois se não existem caminhos entre os nós $X$ e os nós $X^{\prime}$, então o conjunto $C\left(\left\{X, X^{\prime}\right\}\right)$ é vazio. Este fato é o fundamento do método de identificação de ilha.

O método de identificação de ilhas consiste em agregar nós conexos até que todas as linhas da matriz incidência nó-ramo para o grafo agregado sejam nulas. O fluxograma do algoritmo proposto é exposto na fig 4.2 .

\subsection{Testes e Resultados}

Nesta seção os métodos para detecção e identificação de ilhamento, mostrado neste trabalho, serão aplicado ao estudo de SEPs de pequeno e médio porte, sendo sua eficácia comprovada através dos mesmos.

- Teste 1: SEP com 3 barra e 4 ramos.

Considere o seguinte exemplo. Seja um SEP composto de 3 barras e 4 ramos, conforme apresentado na fig (4.3). 


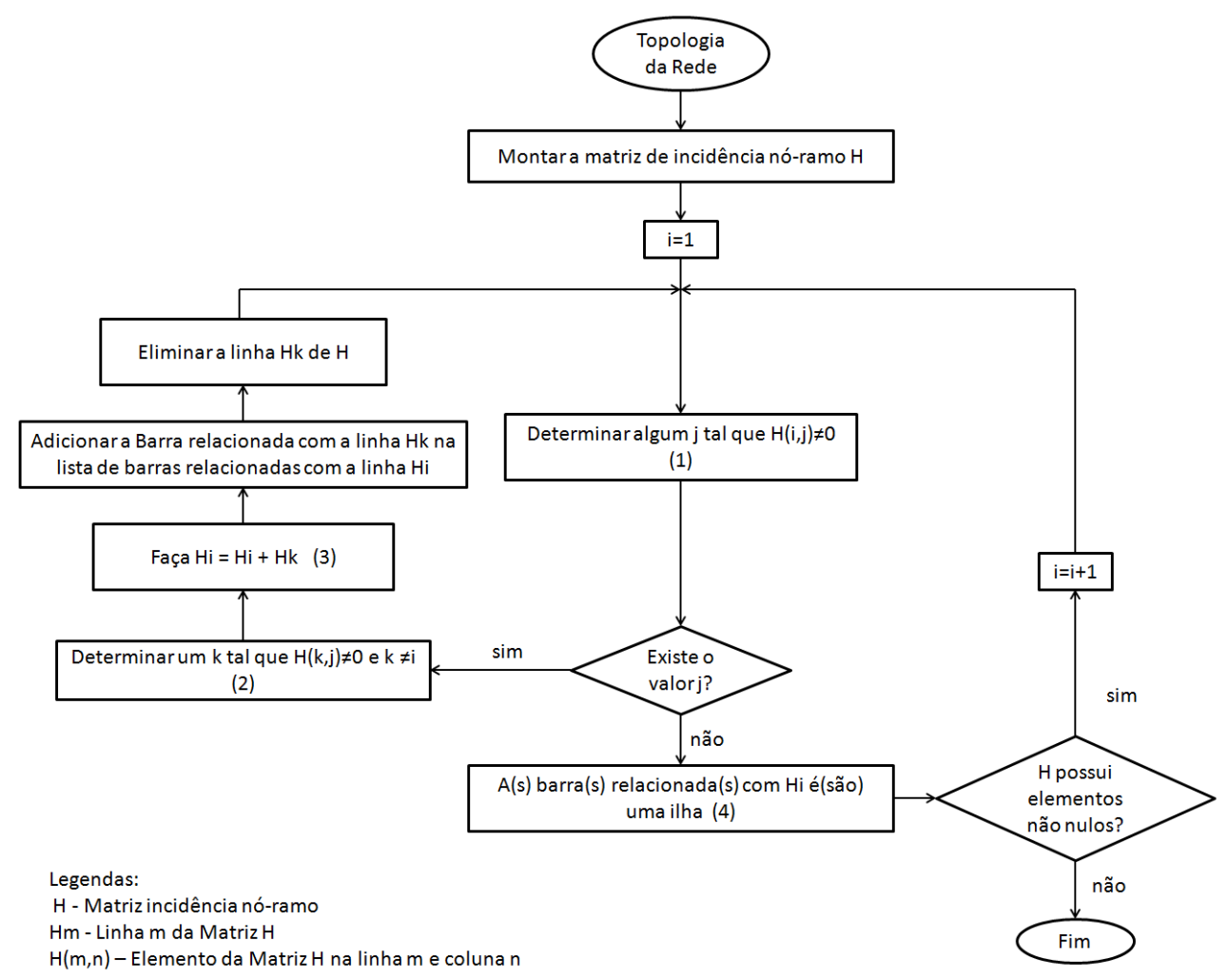

Figura 4.2: Fluxograma do algoritmo de identificação de ilhas.

A matriz incidência nó-ramo, segundo a definição 3.2 .3 , para o sistema da fig 4.3 possui a seguinte forma:

$$
H^{3 B / 4 R}=\left[\begin{array}{cccc}
l_{1} & l_{2} & l_{3} & l_{4} \\
& & & \\
1 & 1 & 0 & 0 \\
-1 & 0 & 1 & 0 \\
0 & -1 & -1 & 1 \\
0 & 0 & 0 & -1
\end{array}\right]
$$

Note que a identificação dos ramos foi adicionada na primeira linha da matriz $H$, com a intenção de facilitar a identificação dos ramos críticos do SEP. Nota-se, que $\rho\left(H^{\prime(3 B / 4 R)}\right)=$ $3=\mathbf{n}-1$, o que indica que o sistema em analise é conexo. Ao fatorar a matriz $H^{3 B / 4 R}$, temos: 


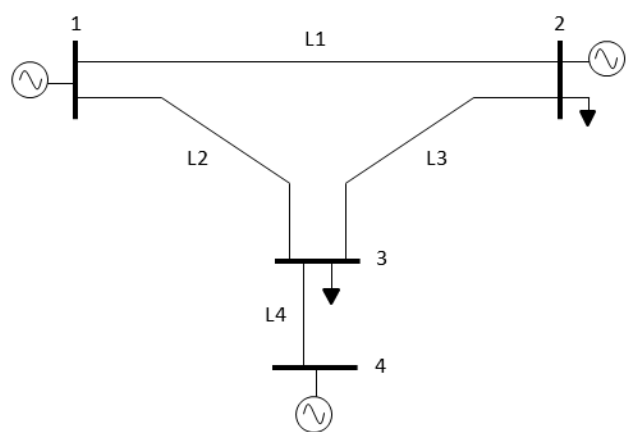

Figura 4.3: SEP composto de 3 barras e 4 ramos.

$$
H_{F}^{\prime(3 B / 4 R)}=\left[\begin{array}{cccc}
l_{1} & l_{2} & l_{4} & l_{3} \\
& & & \\
1 & 0 & 0 & -1 \\
0 & 1 & 0 & 1 \\
0 & 0 & 1 & 0 \\
0 & 0 & 0 & 0
\end{array}\right]
$$

Com isso, através da aplicação do método proposto, verifica-se que $\left\{l_{4}\right\}$ é o único ramo crítico no SEP sob análise, quando da perda de um único equipamento (critério N-1).

- Teste 2: SEP com 13 barra e 16 ramos.

Considere agora um SEP composto por 13 barras e 16 ramos, apresentado na fig (4.4).

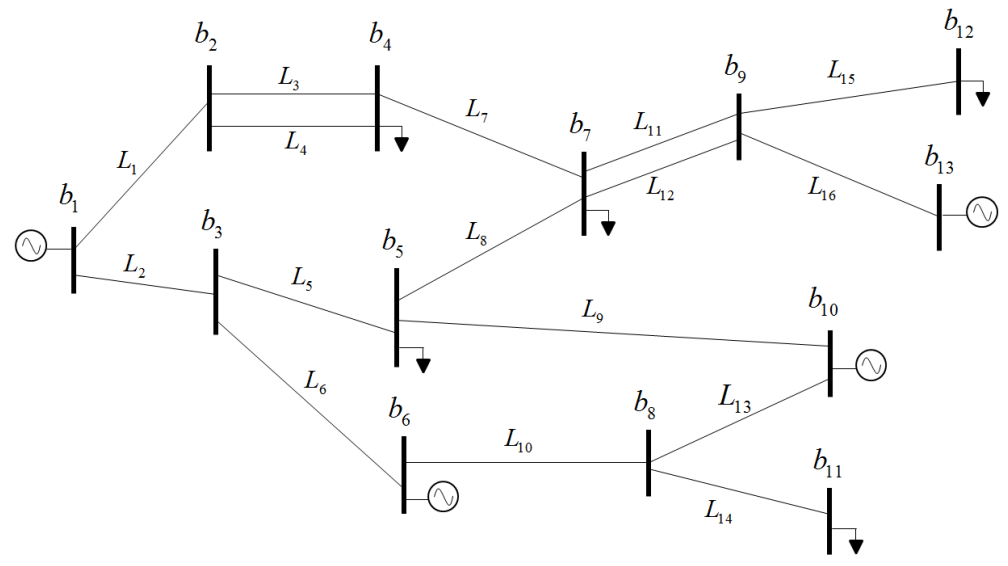

Figura 4.4: SEP composto de 13 barras e 16 ramos.

A matriz incidência nó-ramo, $H$, segundo a definição ([3.2.3), para o SEP da fig (4.4) é dada por: 


$$
H^{13 B / 16 R}=\left[\begin{array}{cccccccccccccccc}
l_{1} & l_{2} & l_{3} & l_{4} & l_{5} & l_{6} & l_{7} & l_{8} & l_{9} & l_{10} & l_{11} & l_{12} & l_{13} & l_{14} & l_{15} & l_{16} \\
1 & 1 & 0 & 0 & 0 & 0 & 0 & 0 & 0 & 0 & 0 & 0 & 0 & 0 & 0 & 0 \\
-1 & 0 & 1 & 1 & 0 & 0 & 0 & 0 & 0 & 0 & 0 & 0 & 0 & 0 & 0 & 0 \\
0 & -1 & 0 & 0 & 1 & 1 & 0 & 0 & 0 & 0 & 0 & 0 & 0 & 0 & 0 & 0 \\
0 & 0 & -1 & -1 & 0 & 0 & 1 & 0 & 0 & 0 & 0 & 0 & 0 & 0 & 0 & 0 \\
0 & 0 & 0 & 0 & -1 & 0 & 0 & 1 & 1 & 0 & 0 & 0 & 0 & 0 & 0 & 0 \\
0 & 0 & 0 & 0 & 0 & -1 & 0 & 0 & 0 & 1 & 0 & 0 & 0 & 0 & 0 & 0 \\
0 & 0 & 0 & 0 & 0 & 0 & -1 & -1 & 0 & 0 & 1 & 1 & 0 & 0 & 0 & 0 \\
0 & 0 & 0 & 0 & 0 & 0 & 0 & 0 & 0 & -1 & 0 & 0 & 1 & 1 & 0 & 0 \\
0 & 0 & 0 & 0 & 0 & 0 & 0 & 0 & 0 & 0 & -1 & -1 & 0 & 0 & 1 & 1 \\
0 & 0 & 0 & 0 & 0 & 0 & 0 & 0 & -1 & 0 & 0 & 0 & -1 & 0 & 0 & 0 \\
0 & 0 & 0 & 0 & 0 & 0 & 0 & 0 & 0 & 0 & 0 & 0 & 0 & -1 & 0 & 0 \\
0 & 0 & 0 & 0 & 0 & 0 & 0 & 0 & 0 & 0 & 0 & 0 & 0 & 0 & -1 & 0 \\
0 & 0 & 0 & 0 & 0 & 0 & 0 & 0 & 0 & 0 & 0 & 0 & 0 & 0 & 0 & -1
\end{array}\right] .
$$

Observa-se que a identificação dos ramos foi adicionada a matriz, na primeira linha da mesma, apenas para facilitar a identificação dos ramos críticos na etapa 4 do método proposto, uma vez que o processo de fatoração realiza uma mudança de base no espaço das barras do SEP, preservando desta maneira os ramos do sistema e possibilitando sua correta identificação.

Calculando então a matriz incidência nó-ramo fatorada $H_{F}$, através da fatoração triangular da matriz incidência $H^{13 B / 16 R}$, obtém-se:

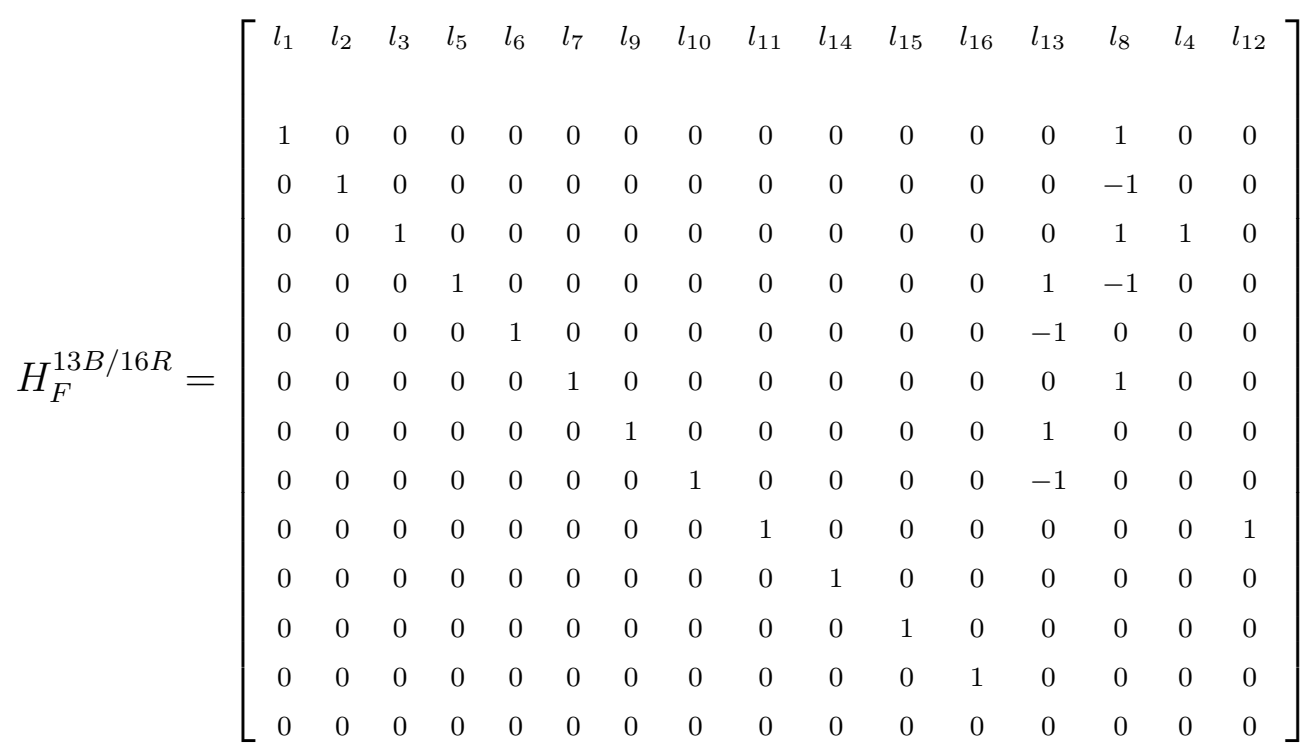


Através da análise da matriz $H_{F}^{13 B / 16 R}$, os ramos críticos para o SEP sob estudo são $\left\{l_{14}, l_{15}, l_{16}\right\}$. Analisando o SEP apresentado na fig (4.4), verifica-se que todos os casos de ilhamento, considerando o critério ( $\mathrm{N}-1)$ para perda de equipamentos, foram identificados pelo método proposto, o que ratifica as bases teóricas sobre as quais o mesmo foi concebido.

Agora, se retirarmos a linha $l_{13}$ do SEP anteriormente analisado, conforme apresentado na fig (4.5), elimina-se a única malha presente no sistema de transmissão, diminuindo o número de possíveis caminhos de interconexão entre as barras do SEP, de modo a aumentar o número de ramos críticos do mesmo.

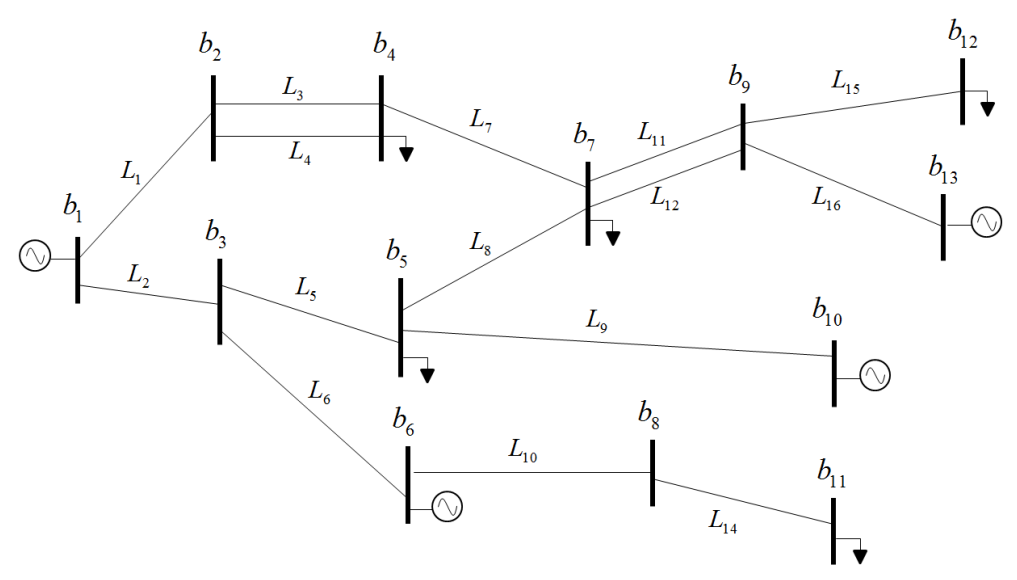

Figura 4.5: SEP composto de 13 barras e 16 ramos.

Desta maneira, segundo a definição (3.2.3), a matriz incidência nó-ramo $H$ para o SEP da fig (4.5) é dada por:

$$
H^{13 B / 15 R}=\left[\begin{array}{ccccccccccccccc}
l_{1} & l_{2} & l_{3} & l_{4} & l_{5} & l_{6} & l_{7} & l_{8} & l_{9} & l_{10} & l_{11} & l_{12} & l_{14} & l_{15} & l_{16} \\
1 & 1 & 0 & 0 & 0 & 0 & 0 & 0 & 0 & 0 & 0 & 0 & 0 & 0 & 0 \\
-1 & 0 & 1 & 1 & 0 & 0 & 0 & 0 & 0 & 0 & 0 & 0 & 0 & 0 & 0 \\
0 & -1 & 0 & 0 & 1 & 1 & 0 & 0 & 0 & 0 & 0 & 0 & 0 & 0 & 0 \\
0 & 0 & -1 & -1 & 0 & 0 & 1 & 0 & 0 & 0 & 0 & 0 & 0 & 0 & 0 \\
0 & 0 & 0 & 0 & -1 & 0 & 0 & 1 & 1 & 0 & 0 & 0 & 0 & 0 & 0 \\
0 & 0 & 0 & 0 & 0 & -1 & 0 & 0 & 0 & 1 & 0 & 0 & 0 & 0 & 0 \\
0 & 0 & 0 & 0 & 0 & 0 & -1 & -1 & 0 & 0 & 1 & 1 & 0 & 0 & 0 \\
0 & 0 & 0 & 0 & 0 & 0 & 0 & 0 & 0 & -1 & 0 & 0 & 1 & 0 & 0 \\
0 & 0 & 0 & 0 & 0 & 0 & 0 & 0 & 0 & 0 & -1 & -1 & 0 & 1 & 1 \\
0 & 0 & 0 & 0 & 0 & 0 & 0 & 0 & -1 & 0 & 0 & 0 & 0 & 0 & 0 \\
0 & 0 & 0 & 0 & 0 & 0 & 0 & 0 & 0 & 0 & 0 & 0 & -1 & 0 & 0 \\
0 & 0 & 0 & 0 & 0 & 0 & 0 & 0 & 0 & 0 & 0 & 0 & 0 & -1 & 0 \\
0 & 0 & 0 & 0 & 0 & 0 & 0 & 0 & 0 & 0 & 0 & 0 & 0 & 0 & -1
\end{array}\right]
$$


Calculando, agora, a "matriz incidência nó-ramo fatorada" $H_{F}$, através da fatoração triangular da matriz incidência $H^{11 B / 11 R}$, obtém-se:

$$
H^{13 B / 15 R}=\left[\begin{array}{ccccccccccccccc}
l_{1} & l_{2} & l_{3} & l_{5} & l_{6} & l_{7} & l_{9} & l_{10} & l_{11} & l_{14} & l_{15} & l_{16} & l_{8} & l_{4} & l_{12} \\
1 & 0 & 0 & 0 & 0 & 0 & 0 & 0 & 0 & 0 & 0 & 0 & 1 & 0 & 0 \\
0 & 1 & 0 & 0 & 0 & 0 & 0 & 0 & 0 & 0 & 0 & 0 & -1 & 0 & 0 \\
0 & 0 & 1 & 0 & 0 & 0 & 0 & 0 & 0 & 0 & 0 & 0 & 1 & 1 & 0 \\
0 & 0 & 0 & 1 & 0 & 0 & 0 & 0 & 0 & 0 & 0 & 0 & -1 & 0 & 0 \\
0 & 0 & 0 & 0 & 1 & 0 & 0 & 0 & 0 & 0 & 0 & 0 & 0 & 0 & 0 \\
0 & 0 & 0 & 0 & 0 & 1 & 0 & 0 & 0 & 0 & 0 & 0 & 1 & 0 & 0 \\
0 & 0 & 0 & 0 & 0 & 0 & 1 & 0 & 0 & 0 & 0 & 0 & 0 & 0 & 0 \\
0 & 0 & 0 & 0 & 0 & 0 & 0 & 1 & 0 & 0 & 0 & 0 & 0 & 0 & 0 \\
0 & 0 & 0 & 0 & 0 & 0 & 0 & 0 & 1 & 0 & 0 & 0 & 0 & 0 & 1 \\
0 & 0 & 0 & 0 & 0 & 0 & 0 & 0 & 0 & 1 & 0 & 0 & 0 & 0 & 0 \\
0 & 0 & 0 & 0 & 0 & 0 & 0 & 0 & 0 & 0 & 1 & 0 & 0 & 0 & 0 \\
0 & 0 & 0 & 0 & 0 & 0 & 0 & 0 & 0 & 0 & 0 & 1 & 0 & 0 & 0 \\
0 & 0 & 0 & 0 & 0 & 0 & 0 & 0 & 0 & 0 & 0 & 0 & 0 & 0 & 0
\end{array}\right]
$$

Com isso, através da análise da matriz incidência fatorada $H_{F}^{13 B / 15 R}$, os ramos críticos para o SEP são $\left\{l_{6}, l_{9}, l_{10}, l_{14}, l_{15}, l_{16}\right\}$. Analisando o SEP apresentado na fig (4.13), verificase que todos os casos de ilhamento, considerando o critério $(\mathrm{N}-1)$ para perda de equipamentos, foram identificados pelo método proposto.

Considere agora o caso em que somente os ramos $l_{1}, l_{2}, l_{5}, l_{6}, l_{7}, l_{9}, l_{10}, l_{11}, l_{12}, l_{13}$, $l_{14}, l_{15}$ e $l_{16}$ estão em operação. Sabemos que para esse caso ocorre um ilhamento, como mostrado na fig (4.6)).

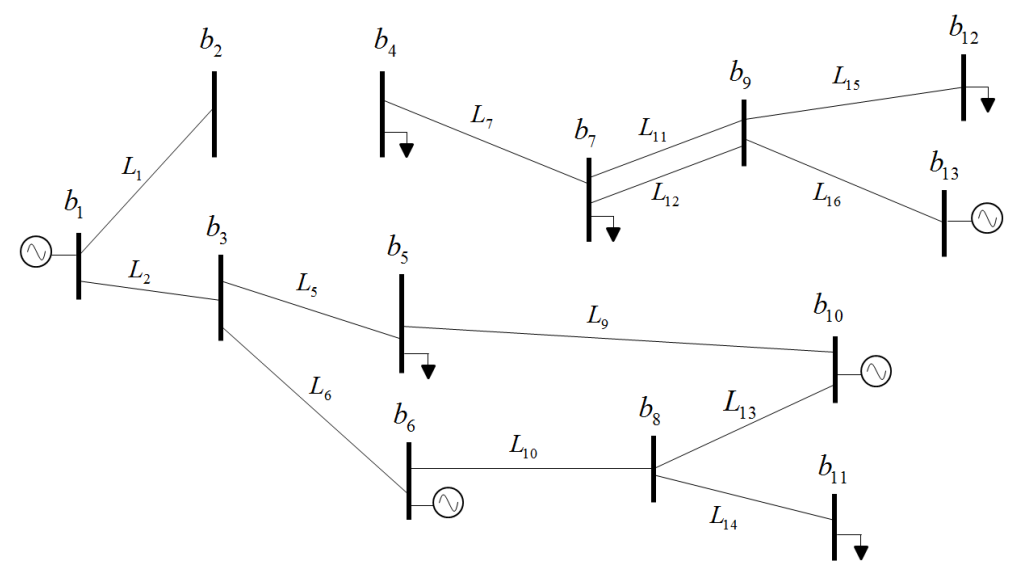

Figura 4.6: SEP composto de 13 barras e 16 ramos. 


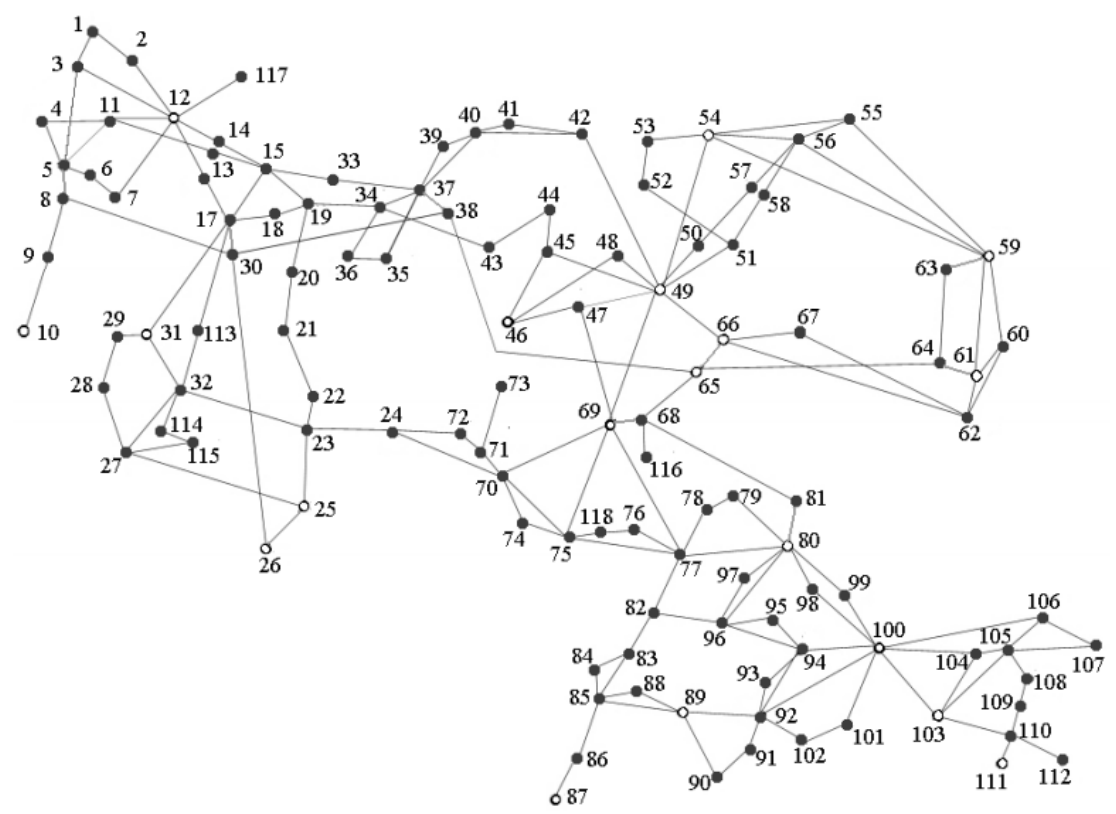

Figura 4.7: Grafo equivalente ao SEP IEEE 118-bus. Fonte: ([NA.JAFI, 200.9)

Pelo algoritmo de identificação de ilhas, temos que existem 2 ilhas: uma constituída pelos conjuntos de nós $X=\{1,2,3,5,6,8,10,11\}$ e outra pelos conjunto de nós $X^{\prime}=$ $\{4,7,9,12,13\}$. Para este caso, o SEP em análise é pequeno, é uma tarefa simples identificar as barras constituintes de cada ilha, porém a identificação das ilhas deixa de ser uma tarefa simples para SEPs de maior escala, como será mostrado a seguir.

- Teste 3: IEEE 118 bus

Considere agora um SEP IEEE 118 bus, apresentado na fig (4.7).

Foi feita a análise de redundância de ramos pela fatoração triangular da matriz incidência nó-ramo proposta na seção (4.4), e a análise de identificação de barramentos nas ilhas proposta na seção (4.4) para o sistema IEEE 118 bus. Os ramos críticos desse sistema são dadas na tabela (4.]).

Se retirarmos os ramos [barra33-barra37], [barra19-barra34], [barra30-barra38], [barra 24 - barra70], [barra70 - barra71], [barra47 - barra69] , [barra49 - barra69] e [barra65 - barra68] do SEP IEEE 118, como mostrado na fig (4.8), o SEP transforma-se em um sistema desconexo. 


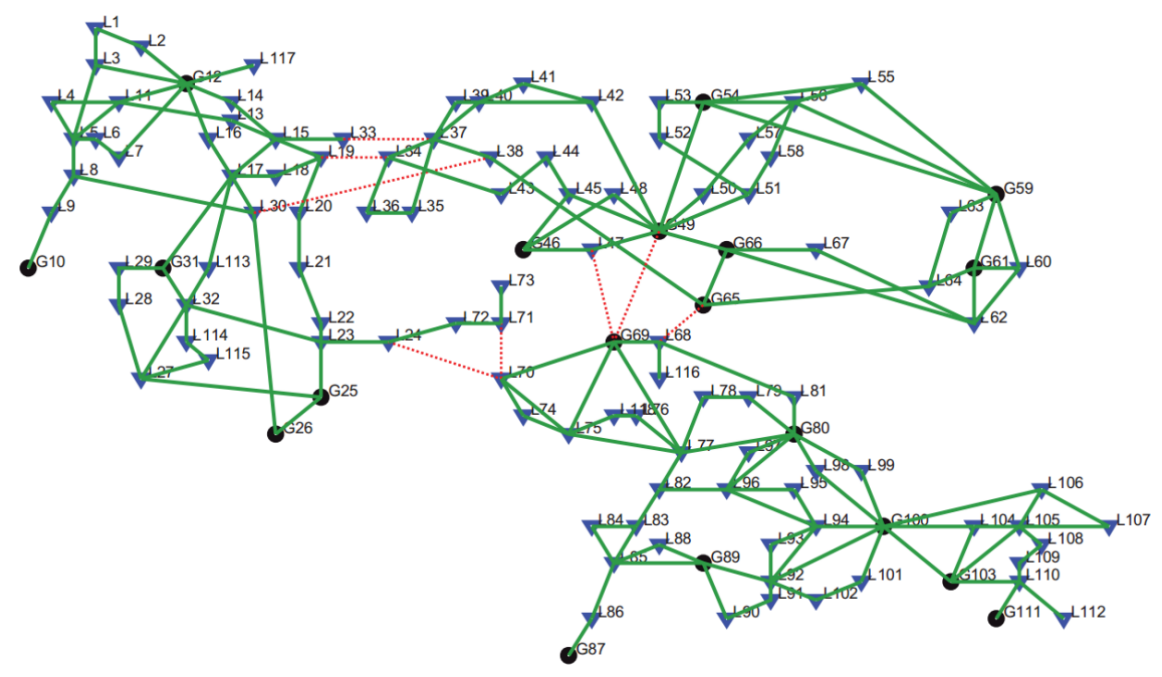

Figura 4.8: Grafo equivalente ao SEP IEEE 118-barra. Fonte: ([NA.IAFI, 2001)

Para determinar as barras que constituem cada ilha, o algoritmo exposto na seção(4.4) foi usado. Como resultado temos que foram criadas 2 ilhas, e a composição de cada ilha é dada na tabela (4.]).

\begin{tabular}{|c|c|c|}
\hline Ramo & Par de barramentos & Composição das Ilhas \\
\hline 7 & [barra8-barra9] & $\begin{array}{l}\text { ILHA 1: } 1234456781112131415161718 \\
1920212223242526272829303132333435 \\
3637383940414243444546474849505152 \\
5354555657585960616263646566676869 \\
70717273747576777879808182838485 \\
8687888990919293949596979899100101 \\
102103104105106107108109110111112113 \\
\text { 114 115 } 116117118 ; \\
\text { ILHA 2: } 910 ;\end{array}$ \\
\hline
\end{tabular}




\begin{tabular}{|c|c|c|}
\hline 9 & [barra9-barra10] & $\begin{array}{l}\text { ILHA 1: } 1234567891112131415161718 \\
1920212223242526272829303132333435 \\
3637383940414243444546474849505152 \\
5354555657585960616263646566676869 \\
70717273747576777879808182838485 \\
8687888990919293949596979899100101 \\
102103104105106107108109110111112113 \\
\text { 114 115 116 } 117118 ; \\
\text { ILHA 2: } 10 ;\end{array}$ \\
\hline 7 & [barra8-barra9] & $\begin{array}{l}\text { ILHA 1: } 123456781112131415161718 \\
1920212223242526272829303132333435 \\
3637383940414243444546474849505152 \\
5354555657585960616263646566676869 \\
70717273747576777879808182838485 \\
8687888990919293949596979899100101 \\
102103104105106107108109110111112113 \\
\text { 114 115 } 116117118 ; \\
\text { ILHA 2: } 910 ;\end{array}$ \\
\hline 113 & [barra71-barra73] & $\begin{array}{l}\text { ILHA 1: } 1234567891011121314151617 \\
1819202122232425262728293031323334 \\
3536373839404142434445464748495051 \\
5253545556575859606162636465666768 \\
69707172747576777879808182838485 \\
8687888990919293949596979899100101 \\
102103104105106107108109110111112113 \\
\text { 114 115 } 116117118 ; \\
\text { ILHA 2: } 73 ;\end{array}$ \\
\hline
\end{tabular}




\begin{tabular}{|c|c|c|}
\hline 133 & [barra85-barra86] & $\begin{array}{l}\text { ILHA 1: } 12234567891011121314151617 \\
1819202122232425262728293031323334 \\
3536373839404142434445464748495051 \\
525354555657585960616263646566 \quad 67 \\
68697071727374757677787980818283 \\
8485888990919293949596979899100101 \\
102103104105106107108109110111112113 \\
114115116117118 ; \\
\text { ILHA 2: } 8687\end{array}$ \\
\hline 134 & [barra86-barra87] & $\begin{array}{l}\text { ILHA 1: } 1234567891011121314151617 \\
1819202122232425262728293031323334 \\
3536373839404142434445464748495051 \\
5253545556575859606162636465666768 \\
69707172737475767778798081828384 \\
8586888990919293949596979899100101 \\
102103104105106107108109110111112113 \\
\text { 114 115 } 116117118 ; \\
\text { ILHA 2: } 87\end{array}$ \\
\hline 176 & [barra110-barra111] & $\begin{array}{l}\text { ILHA 1: } 1234567891011121314151617 \\
1819202122232425262728293031323334 \\
3536373839404142434445464748495051 \\
5253545556575859606162636465666768 \\
6970717273747576777879808182838485 \\
8687888990919293949596979899100101 \\
102103104105106107108109110112113114 \\
\text { 115 116 } 117118 ; \\
\text { ILHA 2: } 111\end{array}$ \\
\hline
\end{tabular}




\begin{tabular}{|c|c|c|}
\hline 177 & [barra110-barra112] & $\begin{array}{l}\text { ILHA 1: } 1234567891011121314151617 \\
1819202122232425262728293031323334 \\
3536373839404142434445464748495051 \\
5253545556575859606162636465666768 \\
6970717273747576777879808182838485 \\
8687888990919293949596979899100101 \\
102103104105106107108109110111113114 \\
115116117118 ; \\
\text { ILHA 2: } 112\end{array}$ \\
\hline 183 & [barra68-barra116] & $\begin{array}{l}\text { ILHA 1: } 1234567891011121314151617 \\
1819202122232425262728293031323334 \\
3536373839404142434445464748495051 \\
5253545556575859606162636465666768 \\
6970717273747576777879808182838485 \\
8687888990919293949596979899100101 \\
102103104105106107108109110111112113 \\
114115117118 ; \\
\text { ILHA 2: } 116\end{array}$ \\
\hline 184 & [barra68-barra116] & $\begin{array}{l}\text { ILHA 1: } 1234567891011121314151617 \\
1819202122232425262728293031323334 \\
3536373839404142434445464748495051 \\
5253545556575859606162636465666768 \\
6970717273747576777879808182838485 \\
8687888990919293949596979899100101 \\
102103104105106107108109110111112113 \\
\text { 114 115 } 116118 ; \\
\text { ILHA 2: } 117\end{array}$ \\
\hline
\end{tabular}

Tabela 4.1: Ramos críticos do sistema ieee 118 barras e analise de ilhamento. 


\begin{tabular}{|c|c|}
\hline Par de barramentos & Composição das Ilhas \\
\hline $\begin{array}{l}\text { [barra33-barra37], [barra19- } \\
\text { barra34], [barra30-barra38], } \\
\text { [barra24-barra70], [barra70- } \\
\text { barra71], [barra47-barra69] } \\
\text { [barra49-barra69] e } \\
\text { [barra65-barra68] }\end{array}$ & 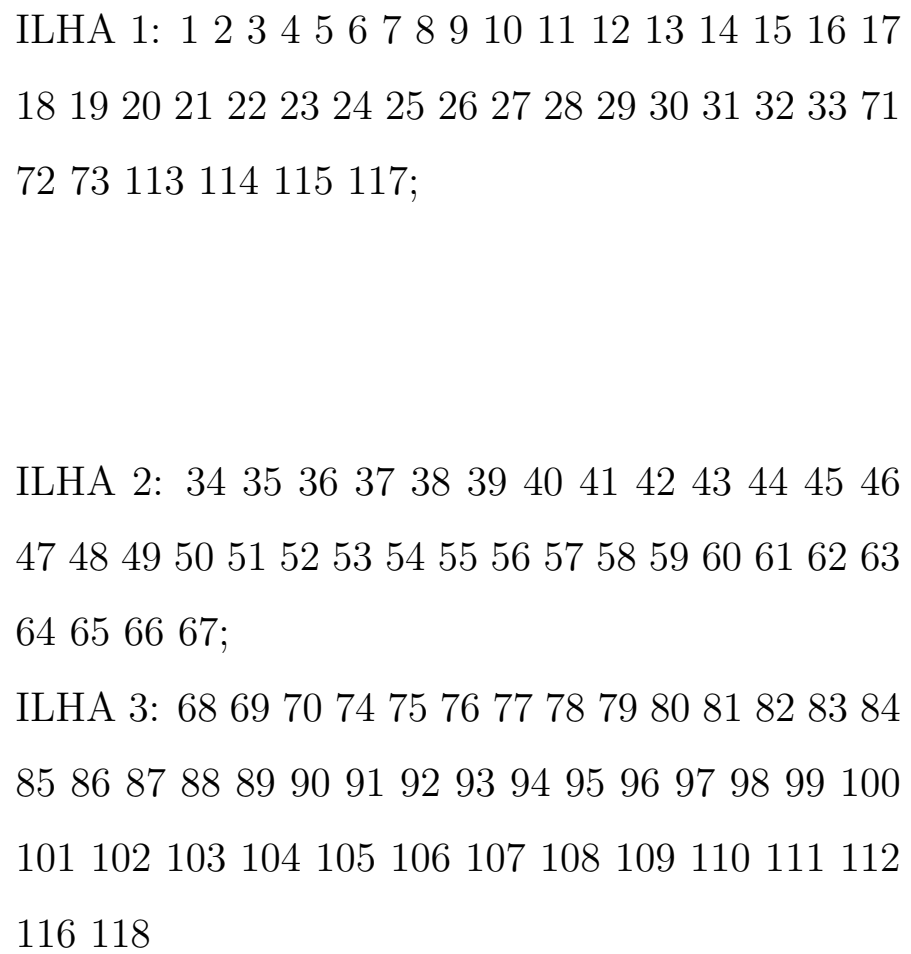 \\
\hline
\end{tabular}

Tabela 4.2: Ilhas formadas no SEP IEEE 118 barra pela retirado das ligações entre os barramentos [barra33 - barra37], [barra19 - barra34], [barra30 - barra38], [barra24 - barra70], [barra70 - barra71], [barra47 - barra69], [barra49 - barra69] e [barra65-barra68]. 



\section{Capítulo 5}

\section{Método Grafo-Algébrico para o Planejamento Ótimo de Ilhamento Intencional}

\subsection{Introdução}

Nesta capítulo, um novo método para projeto de ilhamento intencional é proposto. O objetivo deste método é, dado $n$ subconjuntos de barramentos pré selecionados $U_{1}, U_{2}$, $\ldots, U_{n}$, determinar os ramos cujo interrompimento causa a divisão do SEP em subsistemas (ilhas) de forma que cada subconjunto $U_{j}, j=1,2, \ldots, n$, de barramentos esteja em uma ilha isolada dos demais subconjuntos $U_{i}, i \neq j$, e que a ilha formada não tenha um desequilíbrio de potência maior que um determinado nível. Os subconjuntos de barramentos $U_{i}$ podem ser entendidos como os grupos de geradores coerentes, ou restrições sobre a estratégia de ilhamento, como por exemplo, a manutenção de contratos entre fornecedores/distribuidores/consumidores, entre outras restrições. 


\subsection{Método para o projeto de ilhamento intencional}

O método proposto para a determinação dos elementos da rede de transmissão a serem desligados, a fim de executar o ilhamento é constituído por uma etapa de adequação do grafo a ser analisado e uma etapa iterativa.

Inicialmente o SEP a ser analisado é modelado como um grafo, de modo que os barramentos são associados aos nós, as linhas de transmissão se associam as arestas e o fluxo de potência ativa aos pesos de cada aresta, resultando no grafo $G_{i}$. A matriz incidência nó-ramo $H_{i}$ correspondente ao grafo $G_{i}$ a ser analisado é gerada.

Na etapa de adequação uma matriz incidência nó-ramo $H_{s}$ correspondente a uma simplificação do grafo $G_{S}$ é gerada a partir da matriz $H_{i}$. Essa etapa visa reduzir o custo computacional do algoritmo, na expectativa de acelerar o processo de identificação. A partir do grafo $G_{S}$, tendo conhecimento de quais são as barras que compõem cada grupo $U_{1}, U_{2}, \ldots, U_{n}$, é gerada o grafo agregado $G$, de modo que cada nó agregado $q_{k}$, $k=1,2, \ldots, n$ é obtido a partir da agregação dos nós do conjunto de nós $U_{k}, k=1,2, \ldots, n$. A matriz incidência nó-ramo $H$ relativa ao grafo agregado $G$ é gerada nessa etapa, e toda a análise iterativa é feita baseada na matriz incidência $H$. Portanto a analise iterativa é feita sobre uma grafo com menor número de nós e arestas, com nós agregados. Em outras palavras, analisa-se um grafo menos complexo que o grafo inicial $G_{i}$.

A etapa iterativa pode ser dividida em 3 fases. Durante essa etapa cada nó agregado é analisado em sequência e defini-se o nó agregado $q_{j}, j=1, \ldots, n$ em analise como nó de referência. Na primeira fase, a fatoração triangular inferior ordenada da matriz $H$ é utilizada para determinar candidatos a cortes regulares relativos aos nós agregados $q_{1}$, $q_{2}, \ldots, q_{n}$. Portanto, com base na definição (इ2.17), podemos interpretar o processo de fatoração inferior triangular ordenada da matriz $H$ como uma busca por candidatos a cortes, ou um processo de busca de possíveis nós a serem agregados a um nó agregado de referencia $q_{j}, j=1,2, \ldots, n$, em análise.

Na segunda fase são verificados se os cortes candidatos são de fato cortes regulares, ou seja, se esse cortes dividem a rede em duas componentes conexas com os nós $q_{j}$ e $q_{k \neq j}$ em componentes distintas. Caso um determinado corte não seja regular, conforme a definição 
([2.13), um processo de regularização do corte não regular é realizado.

Finalmente, na terceira fase são verificados quais são os cortes com o menor custo dentre os obtidos na primeira e segunda fase conforme a definição ([.2.15), agregando-se ao nó de referencia $q_{j}$ os nós que proporcionam o menor custo. A analise iterativa é realizada até que todas as ilhas geradas possuam uma diferença percentual entre cargas e geração dentro da ilha $R_{k}$ menor ou igual a um valor $T$ limite (Critério de parada), ou até que não seja mais possível agregar nenhum nó.

O valor da diferença diferença percentual $R_{k}$ entre cargas e geração em cada ilha pode ser calculada pela equação (5.]).

$$
R_{k}=\frac{\left|P g_{k}-P c_{k}\right|}{P g_{k}}
$$

Na equação (5.]) $P g_{k}$ é o somatório da potência gerada pelos geradores da ilha $k$ e $P c_{k}$ é o somatório da carga de todos os barramentos da ilha $k$.

Na fig (5.7) é mostrado o fluxograma do algoritmo.

Também é importante notar que a estrutura esparsa da matriz incidência nó-ramo $H$ pode ser explorada para aumentar a eficiência computacional e de armazenamento ([INNEY; BRANDWAJN; CHAN, 1985). Nas sessões a seguir cada etapa é explicada com mais detalhes.

\subsubsection{Etapa de Adequação}

Inicialmente é gerada a matriz incidência nó-ramo $H_{i}$ relativa a um grafo $G_{i}(\mathcal{N}, \mathcal{E})$ e representante do SEP a ser analisado. A simplificação do grafo $G_{i}$ é feita a partir da matriz $H_{i}$. A complexidade do problema de projeto de ilhamento é proporcional ao tamanho do SEP em questão, especialmente pelo número de nós, o que também é igual ao número de variáveis de decisão no problema de ilhamento.

Porém, ao levar em consideração o contexto de operação do sistema e as propriedades topológicas da rede, se torna possível reduzir os nós e ramos de um grafo, ou seja, reduzir 


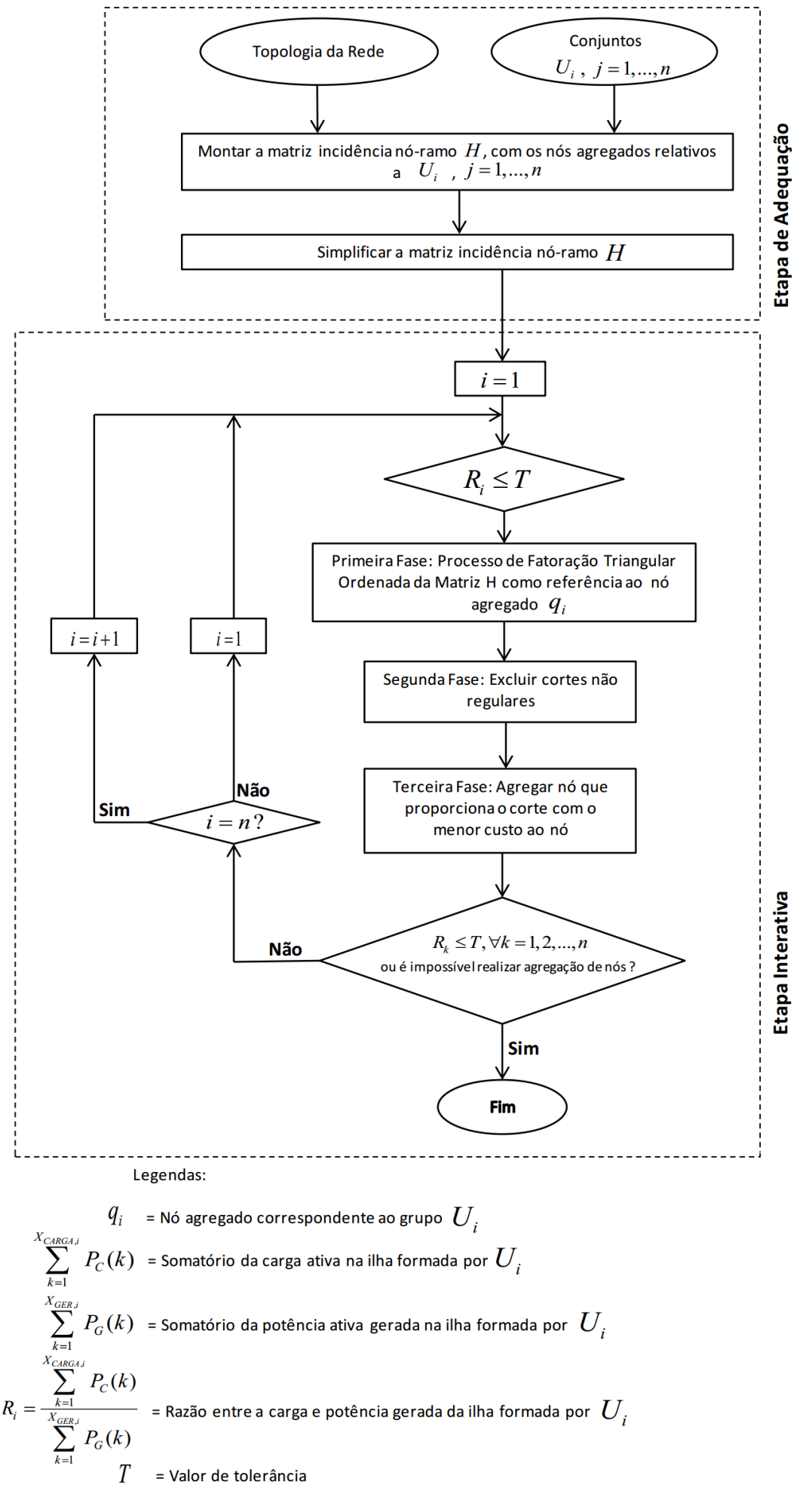

Figura 5.1: Fluxograma do Algoritmo de determinação de cutsets para o ilhamento controlado. 
o número de variáveis de decisão para muitos casos. Esses casos são listados a seguir:

1. Para casos onde existe mais de um ramo que conecta um par de nós: Para fins de ilhamento controlado, ao menos na forma como este problema é tratado nesse trabalho, o número de ramos que conectam um par de nós não é relevante. Então, caso seja necessário separar um par de nós conectas por múltiplos ramos, todos os ramos devem ser "retirados" do grafo, ou para o caso contrário, todos os ramos devem ser mantidos no grafo, ou seja, o que é relevante é a conexão entre nós, e não a forma como esta é feita. Na matriz $H_{i}$ os ramos que ligam o mesmo par de nós apresentarão colunas iguais, como exemplificado na fig (52). Para este caso, a simplificação do grafo consiste na eliminação da coluna de $H_{i}$ que representa os ramos redundantes em relação a conexão de um par de nós.
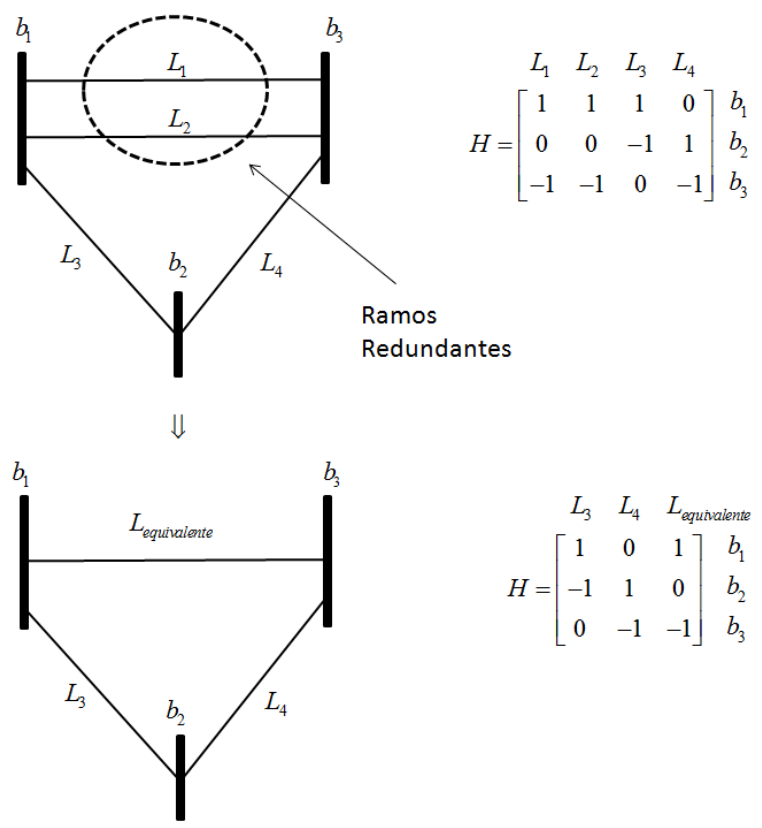

Figura 5.2: Caso 1 para simplificação.

2. Para o caso em que um grupo de nós não geradores $X$ só possam ser agregados a qualquer grupo de geradores $U_{k}, k=1,2, \ldots, n$ : Isso ocorre quando qualquer caminho de um elemento de $X$ a qualquer elemento de $U_{j}, j \neq k$ deve passar obrigatoriamente ao menos por um elemento de $U_{k}$. Em outras palavras, é impossível ter uma ilha que contenha barramentos representados pelo grupo de nós $X$ e do grupo geradores de $U_{j}, j \neq k$ sem que exista algum gerador do grupo $U_{k}$. Como geradores não 
coerentes não podem pertencer a mesma ilha, pode-se concluir que o grupo de nós não geradores em questão só pode pertencer a um grupo de geradores $U_{k}$. Na matriz $H_{i}$ é possível observar que se retirarmos as linhas relativas ao grupo de geradores no qual um nó, ou um grupo de nós devem pertencer de forma exclusiva, será gerada uma matriz com posto menor que $(n-1)$, o que indica que aquele grupo de geradores é fundamental para que haja conexão entre um grupo de nós e o restante do grafo. A fig (5.3) ilustra esse caso.

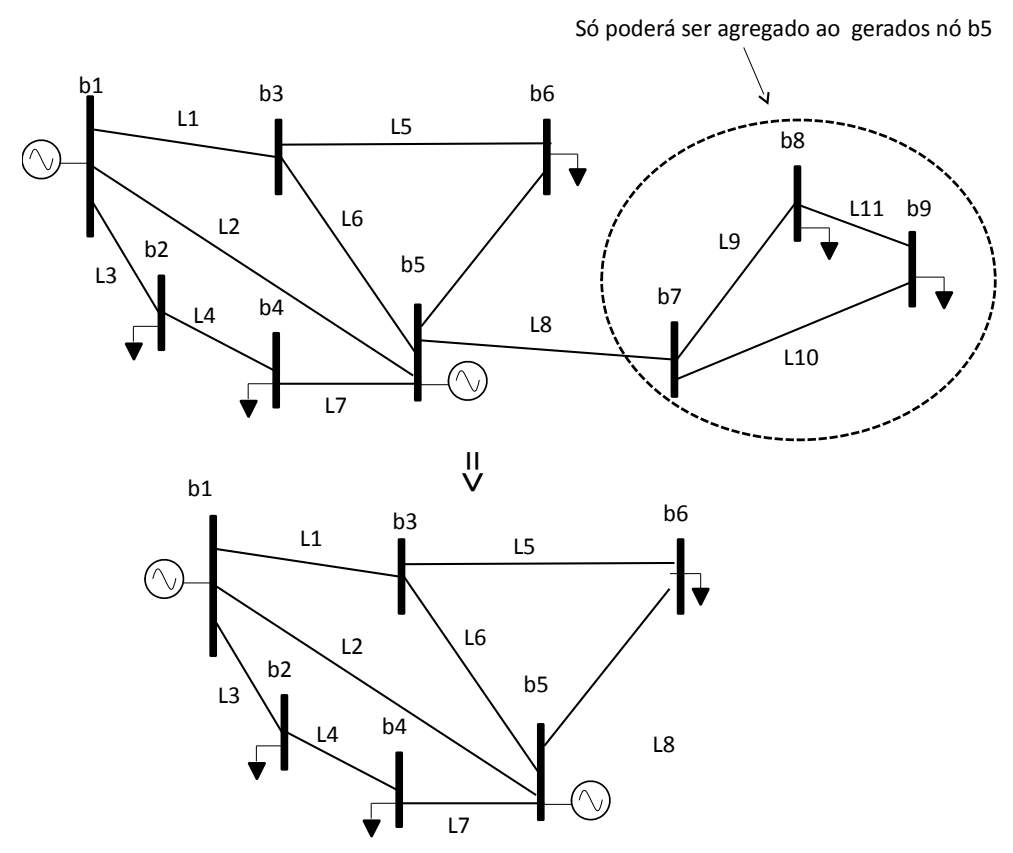

Figura 5.3: Caso 2 para simplificação.

3. Para casos onde os elementos de um grupo de nós não geradores $X$ devem pertencer obrigatoriamente a mesma ilha: Nesses casos, o grupo de nós $X$ passa a ser representado no grafo simplificado por um nó de cargas agregado. Uma forma de identificar casos como esse é através da constatação da existência de apenas um caminho entre os nós $X$ e os nós $X^{\prime}, X^{\prime} \subset \mathcal{N} \neq X$, como mostrado na fig (5.4). Para esses casos, os nós do conjunto $X$ são representados por um nó agregado. Existem casos onde ha múltiplos caminhos entre os grupos de nós $X^{\prime}$ e $X$. Essa etapa de simplificação não consegue detectar casos como esse, porém estes podem ser tratados pela segunda fase da etapa iterativa.

Após a etapa de simplificação, os $n$ subconjuntos de nós $U_{1}, U_{2}, \ldots, U_{n}$ representantes 


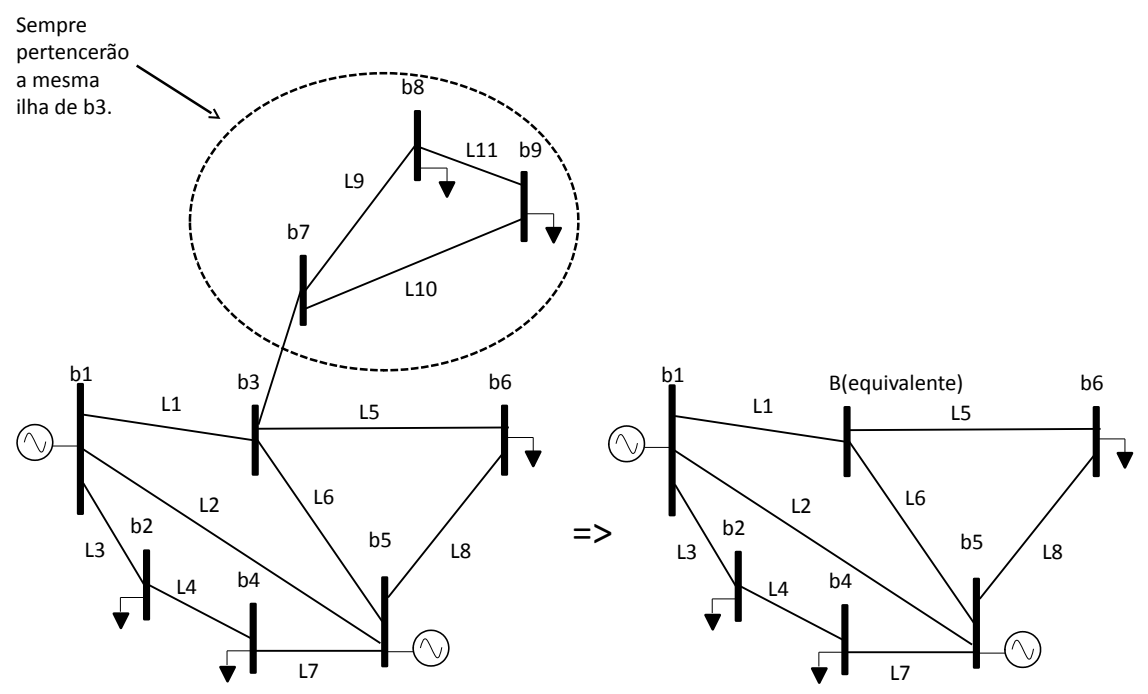

Figura 5.4: Caso 3 para simplificação..

de barramentos que devem ser separados em ilhas distintas. Como todos os nós pertencentes a um mesmo grupo $U_{j}, j=1, \ldots, n$ são agregados, gerando o nó agregado $q_{j}$. Isso se justifica no fato de que todos os nós pertencentes ao grupo $U_{j}$ devem estar em uma mesma ilha ao final do etapa iterativa, e o grafo gerado pela agregação de nós possui uma menor ordem, o que melhora a eficiência do método. A partir do grafo agregado formado, uma nova matriz incidência nó-ramo $H$ é construída.

\subsubsection{Etapa Iterativa}

- Primeira Etapa: Determinação de candidatos a grupo de conte

O método proposto neste trabalho é baseado na fatoração triangular inferior ordenada da matriz incidência nó-ramo $H$ e na análise de ilhamento proposta em (एHE()D)RO et al., (2012). A fatoração ordenada da matriz $H$ é utilizada para identificar os ramos cujo interrompimento causa a divisão do sistema de potência, que de acordo com a definição (3.2.17) é o mesmo que identificar nós a serem agregados a um nó de referência $q_{n}$. O 
propósito do uso da fatoração ordenada é justamente encontrar nós candidatos a agregação para uma seleção de qual possível agregação poderá produzir um menor impacto sobre o equilíbrio entre potência gerada e consumida, e consequentemente uma ilha com maior probabilidade de possuir equilíbrio energético. A fatoração realiza combinações entre as linhas de $H$, gerando nós e grafos agregados equivalentes.

Tanto a fatoração triangular inferior quanto a superior fazem o mesmo tipo de associação, porém a fatoração triangular inferior sempre gera nós agregados (THE()D()RO) et al, 2012 ), tornando seu uso direto para fins de ilhamento intencional, enquanto que a etapa de fatoração triangular superior não é diretamente relacionada a esse tipo de interpretação, de forma que o uso desse passo nem sempre é claro pra fins de ilhamento intencional.

De acordo com o corolário ( 3.2 .201$)$, cada linha de $H$ representa um conjunto de corte para um barramento do sistema. Portanto, na etapa de fatoração triangular inferior, após cada combinação entre as linhas, um novo conjunto de corte é formado. Porém, é preciso certificar-se de que o corte gerado seja um corte regular relativo ao grupo de nós distintos $X$ e $X$.

A primeira medida a ser tomada a fim de evitar a geração de nós agregados indesejados, e consequentemente, cortes não regulares, é a ordenação do processo de fatoração. Além disso, o caminho de fatoração triangular inferior ordenada da matriz $H$ é guiado a buscar cortes com o menor custo $J\left(C\left(\left\{X, X^{\prime}\right\}\right)\right)$, ou seja, a ordem de fatoração é convenientemente escolhida de modo a direcionar a busca por conjuntos de corte minimais locais de cada nó agregado. A fatoração triangular inferior ordenada age como um instrumento de busca pelo melhor conjunto de nós a ser agregado na vizinhança do nó agregado de referência, e consequentemente um melhor grupo de corte pela vizinhança. O algoritmo que demonstra o funcionamento da primeira fase é mostrado na fig 5.5 .

É importante observar que a fatoração não gera todos os conjuntos de corte possíveis. Entretanto veremos que ela gera bons candidatos para cortes minimais locais. Esta aparente fraqueza do método não é uma desvantagem prática, uma vez que os critérios de ilhamento intencional poderiam ser estabelecidos em termos de um impacto máximo permitido ao longo do sistema de potência, e a velocidade do método na procura de uma 


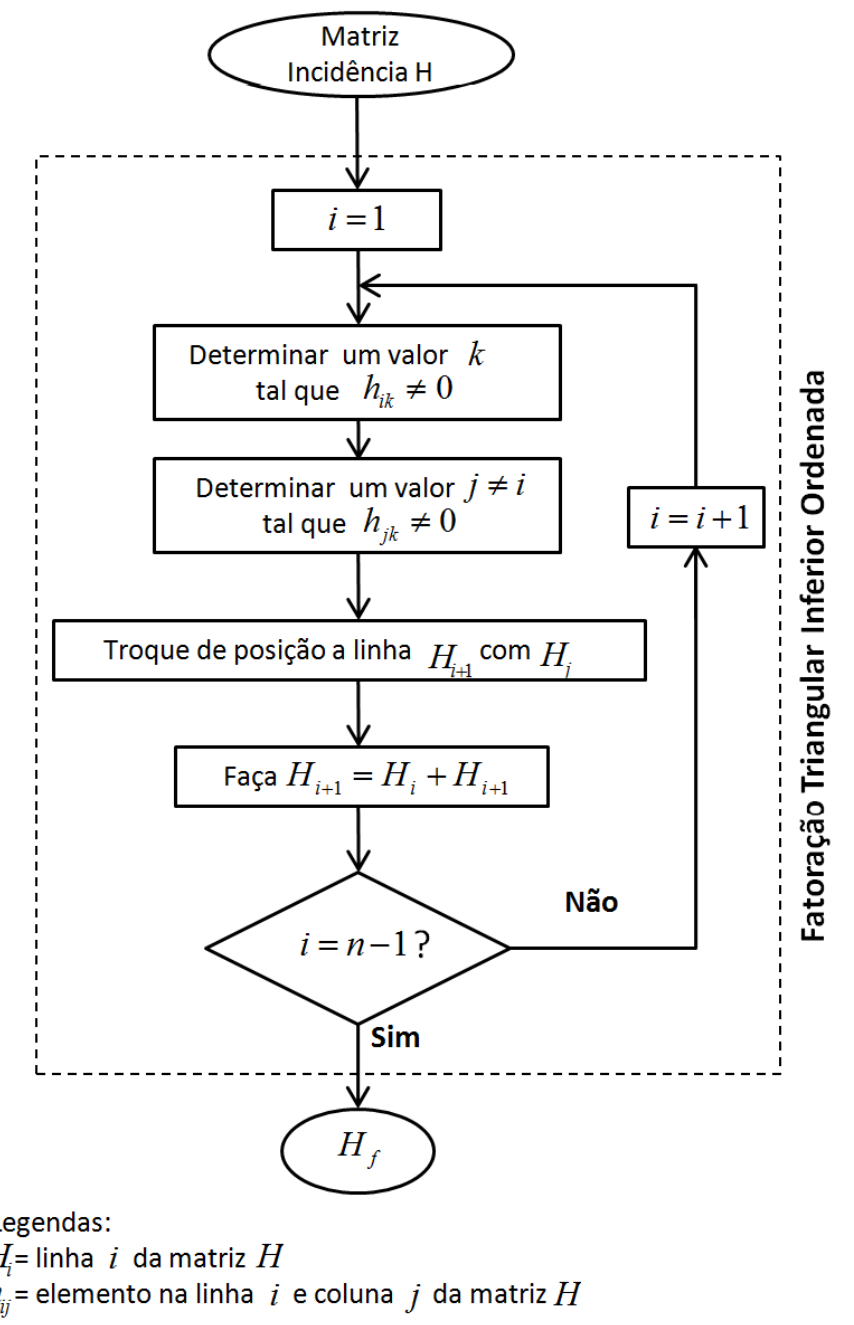

Figura 5.5: Fatoração Triangular Inferior Ordenada. 


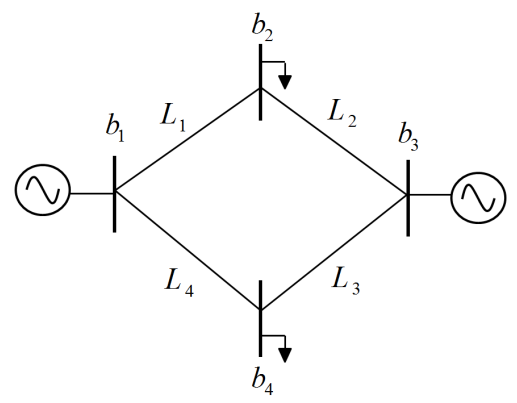

Figura 5.6: Sistema de potência 4-barras / 4-linhas.

solução razoável pode compensar a resposta subótima para aplicações em tempo-real.

O exemplo a seguir ilustra o procedimento da primeira fase da etapa iterativa.

- Exemplo A

Considere o sistema com 4 barramentos e 4 linhas, mostrado na Fig. 5.6 .

Deseja-se propor um ilhamento intencional para separar os barramentos de geradores (barramento 1 e 3), primeiramente sem nenhum critério adicional. E fácil constatar que todos os cortes regulares que separam os barramentos 1 e 3 são: $\left\{L_{1}, L_{4}\right\},\left\{L_{2}, L_{4}\right\}$, $\left\{L_{1}, L_{3}\right\}$ e $\left\{L_{2}, L_{3}\right\}$. A matriz incidência nó-ramo é dada por:

$$
H=\left[\begin{array}{ccccc} 
& L_{1} & L_{2} & L_{3} & L_{4} \\
b_{1} & 1 & 0 & 0 & -1 \\
b_{2} & -1 & 1 & 0 & 0 \\
b_{4} & 0 & 0 & -1 & 1 \\
b_{3} & 0 & -1 & 1 & 0
\end{array}\right]
$$

A primeira linha e primeira coluna na matriz $H$ é um rótulo para simplificar a visualização e identificação do ramo e o correspondente barramento para cada coluna e cada linha. É importante lembrar que a orientação (pseudo) adotada neste exemplo é arbitrária. Na execução da fatoração triangular inferior orientada, obtém-se o seguinte resultado:

$$
H_{f}=\left[\begin{array}{ccccc} 
& L_{1} & L_{4} & L_{2} & L_{3} \\
b_{1} & 1 & -1 & 0 & 0 \\
b_{1}+b_{2} & 0 & -1 & 1 & 0 \\
b 1+b 2+b_{4} & 0 & 0 & 1 & -1 \\
b 1+b 2+b_{4}+b_{3} & 0 & 0 & 0 & 0
\end{array}\right]
$$


Observando as linhas da matriz $H_{f}$, podemos concluir que os conjuntos de corte são: $\left\{L_{1}, L_{4}\right\},\left\{L_{2}, L_{4}\right\}$ e $\left\{L_{2}, L_{3}\right\}$.

Note que, ao posicionar os nós agregados equivalente na primeira e na última linha de $H$, após a fatoração triangular inferior ordenada, a matriz nó-ramo transformada mostra em suas linhas os conjuntos de corte que separam os nós agregados em diferentes ilhas, porém não mostram todos os possíveis conjuntos de corte.

Considere agora a matriz $H^{*}$, do mesmo sistema mostrado na fig (5.6]) e sobre o mesmo ilhamento intencional, mas com uma ordem diferente de linhas e colunas:

$$
H^{*}=\left[\begin{array}{ccccc} 
& L_{4} & L_{3} & L_{1} & L_{2} \\
b_{1} & -1 & 0 & 1 & 0 \\
b_{4} & 1 & -1 & 0 & 0 \\
b_{2} & 0 & 0 & -1 & -1 \\
b_{3} & 0 & 1 & 0 & 1
\end{array}\right]
$$

Após a fatoração, temos:

$$
H_{f}^{*}=\left[\begin{array}{ccccc} 
& L_{4} & L_{1} & L_{3} & L_{2} \\
b_{1} & -1 & 1 & 0 & 0 \\
b_{1}+b_{4} & 0 & 1 & -1 & 0 \\
b_{1}+b_{4}+b_{2} & 0 & 0 & -1 & -1 \\
b_{1}+b_{2}+b_{4}+b_{3} & 0 & 0 & 0 & 0
\end{array}\right]
$$

Então, ao observar as linhas da matriz $H_{f}^{*}$, podemos concluir que os conjuntos de corte são dados por: $\left\{L_{1}, L_{4}\right\},\left\{L_{1}, L_{3}\right\}$ and $\left\{L_{3}, L_{2}\right\}$. Note que os cortes $\left\{L_{1}, L_{2}, L_{4}\right\}$ e $\left\{L_{1}, L_{3}, L_{4}\right\}$ também separam os barramentos 1 e 3, porém geram mais de 2 ilhas, ou seja, são cortes não regulares. A segunda etapa do método de ilhamento proposto nesse trabalho foi feita para excluir esse tipo de corte (corte não regular) do conjunto de corte a ser gerado. Na análise de ilhamento, observa-se que todos os cortes obtidos são regulares e provocam o ilhamento desejado, portanto todos os cortes devem ser considerados. 


\subsubsection{Segunda Etapa}

Caso o objetivo do método de ilhamento seja dividir o SEP modelado pelo grafo $G(\mathcal{N}, \mathcal{E})$, em $n$ subgrafos conexos relativos aos subconjuntos $U_{1}, U_{2}, \ldots, U_{n}$, temos que se um determinado conjunto de corte $C_{j}$ gerar mais de $n$ ilhas conexas, tal corte não é regular.

Como o objetivo do método de determinação de grupos de corte para ilhamento controlado não é somente segregar os $n$ grupos de geradores coerentes, mas também gerar ilhas com uma determinada razão estabelecida de equilíbrio energético, possivelmente cortes irregulares deverão ser considerados. A opção de se efetuar um desligamento de carga para que uma determinada ilha possa ter um nível de equilíbrio de potência gerada versus carga desejado não é descartada. Por outro lado, evitar que grupos de corte irregulares gerados na fase de fatoração sejam considerados, ao menos na agregação de nós, reduz o número de nós candidatos a agregação, o que pode evitar um maior número de variáveis de decisão e acelerar a análise.

A fatoração triangular inferior ordenada não garante que todos os cortes observados na matriz fatorada sejam regulares, ou seja, geram grafos induzidos conexos, como pode ser visto no exemplo B. Para evitar que cortes irregulares sejam considerados em um grupo de corte é necessário verificar, para cada conjunto de corte encontrado, quantas ilhas são formadas.

O principio de funcionamento da segunda fase é o seguinte: Se deseja-se é dividir o SEP, que é modelado pelo grafo $G(\mathcal{N}, \mathcal{E})$, em dois subgrafos conexos relativos aos subconjuntos $U_{1}$ e $U_{2}$, temos que se um determinado conjunto de corte $C_{j}$ gerar mais de duas ilhas conexas, tal corte não é regular. Portanto, para verificar se o corte $C_{j}$ gerado é regular, basta analisar o ilhamento sobre o grafo $\bar{G}(\mathcal{N}, \overline{\mathcal{E}})$ gerado pelo corte $C_{j}$ a partir de $G(\mathcal{N}, \mathcal{E})$, onde $\overline{\mathcal{E}}=\mathcal{E} \backslash C_{j}$.

Na execução desta análise, são retiradas da matriz incidência nó-ramo $H$ as colunas que representam as arestas pertencentes ao conjunto de corte $C_{j}$, formando uma nova matriz incidência nó-ramo $\bar{H}$. Com a ajuda do algoritmo proposto por (CHE()D()RO) et al., (2012) para a análise de ilhamento não intencional, verifica-se se a matriz incidência 
nó-ramo $\bar{H}$ representa um grafo com duas ilhas: uma formada pelo nó de referencia $q_{j}$ e outra com os demais nós agregados $q_{k}, k \neq j$. Se na análise de $\bar{H}$ forem detectadas mais de duas ilhas ou ilhas indesejadas, temos um indicativo de que o corte $C_{j}$ não seja regular.

Caso algum corte encontrado não seja um corte regular, este deverá ser regularizado. O processo de regularização de um corte consiste em retirar do conjunto de corte as arestas que não separam os conjuntos $U_{j}, j=1, \ldots, n$ e que provocam um ilhamento não regular. Em outras palavras, é adicionado ao conjunto de nós a serem agregados ao nó de referência $q_{j}$ o conjunto de nós que estaria formando as ilhas indesejadas, desde que esses nós não representem geradores. O exemplo a seguir ilustra o procedimento da primeira e segunda etapa do algoritmo.

- Exemplo B

Considere o sistema com 7 barramentos e 8 linhas, mostrado na Fig. 5.7.

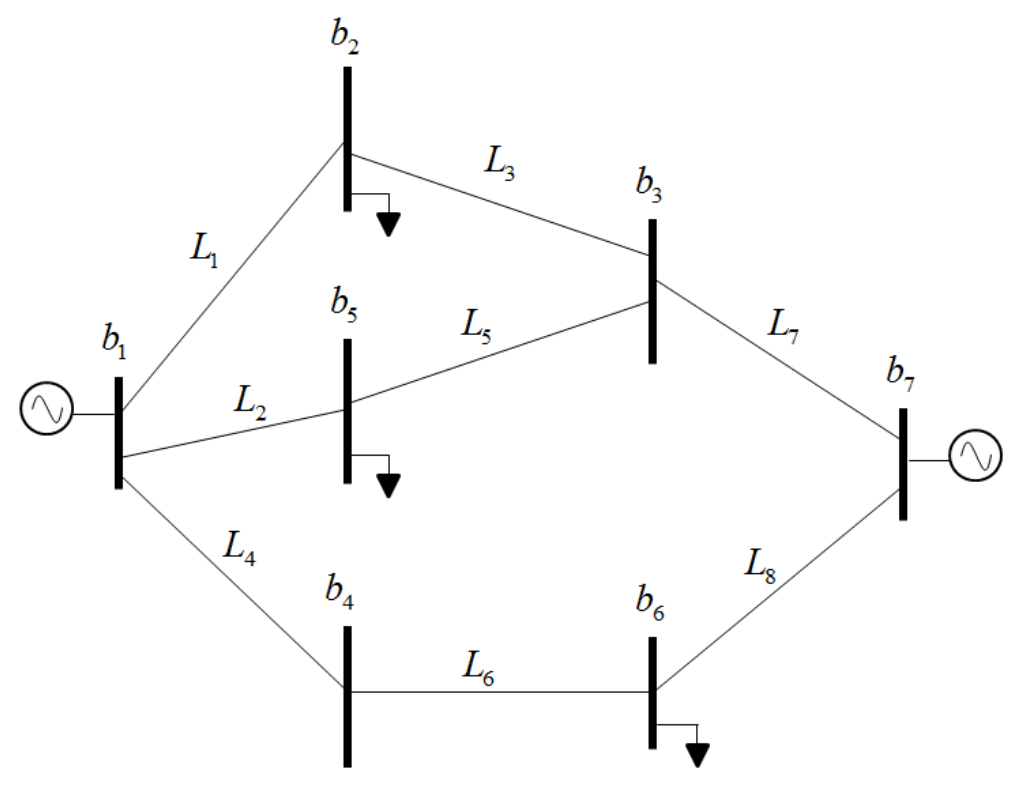

Figura 5.7: Sistema de potência 7-barras/8-linhas.

Neste exemplo é desejado efetuar um ilhamento intencional para separar os barramentos de geradores (barramento 1 e 7), primeiramente sem nenhum critério adicional. É possível constatar que todos os cortes regulares que separam os barramentos 1 e 7 são: $\left\{L_{1}, L_{2}, L_{4}\right\},\left\{L_{1}, L_{2}, L_{6}\right\},\left\{L_{1}, L_{2}, L_{8}\right\},\left\{L_{1}, L_{4}, L_{5}\right\},\left\{L_{1}, L_{5}, L_{6}\right\},\left\{L_{1}, L_{5}, L_{8}\right\}$, 
$\left\{L_{2}, L_{3}, L_{4}\right\},\left\{L_{2}, L_{3}, L_{6}\right\},\left\{L_{2}, L_{3}, L_{8}\right\},\left\{L_{3}, L_{5}, L_{4}\right\},\left\{L_{3}, L_{5}, L_{6}\right\},\left\{L_{3}, L_{5}, L_{8}\right\},\left\{L_{4}, L_{7}\right\}$, $\left\{L_{6}, L_{7}\right\}$ e $\left\{L_{7}, L_{8}\right\}$. A matriz incidência nó-ramo é dada por:

$$
H=\left[\begin{array}{ccccccccc} 
& L_{1} & L_{2} & L_{3} & L_{4} & L_{5} & L_{6} & L_{7} & L_{8} \\
b_{1} & 1 & 1 & 0 & 1 & 0 & 0 & 0 & 0 \\
b_{2} & -1 & 0 & 1 & 0 & 0 & 0 & 0 & 0 \\
b_{3} & 0 & 0 & -1 & 0 & 1 & 0 & 1 & 0 \\
b_{4} & 0 & 0 & 0 & -1 & 0 & 1 & 0 & 0 \\
b_{5} & 0 & -1 & 0 & 0 & -1 & 0 & 0 & 0 \\
b_{6} & 0 & 0 & 0 & 0 & 0 & -1 & 0 & 1 \\
b_{7} & 0 & 0 & & 0 & 0 & 0 & -1 & -1
\end{array}\right]
$$

Assim como no exemplo A, a primeira linha e a primeira coluna na matriz H são apenas rótulos para simplificar a visualização e identificação do ramo e o correspondente barramento para cada coluna e cada linha.

Na execução da fatoração triangular inferior orientada, obtém-se o seguinte resultado:

$$
H_{f}=\left[\begin{array}{ccccccccc} 
& L_{1} & L_{3} & L_{4} & L_{5} & L_{6} & L_{7} & L_{2} & L_{8} \\
b_{1} & 1 & 0 & 1 & 0 & 0 & 0 & 1 & 0 \\
b_{1}+b_{2} & 0 & 1 & 1 & 0 & 0 & 0 & 1 & 0 \\
b_{1}+b_{2}+b_{3} & 0 & 0 & 1 & 1 & 0 & 1 & 1 & 0 \\
b_{1}+b_{2}+b_{3}+b_{4} & 0 & 0 & 0 & 1 & 1 & 1 & 1 & 0 \\
b_{1}+b_{2}+b_{3}+b_{4}+b_{5} & 0 & 0 & 0 & 0 & 1 & 1 & 0 & 0 \\
b_{1}+b_{2}+b_{3}+b_{4}+b_{5}+b_{6} & 0 & 0 & 0 & 0 & 0 & 1 & 0 & 1 \\
b_{1}+b_{2}+b_{3}+b_{4}+b_{5}+b_{6}+b_{7} & 0 & 0 & & 0 & 0 & 0 & 0 & 0
\end{array}\right]
$$

Observando as linhas da matriz $H_{f}$, podemos concluir que os conjuntos de corte sugeridos são: $\left\{L_{1}, L_{2}, L_{4}\right\},\left\{L_{2}, L_{3}, L_{4}\right\},\left\{L_{2}, L_{4}, L_{5}, L_{7}\right\},\left\{L_{2}, L_{5}, L_{6}, L_{7}\right\},\left\{L_{6}, L_{7}\right\}$ e $\left\{L_{7}, L_{8}\right\}$.

Note que, ao posicionar os nós agregados equivalente na primeira e na última linha de $H$, após a fatoração triangular inferior ordenada, a matriz nó-ramo transformada mostra em suas linhas os conjuntos de corte que separam os nós agregados em diferentes ilhas, porém os cortes $\left\{L_{2}, L_{4}, L_{5}, L_{7}\right\}$ e $\left\{L_{2}, L_{5}, L_{6}, L_{7}\right\}$ geram mais de 2 ilhas, ou seja, são cortes não regulares.

Na fig (5.8) podemos visualizar essa condição.

Por esse exemplo, podemos observar que nem todos os corte gerados pela fatoração ordenada são cortes regulares, ou seja, devem ser considerados, o que justifica a imple- 


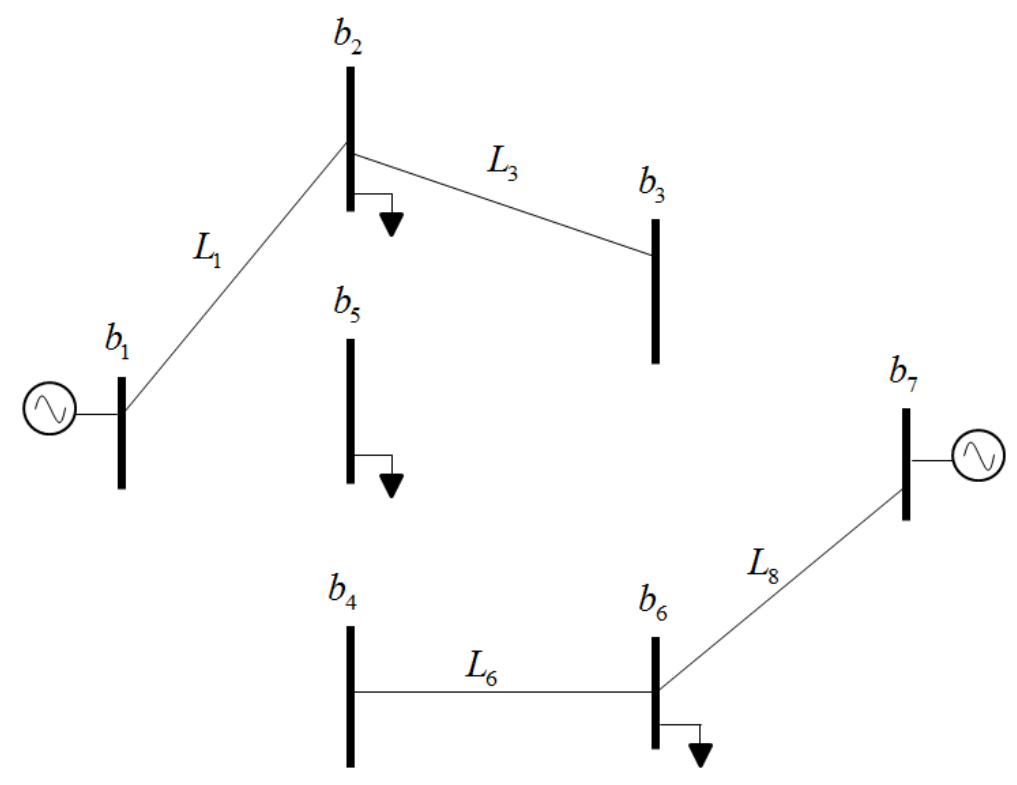

Figura 5.8: Corte $\left\{L_{2}, L_{4}, L_{5}, L_{7}\right\}$ aplicado ao Sistema de potência 7-barras / 8-linhas.

mentação da segunda fase sobre a análise de ilhamento.

\subsubsection{Terceira Etapa}

Nessa etapa é feita uma avaliação da qualidade de cada conjunto de corte, considerando o custo de cada conjunto de corte identificado. O conceito de custo de um conjunto de corte foi definido na definição (3.2.12).

Para essa análise, são considerados os pesos relacionados a cada aresta do grafo que representa o SEP. Esse peso relativo das arestas são estabelecidos de acordo com os atributos diversos, como o número de elementos de transmissão ou o fluxo de potência interrompido. Verifica-se dentre os candidatos qual é o corte com o menor custo dentre os obtidos nesse processo, sendo esse selecionado para a execução do ilhamento intencional.

\subsubsection{Aplicação para o mínimo número prático de interrupções}

Em aplicações práticas, é interessante projetar ilhamentos que possam ser implementados com o desligamento de um pequeno número de equipamentos de transmissão (WANG: VIT"TAL, 2004). 
Uma vez que o problema de encontrar o conjunto de corte com o menor número de arestas é um problema de otimização sujeito à explosão combinatória, procuraremos por soluções que são mínimos locais do problema de otimização.

Considerando a decisão do operador do sistema que estabelece um máximo aceitável de interrupções para um ilhamento intencional, o método grafo-algébrico proposto neste trabalho é adequado para esse propósito;

Supondo inicialmente um SEP conexo, dado 2 nós agregados equivalentes e considerando um máximo número de interrupções, a análise de ilhamento pode ser realizada seguindo os passos abaixo:

1. Construir a matriz incidência nó-ramo $H$ para o sistema de potência em análise;

2. Obter a matriz $H_{f}$, por meio da fatoração triangular inferior ordenada;

3. Para cada linha de $H_{f}$ construir um conjunto de corte composto por todos os ramos associados com os elementos não nulos desta linha;

4. Ordenar os cortes obtidos no passo anterior em ordem crescente de custo e selecionar o primeiro como candidato para o ilhamento.

5. Se o corte selecionado não for regular, selecionar o próximo corte da lista e repetir este passo.

Neste algoritmo, algumas características especiais devem ser observadas: (i) Se mais de um conjunto de corte for identificado no passo 4 como possuindo o mesmo custo, a ordenação do conjunto de cortes deve ser realizada levando-se em consideração outros critérios, como por exemplo o menor número de interrupções, ou menor fluxo interrompido; (ii) técnicas de refatoração parcial (ZHANG; TINNEY, 199.5) podem ser adaptadas para uma rápida pesquisa de conjuntos de ramos críticos quando o primeiro algoritmo não produz soluções razoáveis. Este algoritmo será aplicado para estudar o problema de ilhamento de um sistema de 9 barras na secção 5.3 . 


\subsubsection{Aplicação para o mínimo fluxo interrompido}

Outra exigência comum no projeto de ilhamento intencional é a interrupção de um fluxo mínimo de potência ativa (WANG; VIT"TAL, 20(14). Como discutido no início deste trabalho, problemas de explosão combinatorial podem ser evitados através do estabelecimento de uma quantidade máxima admissível de fluxo de potência ativa a ser interrompido e aplicando uma versão ligeiramente modificada do algoritmo mostrado na fig $\mathbf{5 . 5}$.

Primeiramente, a matriz incidência nó-ramo $H$ é modificada para representar a potência ativa que transita sobre a rede.

Definição 5.2.1 (Matriz $\mathcal{H}$ ): Considerando que não há perdas no sistemas de transmissão e uma orientação para o fluxo de potência nos ramos, a matriz de fluxo nó-ramo, denotada por $\mathcal{H}$, é uma matriz $\boldsymbol{n} \times \boldsymbol{m}$ que representa a topologia do sistema e o fluxo de potência da rede em seus elementos, de acordo com a seguinte regra:

$$
\mathcal{H}_{i j}= \begin{cases}P_{j}\left(-P_{j}\right) & \text { se o ramo } j \text { é conectado ao } \\ & \text { barramento } i \text { no } \\ & \text { ponto inicial (final); } \\ 0 & \text { caso contrario } ;\end{cases}
$$

Onde $\mathcal{H}_{i j}$ é o elemento da i-ésima linha e j-ésima coluna da matriz $\mathcal{H}$, e $P_{j}$ é o fluxo de potência ativa no j-ésimo equipamento de transmissão.

De acordo com (D) problemas de ilhamento controlado, como função objetivo cria ilhas com níveis similares de geração e carga, isto é, um bom balanço de geração-carga. Esta propriedade (característica) da função objetivo minimiza a quantidade de carga que deve ser cortada após o ilhamento.

O uso do mínimo fluxo de potência interrompido como função objetivo cria ilhas com uma modificação mínima no padrão da distribuição dos fluxos de potência. Esta 
propriedade (característica) da função objetivo melhora a estabilidade transitória das ilhas, reduzindo a possibilidade de sobrecarga nos equipamentos de transmissão dentro das ilhas, e facilita a eventual reintegração com o restante do sistema.

Quando do projeto do ilhamento intencional, deve-se assegurar a estabilidade das ilhas depois do ilhamento, logo prioriza-se a condição de mínimo fluxo interrompido a condição de balanço geração-carga, uma vez que uma ilha com margem de estabilidade negativa e um bom balanço geração-carga irá colapsar. Entretanto, uma ilha com margem de estabilidade positiva e um balanço de geração-carga pobre pode ser estabilizada através de um corte de carga (1DING et al, [201:3).

\subsection{Testes e Discussões}

Nesta seção, o método proposto para a identificação do ilhamento intencional será aplicado para sistemas de potência de pequeno e médio porte. O objetivo desses teste é demonstrar e eficiência do método proposto.

\subsubsection{Mínimo número prático de interrupções de sistema de 9 barras}

Seja o SEP composto por 9 barras e 10 ramos da fig 5.9 .

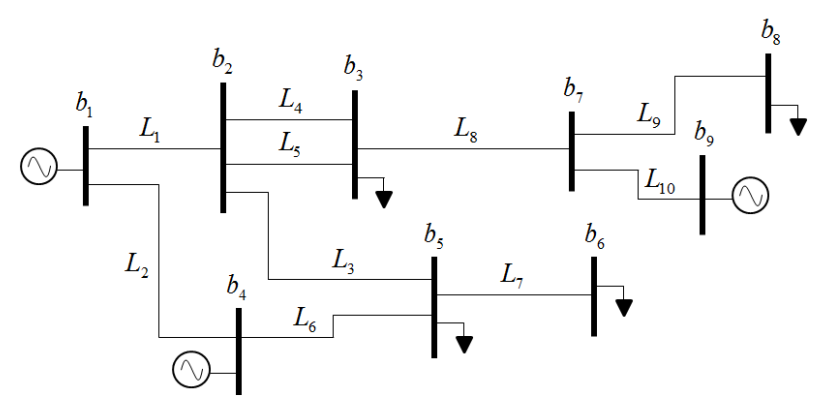

Figura 5.9: Sistema de potência com 9 barras / 10 linhas.

A matriz incidência nó-ramo para este sistema é dada por:

$$
H^{9 b}=
$$




$$
\left[\begin{array}{ccccccccccc} 
& L_{1} & L_{2} & L_{3} & L_{4} & L_{5} & L_{6} & L_{7} & L_{8} & L_{9} & L_{10} \\
b_{1} & 1 & -1 & 0 & 0 & 0 & 0 & 0 & 0 & 0 & 0 \\
b_{2} & -1 & 0 & 1 & -1 & 1 & 0 & 0 & 0 & 0 & 0 \\
b_{3} & 0 & 0 & 0 & 1 & -1 & 0 & 0 & 1 & 0 & 0 \\
b_{4} & 0 & 1 & 0 & 0 & 0 & -1 & 0 & 0 & 0 & 0 \\
b_{5} & 0 & 0 & -1 & 0 & 0 & 1 & 1 & 0 & 0 & 0 \\
b_{6} & 0 & 0 & 0 & 0 & 0 & 0 & -1 & 0 & 0 & 0 \\
b_{7} & 0 & 0 & 0 & 0 & 0 & 0 & 0 & -1 & -1 & -1 \\
b_{8} & 0 & 0 & 0 & 0 & 0 & 0 & 0 & 0 & 1 & 0 \\
b_{9} & 0 & 0 & 0 & 0 & 0 & 0 & 0 & 0 & 0 & 1
\end{array}\right]
$$

Neste exemplo, considera-se que os geradores conectados aos barramentos 1 e 4 sejam coerentes, portanto, propõe-se um ilhamento intencional para separar os geradores 1 e 4 do gerador 9. Um nó agregado equivalente é formado pelos barramentos 1 e 4, e a matriz incidência nó-ramo é obtida:

$$
\begin{array}{cccccccccc}
\multicolumn{10}{c}{\tilde{H}^{9 b}=} \\
{\left[\begin{array}{cccccccccc}
L_{1} & L_{3} & L_{4} & L_{5} & L_{6} & L_{7} & L_{8} & L_{9} & L_{10} \\
b_{1+4} & 1 & 0 & 0 & 0 & -1 & 0 & 0 & 0 & 0 \\
b_{2} & -1 & 1 & -1 & 1 & 0 & 0 & 0 & 0 & 0 \\
b_{5} & 0 & -1 & 0 & 0 & 1 & 1 & 0 & 0 & 0 \\
b_{3} & 0 & 0 & 1 & -1 & 0 & 0 & 1 & 0 & 0 \\
b_{6} & 0 & 0 & 0 & 0 & 0 & -1 & 0 & 0 & 0 \\
b_{7} & 0 & 0 & 0 & 0 & 0 & 0 & -1 & -1 & -1 \\
b_{8} & 0 & 0 & 0 & 0 & 0 & 0 & 0 & 1 & 0 \\
b_{9} & 0 & 0 & 0 & 0 & 0 & 0 & 0 & 0 & 1
\end{array}\right]}
\end{array}
$$

Após o processo de fatoração ordenada obtemos:

$$
\begin{aligned}
& \tilde{H}^{9 b}= \\
& {\left[\begin{array}{cccccccccc} 
& L_{1} & L_{3} & L_{4} & L_{5} & L_{6} & L_{7} & L_{8} & L_{9} & L_{10} \\
b_{a}=b_{1+4} & 1 & 0 & 0 & 0 & -1 & 0 & 0 & 0 & 0 \\
b_{b}=b_{a+2} & 0 & 1 & -1 & 1 & -1 & 0 & 0 & 0 & 0 \\
b_{c}=b_{b+5} & 0 & 0 & -1 & 1 & 0 & 1 & 0 & 0 & 0 \\
b_{d}=b_{c+3} & 0 & 0 & 0 & 0 & 0 & 1 & 1 & 0 & 0 \\
b_{e}=b_{d+6} & 0 & 0 & 0 & 0 & 0 & 0 & 1 & 0 & 0 \\
b_{f}=b_{e+7} & 0 & 0 & 0 & 0 & 0 & 0 & 0 & -1 & -1 \\
b_{g}=b_{f+8} & 0 & 0 & 0 & 0 & 0 & 0 & 0 & 0 & -1 \\
b_{h}=b_{g}+9 & 0 & 0 & 0 & 0 & 0 & 0 & 0 & 0 & 0
\end{array}\right]}
\end{aligned}
$$

Ao observar as linhas da matriz $H_{f}$, podemos concluir que os conjuntos de corte são: $\left\{L_{1}, L_{6}\right\},\left\{L_{3}, L_{4}, L_{5}, L_{6}\right\},\left\{L_{4}, L_{5}, L_{7}\right\},\left\{L_{7}, L_{8}\right\},\left\{L_{8}\right\},\left\{L_{9}, L_{10}\right\}$ e $\left\{L_{10}\right\}$. Após a análise de ilhamento, podemos concluir que os cortes $\left\{L_{3}, L_{4}, L_{5}, L_{6}\right\},\left\{L_{4}, L_{5}, L_{7}\right\},\left\{L_{7}, L_{8}\right\}$ e $\left\{L_{9}, L_{10}\right\}$ não são regulares e portanto serão desconsiderados. Os conjuntos de corte regulares encontrados são: $\left\{L_{1}, L_{6}\right\},\left\{L_{8}\right\}$ e $\left\{L_{10}\right\}$. Do ponto de vista de interrupção 


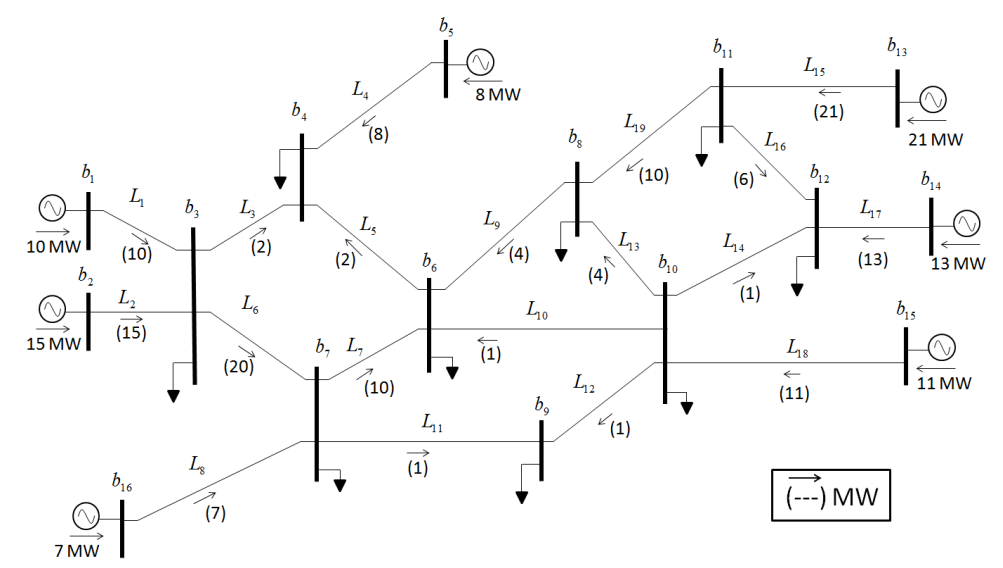

Figura 5.10: Sistema de potência com 16 barras e 19 linhas.

de um menor número de equipamentos de transmissão, escolhemos um dentre os cortes minimais locais $\left\{L_{8}\right\}$ ou $\left\{L_{10}\right\}$.

\subsubsection{Ilhamento controlado de uma sistema de 16 barras e 18 ramos}

Considere o SEP composto por 16 barras e 19 ramos da fig 5.10 .

A matriz incidência nó-ramo para este sistema é dada por:

$\left[\begin{array}{ccccccccccccccccccc}\multicolumn{10}{c}{H_{1}^{16 b-19 L}=} \\ 10 & L_{2} & L_{3} & L_{4} & L_{5} & L_{6} & L_{7} & L_{8} & L_{9} & L_{10} & L_{11} & L_{12} & L_{13} & l_{14} & l_{15} & L_{16} & L_{17} & L_{18} & L_{19} \\ 0 & 0 & 0 & 0 & 0 & 0 & 0 & 0 & 0 & 0 & 0 & 0 & 0 & 0 & 0 & 0 & 0 & 0 \\ -10 & -15 & 0 & 0 & 0 & 0 & 0 & 0 & 0 & 0 & 0 & 0 & 0 & 0 & 0 & 0 & 0 & 0 & 0 \\ 0 & 0 & -2 & -8 & -2 & 0 & 0 & 0 & 0 & 0 & 0 & 0 & 0 & 0 & 0 & 0 & 0 & 0 & 0 \\ 0 & 0 & 0 & 8 & 0 & 0 & 0 & 0 & 0 & 0 & 0 & 0 & 0 & 0 & 0 & 0 & 0 & 0 & 0 \\ 0 & 0 & 0 & 0 & 2 & 0 & -10 & 0 & -4 & -1 & 0 & 0 & 0 & 0 & 0 & 0 & 0 & 0 & 0 \\ 0 & 0 & 0 & 0 & 0 & -20 & 10 & -7 & 0 & 0 & 1 & 0 & 0 & 0 & 0 & 0 & 0 & 0 & 0 \\ 0 & 0 & 0 & 0 & 0 & 0 & 0 & 0 & 4 & 0 & 0 & 0 & -4 & 0 & 0 & 0 & 0 & 0 & -10 \\ 0 & 0 & 0 & 0 & 0 & 0 & 0 & 0 & 0 & 0 & -1 & -1 & 0 & 0 & 0 & 0 & 0 & 0 & 0 \\ 0 & 0 & 0 & 0 & 0 & 0 & 0 & 0 & 0 & 1 & 0 & 1 & 4 & 1 & 0 & 0 & 0 & -11 & 0 \\ 0 & 0 & 0 & 0 & 0 & 0 & 0 & 0 & 0 & 0 & 0 & 0 & 0 & 0 & -21 & 6 & 0 & 0 & 10 \\ 0 & 0 & 0 & 0 & 0 & 0 & 0 & 0 & 0 & 0 & 0 & 0 & 0 & -1 & 0 & -6 & -13 & 0 & 0 \\ 0 & 0 & 0 & 0 & 0 & 0 & 0 & 0 & 0 & 0 & 0 & 0 & 0 & 0 & 21 & 0 & 0 & 0 & 0 \\ 0 & 0 & 0 & 0 & 0 & 0 & 0 & 0 & 0 & 0 & 0 & 0 & 0 & 0 & 0 & 0 & 13 & 0 & 0 \\ 0 & 0 & 0 & 0 & 0 & 0 & 0 & 0 & 0 & 0 & 0 & 0 & 0 & 0 & 0 & 0 & 0 & 11 & 0 \\ 0 & 0 & 0 & 0 & 0 & 0 & 0 & 7 & 0 & 0 & 0 & 0 & 0 & 0 & 0 & 0 & 0 & 0 & 0\end{array}\right]$




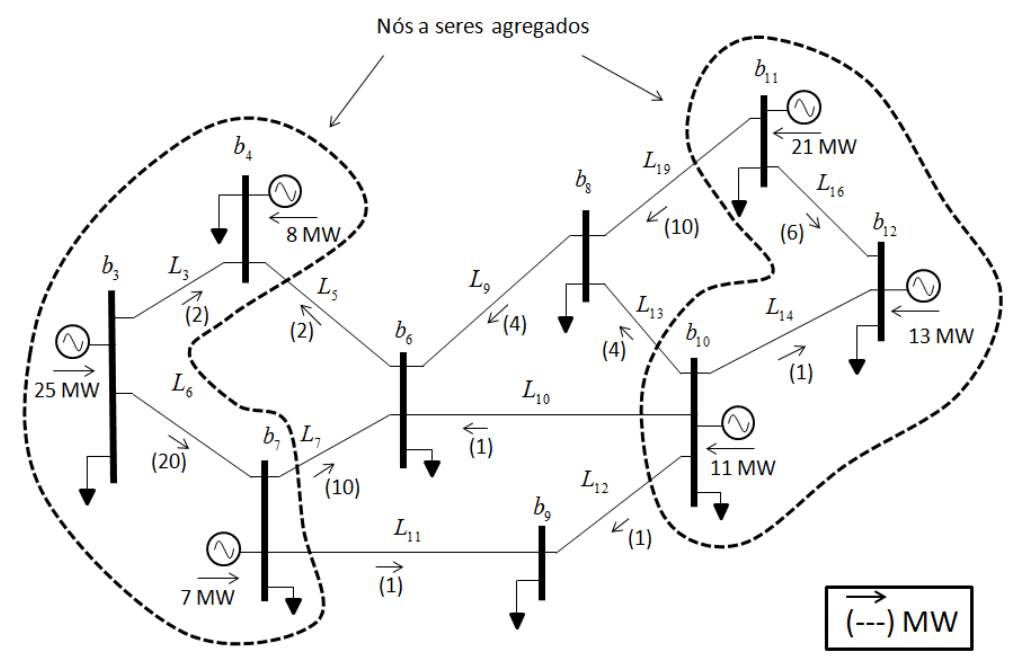

Figura 5.11: Sistema de potência com 16 barras e 19 linhas após a primeira simplificação.

Nesse exemplo, deseja-se separar os geradores conectados aos barramentos $b_{1}, b_{2}, b_{5}$ e $b_{16}$ dos geradores conectados aos barramentos $b_{13}, b_{14}$ e $b_{15}$ em ilhas distintas, de modo o critério de parada para a formação de cada ilha seja uma diferença entre potência gerada e carga da ilha sobre analise igual a $10 \%$ da potência gerada na ilha.

E possível constatar que o grafo apresentada pode ser simplificado. Em uma primeira etapa de simplificação, podemos notar que nó $b_{1}, b_{2}, b_{5}, b_{16}, b_{13}, b_{14}$ e $b_{17}$ se enquadram no Caso 3 para simplificação, portanto esse nós são agregado a nós vizinhos. Como todos os nós agregados são correspondentes a nós geradores, temos que as características destes nós devem ser "herdadas"pelo nó agregado. A fig (5.T]) ilustra esse processo.

Após a primeira simplificação os nós relativos a geradores coerentes, ou neste caso os representantes desses nós, são agregados, gerando um grafo ainda mais simples para a análise. A fig (5.T2) mostra o grafo resultante desse processo.

Após a etapa de agregação de nós geradores ou de seus representantes, é possível constatar que existem ramos redundantes, ou seja, existem ramos que conectam o mesmo par de nós. Para esse caso, temos que os ramos redundantes devem ser convertidos em um ramo equivalente. Esse processo é ilustrado na fig (5.T3)

Note que o grafo simplificado possui apenas 5 nós e 6 ramos, enquanto o grafo original possui 16 nós e 19 ramos. Deste modo espera-se que a tarefa de determinar os cortes pela etapa iterativa, sobre o sistema simplificado seja mais simples que o original. 


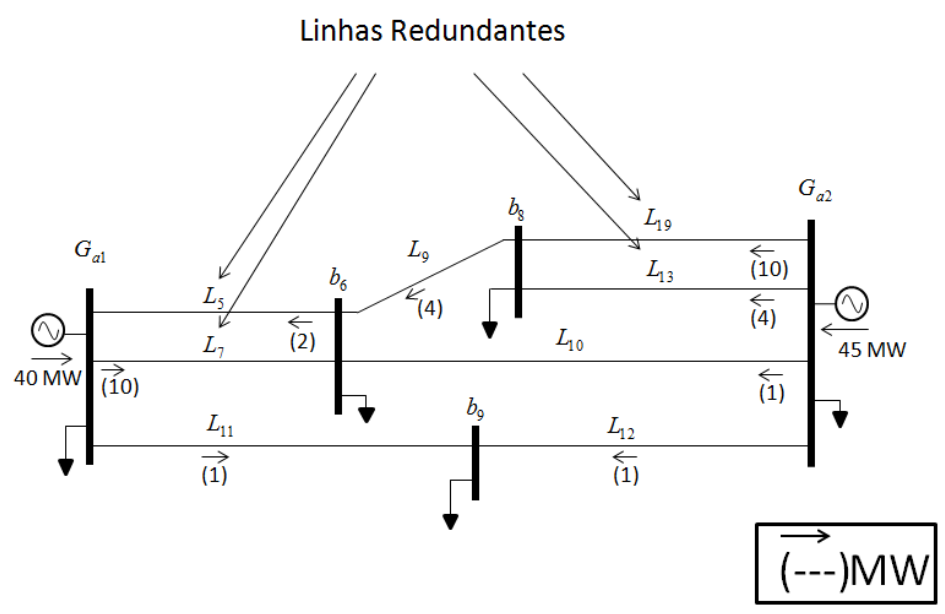

Figura 5.12: Agregação de nós geradores Sistema de potência com 16 barras e 19 linhas.

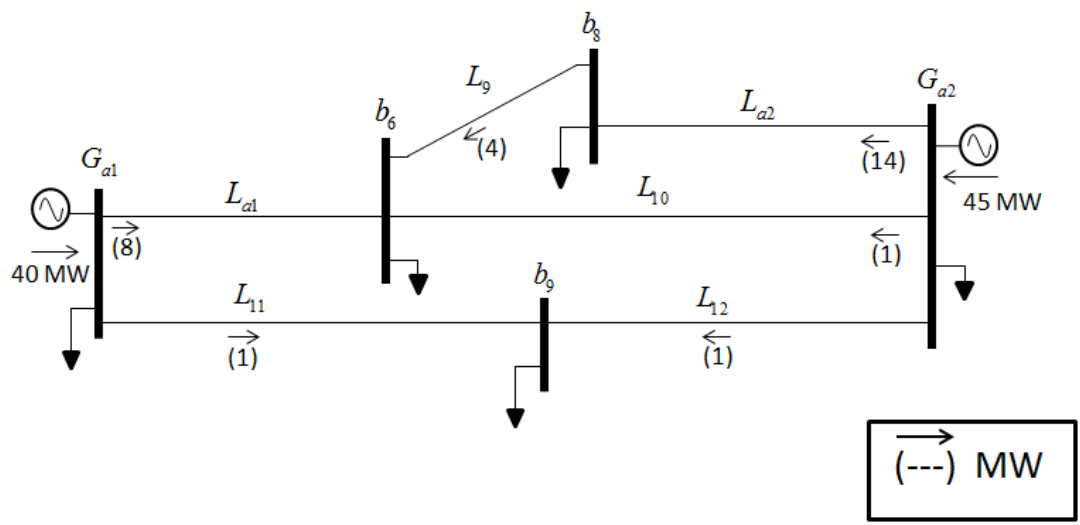

Figura 5.13: Sistema de potência com 16 barras e 19 linhas simplificada e com nós agregados. 
A matriz nó-ramo do grafo simplificado é dada por:

$$
H_{\text {simplificada }}=\left[\begin{array}{cccccc}
L a_{1} & l_{9} & l_{1} 0 & l_{1} 1 & l a_{2} & l_{1} 2 \\
& & & & & \\
1 & 0 & 0 & 1 & 0 & 0 \\
-1 & 1 & 1 & 0 & 0 & 0 \\
0 & -1 & 0 & 0 & 1 & 0 \\
0 & 0 & 0 & -1 & 0 & 1 \\
0 & 0 & 0 & -1 & 0 & 1 \\
0 & 0 & -1 & 0 & -1 & -1
\end{array}\right]
$$

Na primeira fase da etapa iterativa optou-se por realizar a fatoração somente da primeira vizinhança do nó de referência, para facilitar a demonstração do método.

Na primeira iteração foi analisado o nó agregado $G a_{1}$. Temos que na primeira vizinhança de $G a_{1}$, os nós candidatos a e serem agregados são $b_{6}$ e $B_{9}$. Todos os nós candidatos produzem cortes regulares, portanto não são eliminados do grupo de candidatos na segunda fase. Na terceira fase é avaliado o custo de cada corte, e nesse caso o corte que apresentou o menos custo foi o corte $\left\{L_{9}, L_{10}, L_{11}\right\}$, portanto o nó b9 é agregado ao nó $G a_{1}$. Na próxima iteração, esse mesmo processo é repetido, tendo agora o nó $G a_{2}$ como o nó agregado de referência. O resultado dessa iteração foi que o nó $b_{8}$ deve ser agregado ao nó $G a_{2}$.

Uma terceira iteração é executada, pois ainda é possível agregar nós e as ilhas não atingiram o critério de parada, dada pela relação ((Potência Gerada)-Carga)/(Potência Gerada) desejada. Para esse exemplo o critério de parada é igual a 0,10. Como a ilha representada pelo nó $G a_{1}$ possui uma razão de desbalanço de carga de exatamente 0,10 , temos que a terceira iteração é realizada com o nó agregado $G a_{2}$ sendo a referência. Neste caso, o grupo de corte obtido foi $\left\{L_{9}, L_{10}, L_{11}\right\}$.

\subsubsection{Ilhamento controlado sobre o Sistema Sul Reduzido}

O sistema sul reduzido é utilizado para as simulações com o algoritmo proposto. Tal sistema é constituído por 10 geradores, 45 barras e 57 linhas. O mesmo está ilustrado na fig $(5.14)$. Os dados deste sistema estão disponíveis no Apêndice (A).

São realizadas simulações no sistema sul reduzido para diferentes contingências aplica- 


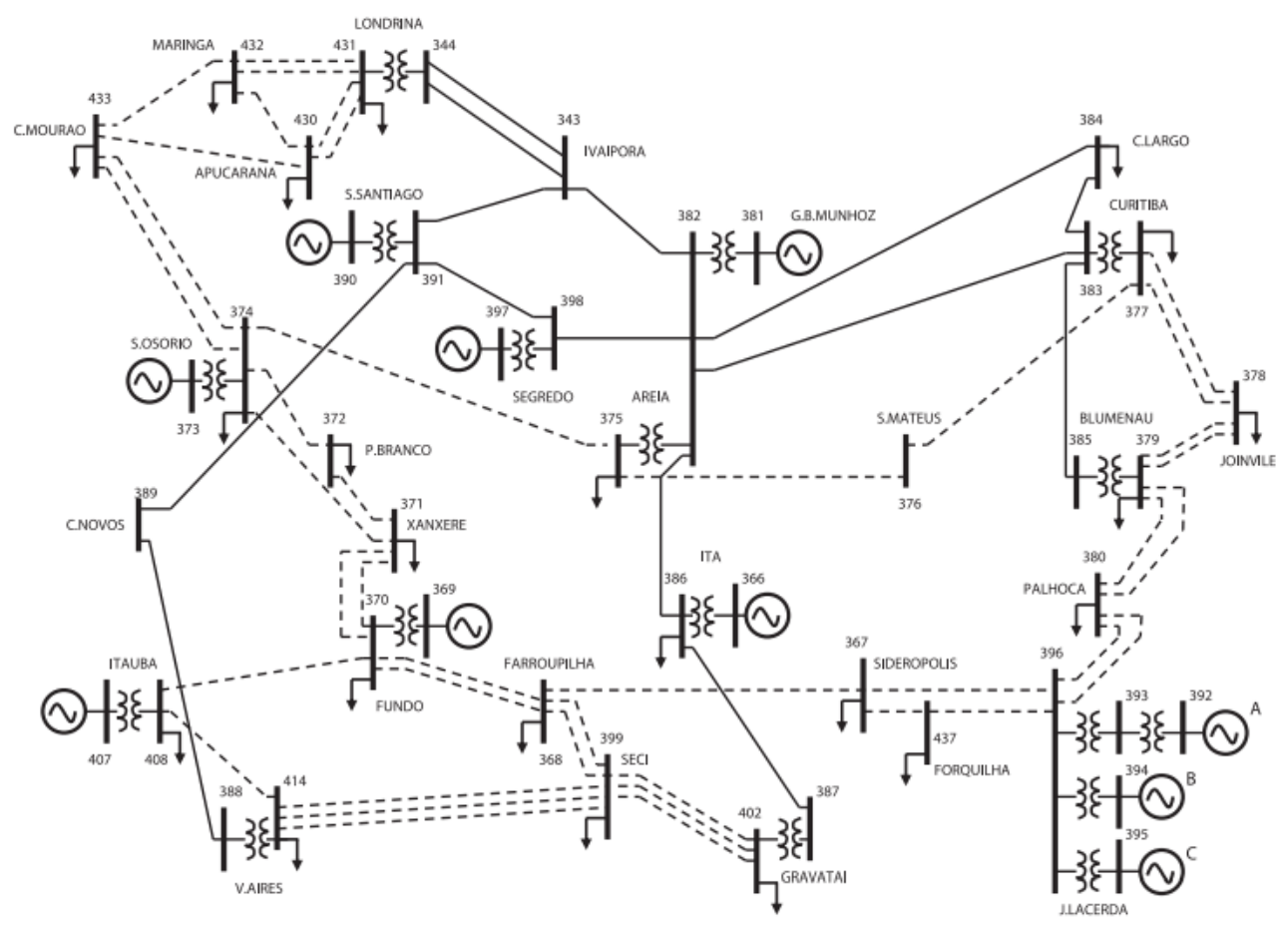

Figura 5.14: Sistema Elétrico Brasileiro Sul Reduzido. Fonte: (एHसOD()R() et al, 2012)

das (perda da linha) que após um tempo critico de abertura ha a ocorrência de ilhamento. Tais contingências são listadas na tabela (5.]).

\begin{tabular}{|l|l|}
\hline $\begin{array}{l}\text { Contingência entre as bar- } \\
\text { ras }\end{array}$ & Barra Curto Circuitada \\
\hline [barra 397 - barra 398$]$ & barra 398 \\
\hline [barra 375 - barra 382] & barra 382 \\
\hline [barra 367 - barra 396] & barra 396 \\
\hline [barra 379 - barra 380] & barra 380 \\
\hline [barra 390 - barra 391] & barra 391 \\
\hline
\end{tabular}

Tabela 5.1: Lista de Contingências.

- Curto Circuito na linha [barra 397 - barra 398] e curto na barra 398

Na fig (5.15) são apresentados os resultados da variação dos ângulos dos rotores e da variação da velocidade dos rotores, na ocorrência de um curto circuito nas vizinhanças da barra 398 na linha [397-398]. O defeito é isolado pela eliminação da linha [397-398], em um tempo de abertura de 2 segundos. Para esse tempo de abertura, tem-se como 

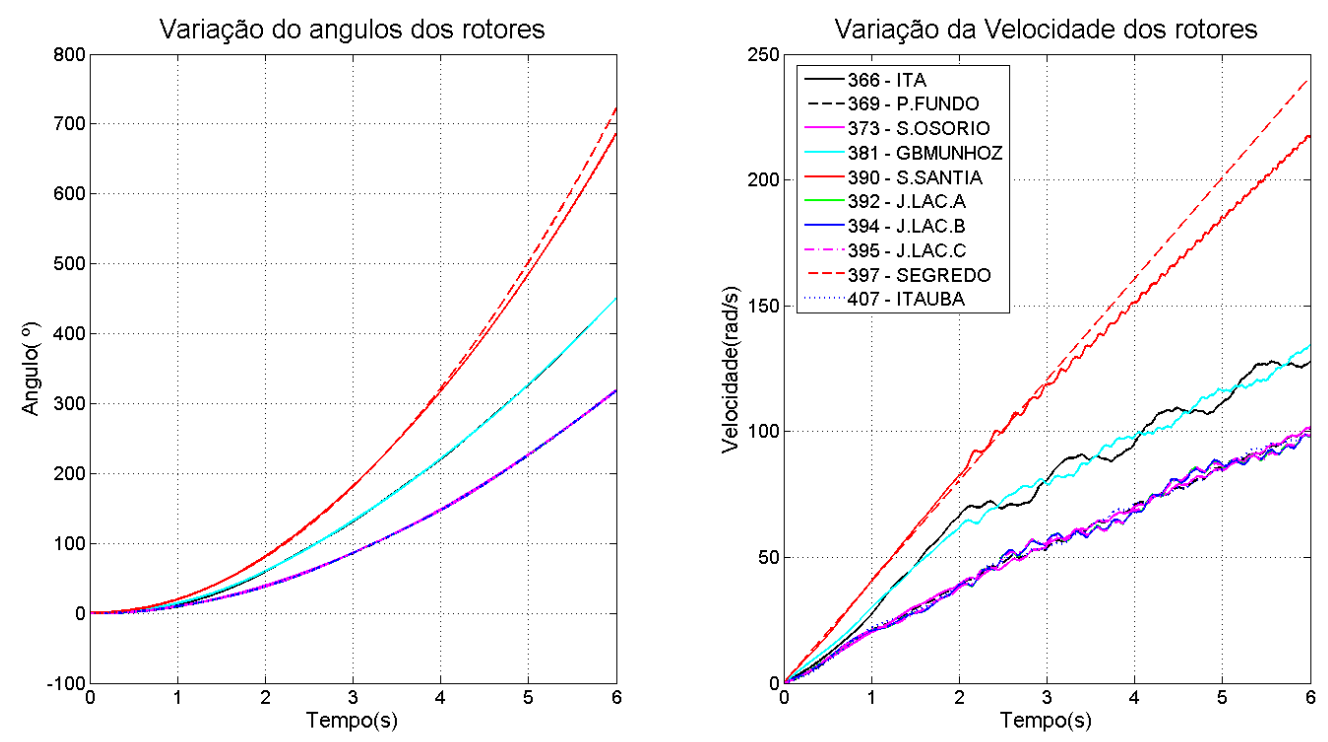

Figura 5.15: Variação do angulo e velocidade dos rotores.

resultado a perda de sincronismo dos geradores, portanto o sistema é transitoriamente instável.

Após a eliminação do defeito podemos observar a formação de 5 grupos de geradores "oscilam" em conjunto, o que sugere que ha a formação de grupo de geradores coerentes. Podemos observar a formação desses 5 grupos abaixo:

1. Grupo 1: $\{369,373$ e 407$\}$

2. Grupo 2: $\{392,394$ e 395$\}$

3. Grupo 3: $\{366$ e 381$\}$

4. Grupo 4: $\{390\}$;

5. Grupo 5: $\{397\}$

Como exemplo, deseja-se determinar um esquema de ilhamento de modo a separar os grupos de geradores coerentes. Neste caso, o método para projeto de ilhamento intencional proposto nesse trabalho foi usado, com um critério de parada igual a $10 \%$ de desbalanço de potência ativa na ilha analisada. O grupo de corte gerado é mostrado abaixo: 

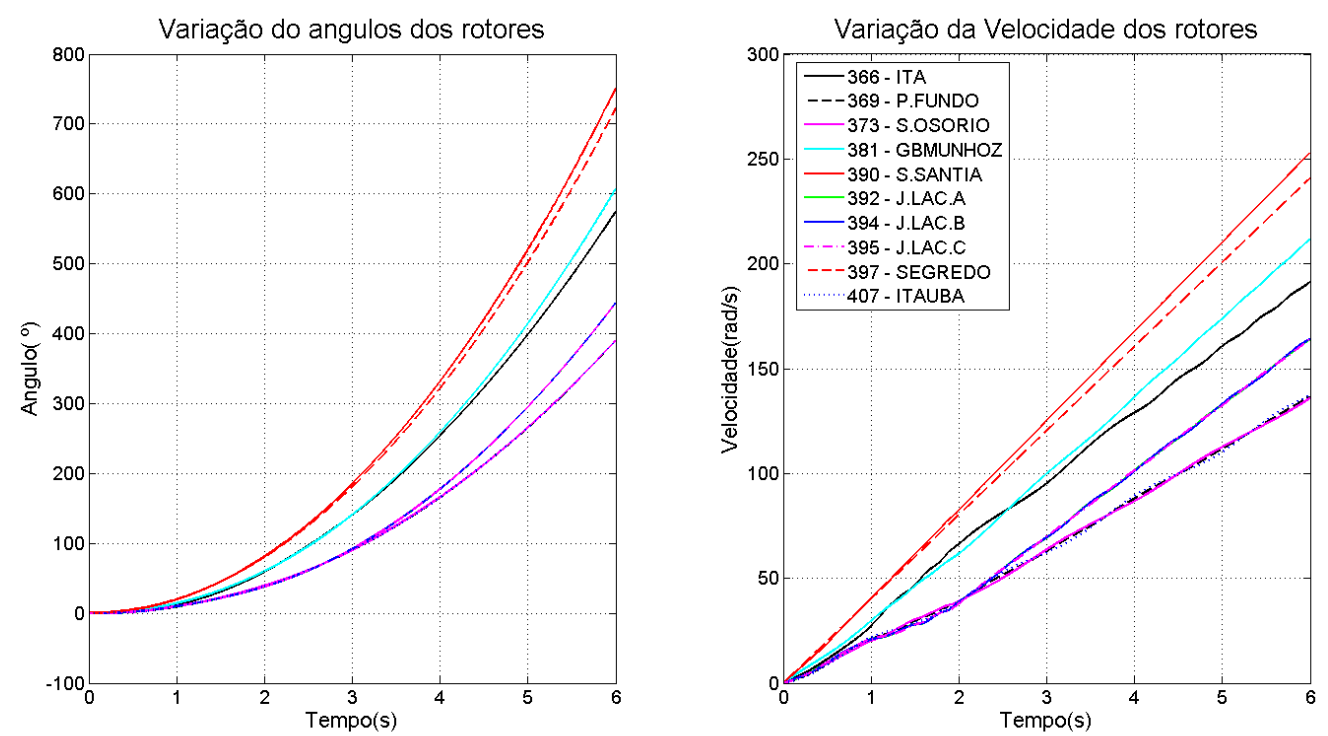

Figura 5.16: Variação do angulo e velocidade dos rotores.

1. Grupos de corte: $\{[343$ - 382], [367 - 368], [368 - 399], [375 - 382], [376 - 377], [379 - 380], [382 - 398], [388 - 414], [391 - 398], [397 - 398], [399 - 402], [399 - 414], [430 432], [430 - 433], [431 - 432], [432 - 433] \}.

Ao simular a dinâmica pré-falta, em falta e pós-falta do sistema sul reduzido com a implementação da estratégia de ilhamento intencional efetuada após 0,65 s a ocorrência da contingência, temos a variação do ângulo e velocidade dos rotores indicadas na figura (5.16)

Podemos perceber que no cenário gerado pela aplicação da estratégia de ilhamento controlado determinado pelo método, os geradores de cada ilha formada permanecem coerentes entre si, portanto nesse cenário o sistema é transitoriamente estável.

O desbalanço de potência em cada ilha gerada pelo grupo de corte é dado abaixo:

1. Grupo 1: $4,22 \%$

2. Grupo 2: $-11,05 \%$ (Demanda maior que a potência gerada)

3. Grupo 3: - 4,09\%

4. Grupo 4: 8,69\% 


\section{Grupo 5: $100 \%$}

Note que o gerador conectado a barra 397 foi isolado do resto do sistema, com a eliminação da linha [397-398] devido a falta ter ocorrido nessa linha. Consequentemente, a linha [397-398] deve estar de forma obrigatória no grupo de corte determinado pelo método proposto. Então temos que o grupo 5, que é composto por somente pelo barramento 397 conectada a um gerador, possui o desbalanço de potência igual a 100 \%, pois não ha nenhuma carga conectada ao barramento 397.

- Curto Circuito na linha [barra 375 - barra 382] e curto na barra 382

Considere agora que um curto circuito trifásico ocorre na linha [375 - 382], nas vizinhanças da barra 382, e a falha dura 0,8 segundos. O defeito é eliminando ao retirar a linha [375 - 382]. Ao simular o comportamento dinâmico do sistema sul reduzido para esse tipo de falta, temos que a variação do ângulo e velocidade dos rotores indicam que o sistema é transitoriamente instável, como mostrado na fig (5.57), uma vez que os geradores que estão numa mesma ilha não estarem em sincronia. Ao analisar a fig (5.17), podemos notar a formação de 4 grupos de geradores coerentes após a eliminação da linha [375 - 382]. Abaixo são listadas as barras dos 4 grupos de geradores coerentes.

1. Grupo 1: $\{369,373$ e 407$\}$

2. Grupo 2: $\{392,394$ e 395$\}$

3. Grupo 3: $\{381,390$ e 397$\}$

4. Grupo 4: $\{366\}$;

Nesse exemplo, deseja-se separar os grupos de geradores coerentes, portanto é necessário determinar um esquema de ilhamento.

Assumindo o critério de parada para a formação de cada ilha igual a $10 \%$ de desbalanço de potência ativa na ilha analisada, o método proposto foi utilizado. O grupo de corte gerado é mostrado abaixo: 

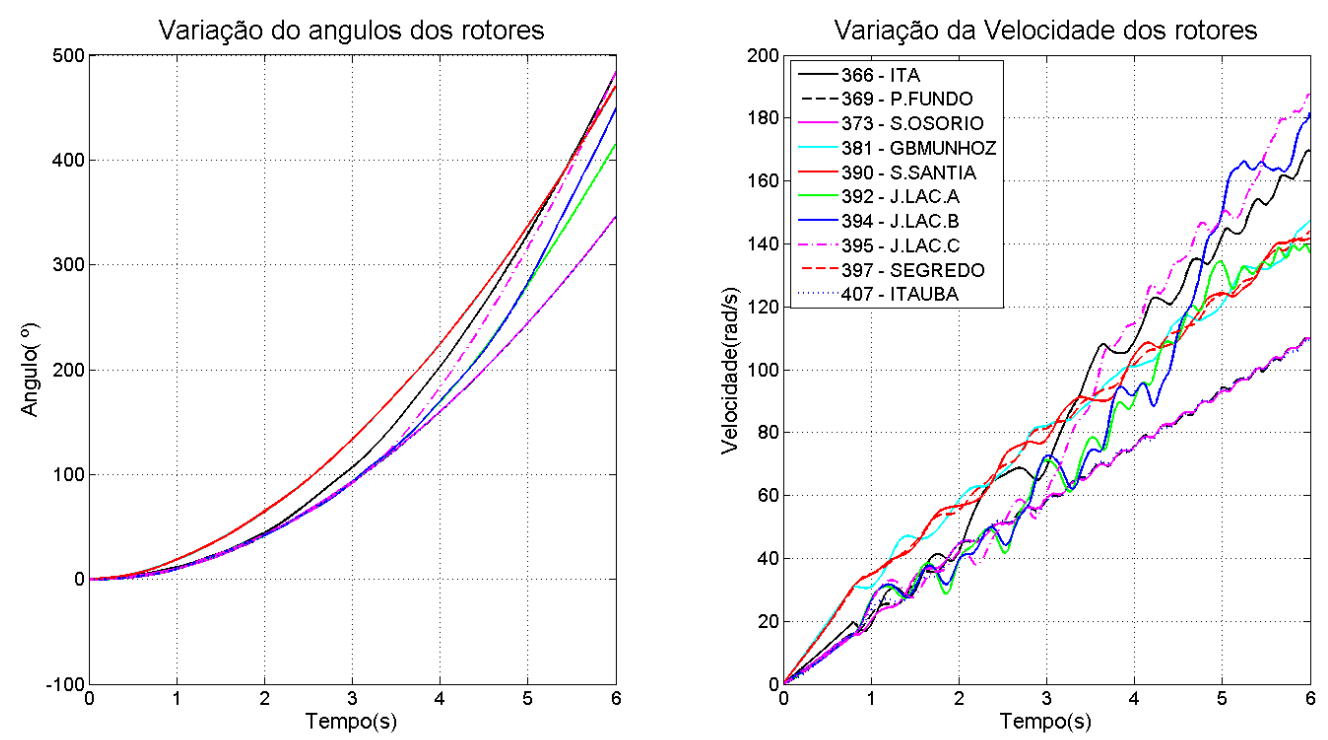

Figura 5.17: Variação do angulo e velocidade dos rotores.

1. Grupos de corte: $\{[367$ - 368], [368 - 399], [375 - 382], [376 - 377], [380 - 396], [382 - 386], [388 - 414], [399 - 402], [399 - 414], [430 - 433], [432 - 433] \}.

Ao simular a dinâmica do sistema sul reduzido para esse cenário de falta, com a implementação da estratégia de ilhamento intencional efetuada após 0,8 segundos da ocorrência da contingência, temos a variação do ângulo e velocidade dos rotores indicadas na figura (5.18).

Note que para esse cenário temos geradores sincronizados em cada ilha, portanto o sistema é transitoriamente estável.

O desbalanço de potência em cada ilha gerada pelo grupo de corte é dado abaixo:

1. Grupo 1: $2,21 \%$

2. Grupo 2: 13,46 \% (Demanda maior que a potência gerada)

3. Grupo 3: $19,82 \%$

4. Grupo 4: $0,76 \%$

- Curto Circuito na linha [barra 367 - barra 396] e curto na barra 396 

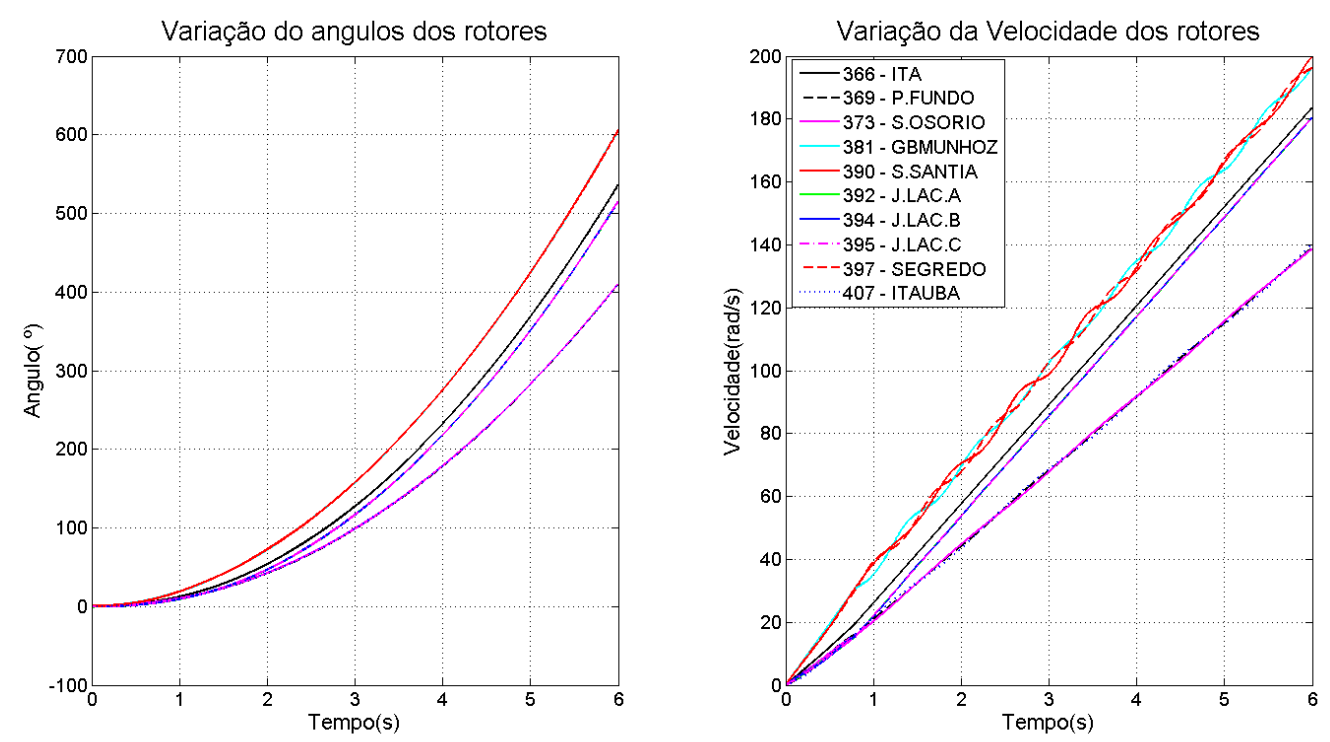

Figura 5.18: Variação do angulo e velocidade dos rotores.

Supondo a ocorrência de um curto circuito trifásico na linha que conecta as barra 367 a 396, vizinhanças da barra 396. A falta tem uma duração e 2 segundos e o defeito é eliminando pela retirada da linha entre as barras 367 a 396 do sistema. Ao simular o sistema sul reduzido na dinâmica, temos a variação do ângulo e velocidade dos rotores da dinâmica pré-falta, em falta e pós-falta mostrada na figura (5.19), onde podemos observar a formação de 2 grupos de geradores coerentes. O barramento dos geradores de cada grupo é mostrado abaixo:

1. Grupo 1: $\{366,369,374,381,390,397$ e 407\};

2. Grupo 2: $\{392,394$ e 395$\}$

Assumindo um critério de parada igual a $10 \%$, e a estratégia de ilhamento intenciona implementada com base nesses grupos de geradores coerentes pelo método proposto gera seguinte o grupo de corte:

1. Grupos de corte: $\{[367-368],[378-379],[379-380],[379-385],[383-385]\}$.

Ao simular a dinâmica do sistema sul reduzido considerando a implementação da estratégia de ilhamento intencional efetuada após 2 segundos da ocorrência da contingência, temos a variação do ângulo e velocidade dos rotores indicadas na fig (5.20). 

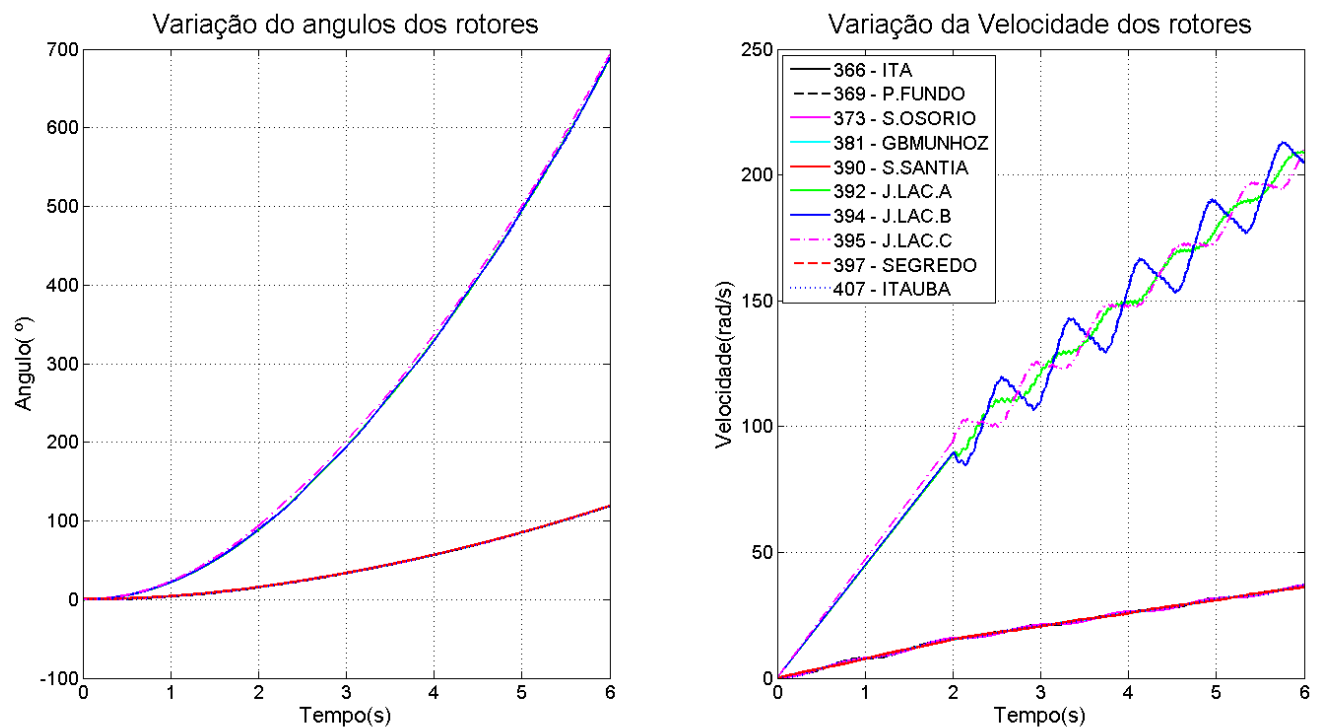

Figura 5.19: Variação do angulo e velocidade dos rotores.
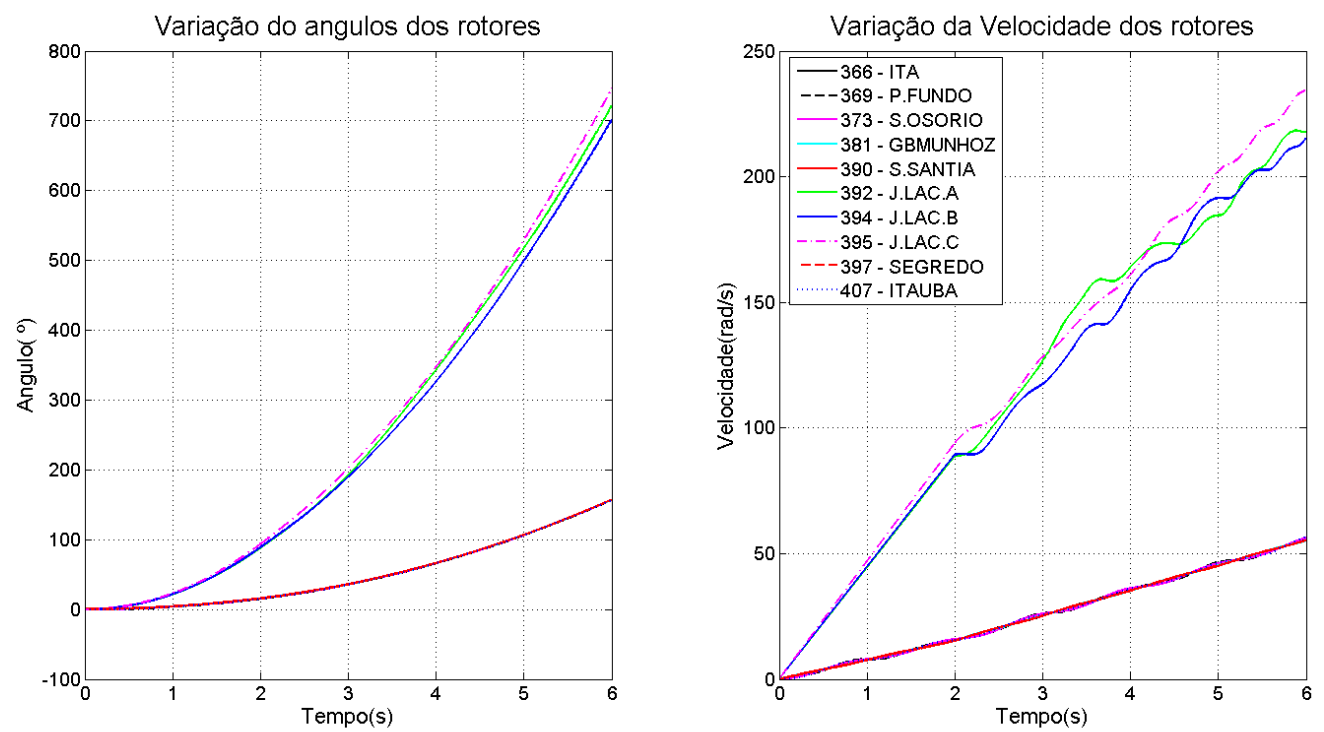

Figura 5.20: Variação do angulo e velocidade dos rotores. 
O desbalanço de potência em cada ilha gerada pelo grupo de corte é dado abaixo:

1. Grupo 1: $7,48 \%$

2. Grupo 2: - 11,05 \% (Demanda maior que a potência gerada)

- Curto Circuito na linha [barra 379 - barra 380] e curto na barra 380

Agora considera a ocorrência de uma contingência na linha [379 - 380], na vizinhança do barramento 380. Após 2 segundos, a linha [379 - 380] é retirada do sistema e o defeito é eliminado. A dinâmica pré-falta, em falta e pós-falta do sistema sul reduzido para esse tipo de falta foi simulado. A fig (5.27) mostra a variação do ângulo e velocidade dos rotores do sistema, onde podemos observar indícios que o sistema sul reduzido se torna transitoriamente instável, pois os geradores de uma mesma ilha não são sincronizados após a eliminação da linha [379 - 380]. Podemos observar a formação de 3 grupos de geradores coerentes:

1. Grupo 1: $\{366,381,390$ e 397$\}$;

2. Grupo 2: $\{369,373$ e 407\};

3. Grupo 3: $\{392,394$ e 395\};

Da mesma forma como nos exemplos anteriores, deseja-se determinar um grupo de corte de modo a separar em diferentes ilhas cada grupo de geradores, assumindo um critério de parada igual a $10 \%$ de toda potência gerada em cada ilha. O grupo de core determinado pelo método é dado abaixo:

1. Grupos de corte: $\{[367-368],[368$ - 399], [374 - 375], [379 - 380], [388 - 414], [399 - 414], [430 - 431], [431 - 432] \}.

Ao simular novamente a dinâmica do sistema sul reduzido com a implementação da estratégia de ilhamento intencional efetuada após 2 segundos, temos a variação do ângulo e velocidade dos rotores indicadas na figura (5.22).

O desbalanço de potência em cada ilha gerada pelo grupo de corte é dado abaixo: 

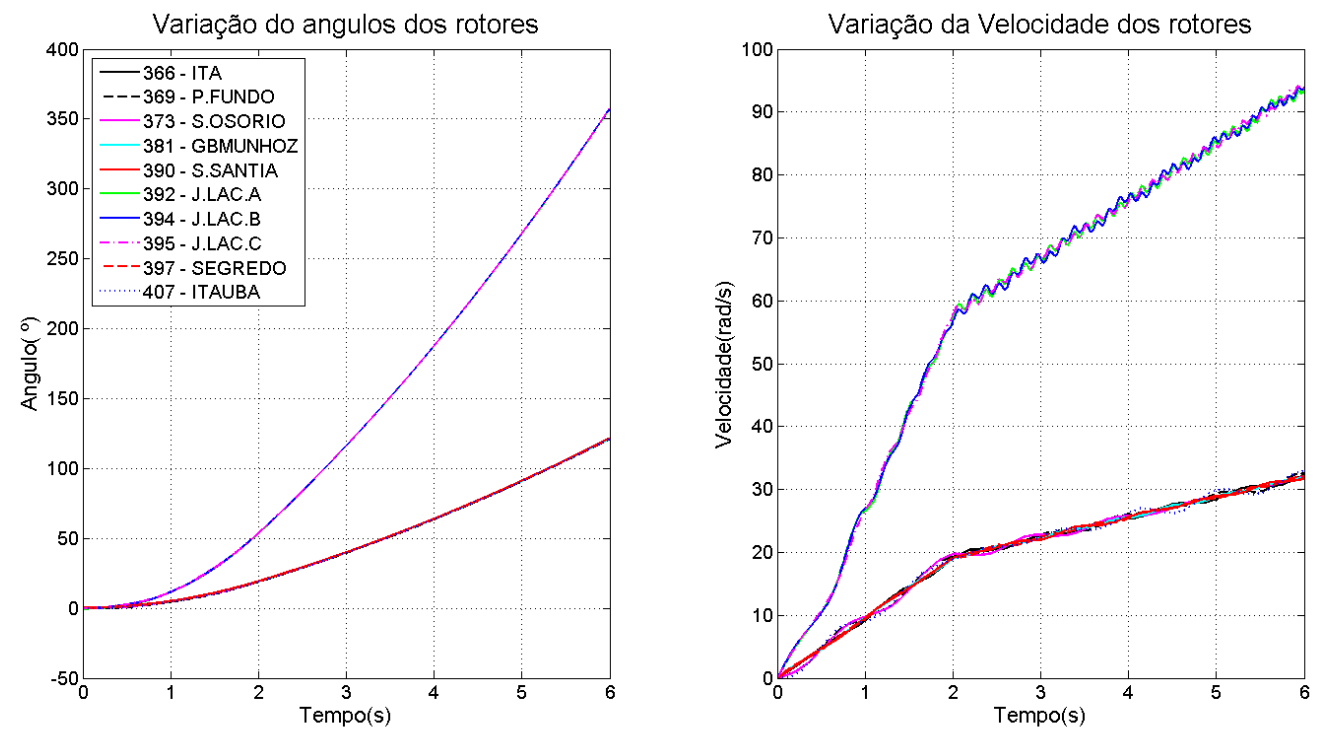

Figura 5.21: Variação do angulo e velocidade dos rotores.
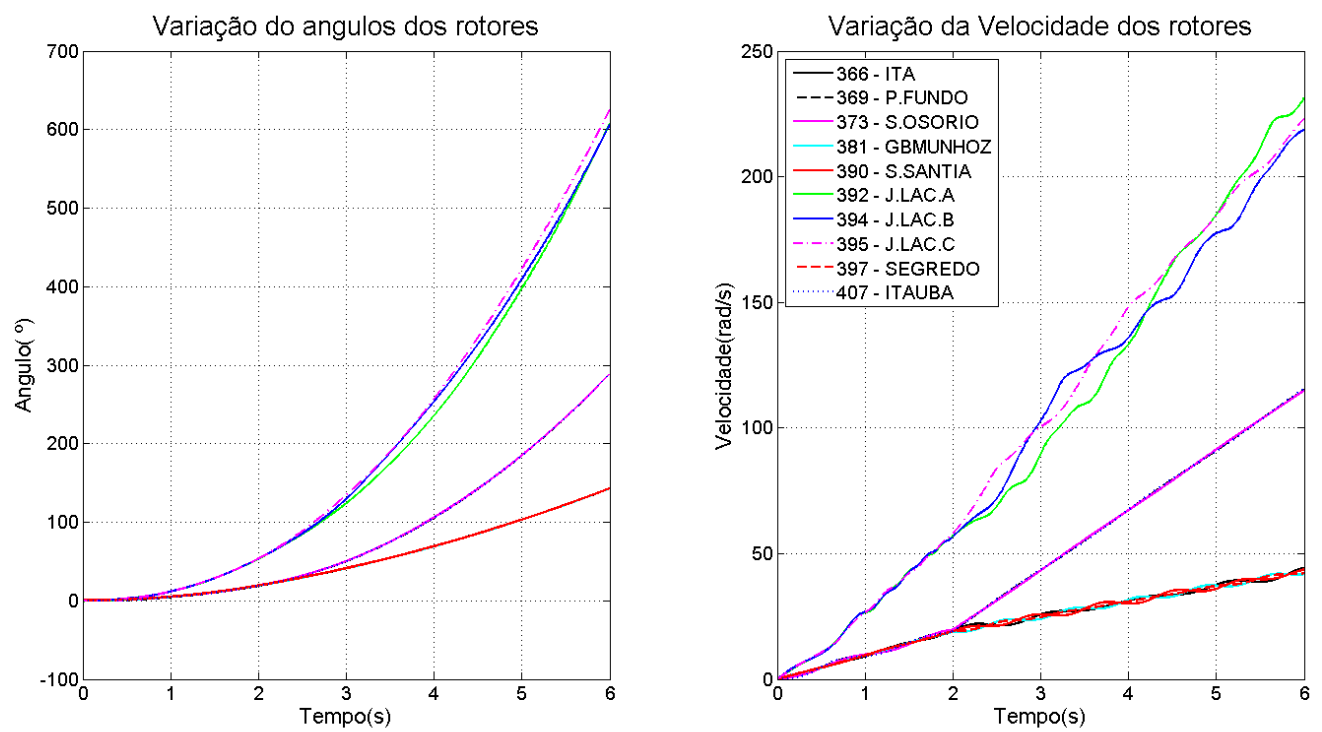

Figura 5.22: Variação do angulo e velocidade dos rotores. 

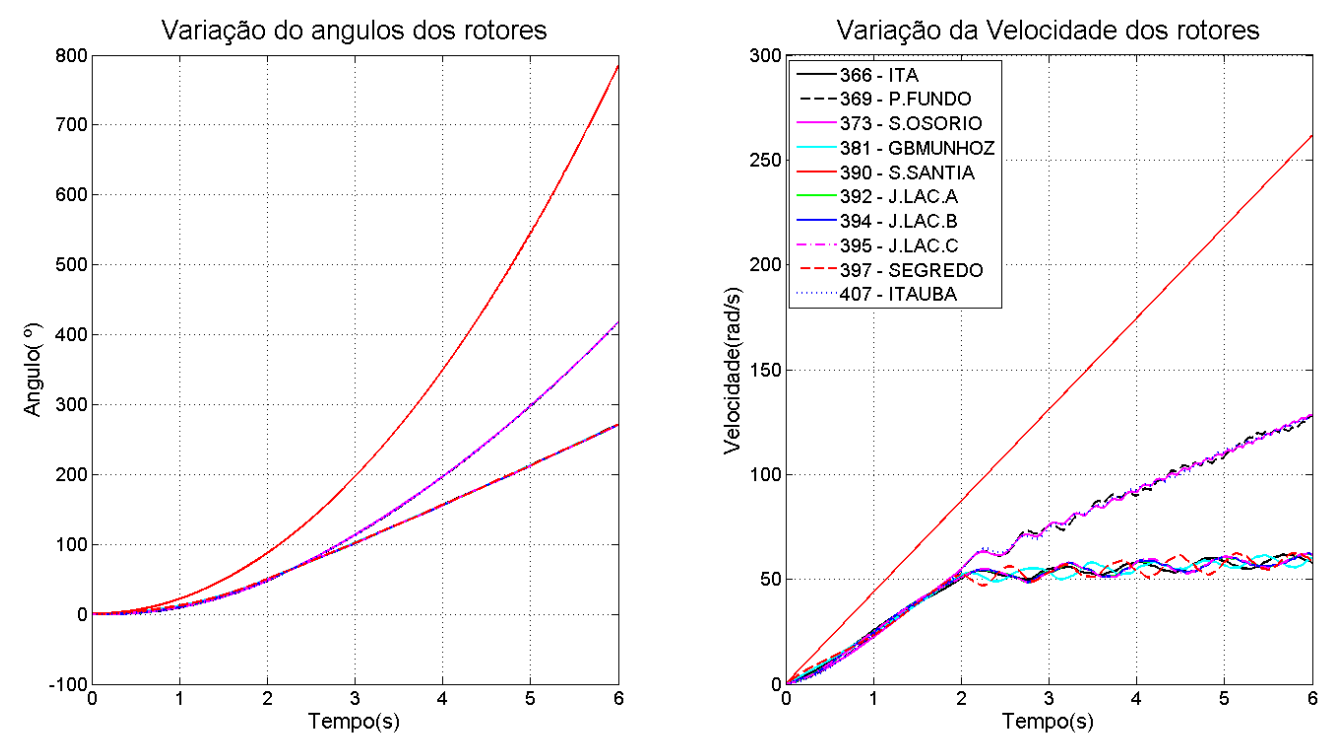

Figura 5.23: Variação do angulo e velocidade dos rotores.

1. Grupo 1: $0,73 \%$

2. Grupo 2: $0,94 \%$

3. Grupo 3: $-11,05 \%$ (Demanda maior que a potência gerada)

- Curto Circuito na linha [barra 390 - barra 391] e curto na barra 391

Um curto circuito trifásico ocorre nas vizinhanças da barra 391, e a falha dura 2 segundos. O defeito e retirado eliminando a linha entre as barras 390 e 391 . Ao simular o sistema sul reduzido na dinâmica, temos que a variação do ângulo e velocidade dos rotores indicam que o sistema é transitoriamente instável, como mostrado na figura (5.23)). Podemos observar a formação de 4 grupos de geradores coerentes:

1. Grupo 1: $\{390\}$;

2. Grupo 2: $\{369,373$ e 407$\}$

3. Grupo 3: $\{366,381$ e 397$\}$

4. Grupo 4: $\{392,394$ e 395$\}$ 

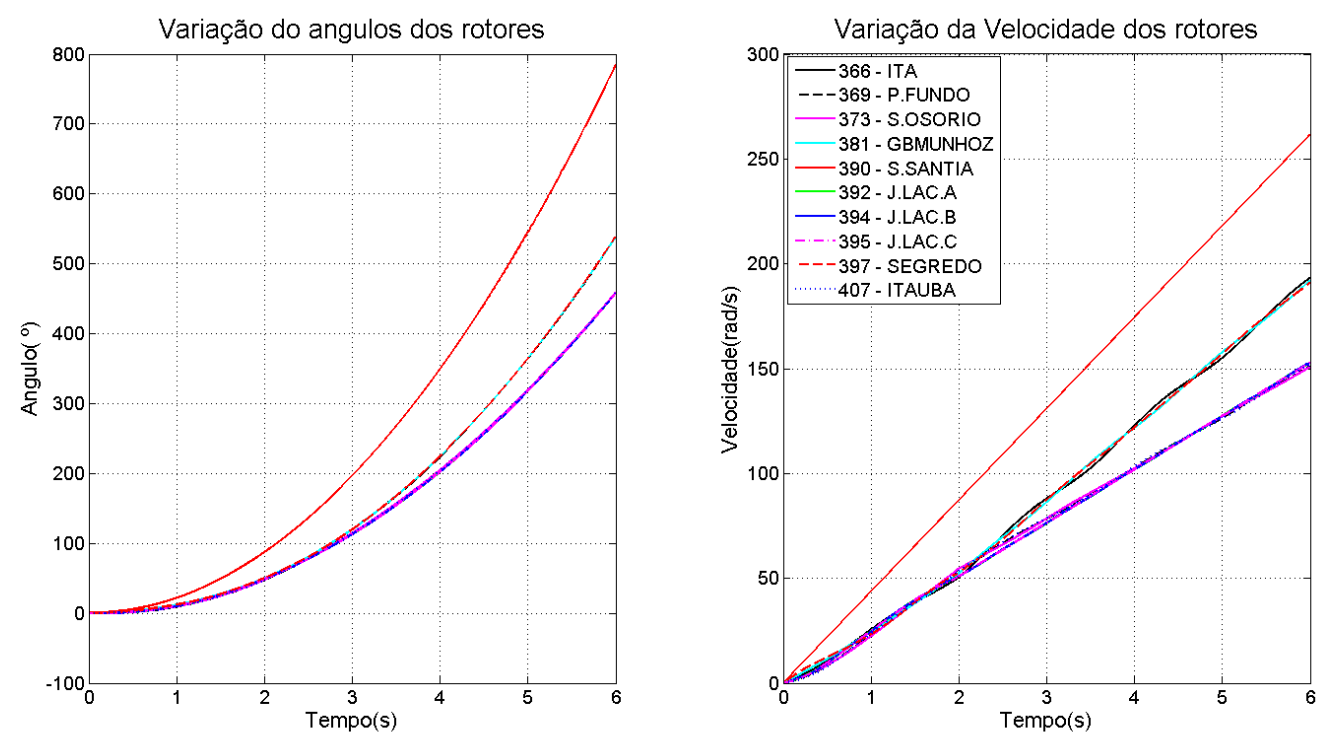

Figura 5.24: Variação do angulo e velocidade dos rotores.

Assumindo que uma estratégia de ilhamento intenciona será implementada com base nesses grupos de geradores coerentes, com um critério de parada igual a 0,1, o algoritmo gera o seguinte o grupo de corte:

1. Grupos de corte: $\{[343$ - 344], [343 - 391], [344 - 431], [367 - 368], [368 - 399], [375 - 382], [376 - 377], [379 - 380], [388 - 414], [390 - 391], [391 - 398], [399 - 414], [430 433], [432-433] \}.

Ao simular a dinâmica do sistema sul reduzido com a implementação da estratégia de ilhamento intencional efetuada após 2 segundos da ocorrência da contingência, temos a variação do ângulo e velocidade dos rotores indicadas na fig (5.24).

Note que para esse cenário os geradores de cada ilha gerada estão coerentes, o que indica que nesse cenário o sistema é transitoriamente estável. O desbalanço de potência em cada ilha gerada pelo grupo de corte é dado abaixo:

1. Grupo 1: $100 \%$

2. Grupo 2: $4,22 \%$

3. Grupo 3: $2,18 \%$ 
4. Grupo 4: $-11,05 \%$ 



\section{Capítulo 6}

\section{Conclusões e Perspectivas Futuras}

\subsection{Introdução}

Neste capítulo, as conclusões parciais deste trabalhos são apresentadas, e as perspectivas futuras para a continuação deste trabalho são discutidas. Também é apresentado um cronograma para as atividades que serão desenvolvidas.

\subsection{Conclusões Parciais}

Neste trabalho foi apresentado um método grafo-algébrico para o planejamento para o ilhamento intencional em sistemas elétricos de potência. Este método é baseado na fatoração triangular inferior ordenada da matriz de incidência nó-ramo $H$. Sua base teórica e sua implementação foi discutida.

Por meio de simulação, foi possível observar que o método foi capaz de gerar estratégias de ilhamentos viáveis para SEPs de pequeno e meio porte. Este método apresentou boas características que sugerem que o mesmo seja adequado para aplicações em tempo real. O método fornece a informação das barras que formam cada ilha, adapta-se facilmente a mudanças na topologia e pode ser facilmente implementado com rotinas já existentes nos programas de computador comumente utilizados para an alise de sistemas elétricos de potência. 
As vantagens deste novo método foram mostradas e testadas em sistemas de pequenas dimensões. As análises dão indícios que o método proposto é adequado para análise de controle corretivo de grandes redes de sistemas de potência, e representa um avanço, no sentido que os conjuntos de corte convenientes são obtidos de forma rápida e fácil pela etapa da fatoração triangular inferior ordenada, evitando problemas de explosão combinatorial.

Ainda é necessário testar essa metodologia em sistemas de maior porte, para avaliar a eficiência computacional do método e comparar com a eficiência de outros métodos relatados na literatura.

\subsection{Perspectivas Futuras}

No futuro, pretende-se aplicar esta metodologia em controle corretivo (formação de ilhas de forma intencional) em sistemas grande porte, incorporar outros critérios na pesquisa de conjuntos de corte e métodos de otimização junto a pesquisa do corte minimal local e avaliar a estabilidade dinâmica do sistema. 


\section{Referências Bibliográficas}

AGHAMOHAMMADI, M. R.; SHAHMOHAMMADI, A. Intentional islanding using a new algorithm based on ant search mechanism. International Journal of Electrical Power and Energy Systems, [S.l.], v.35, n.1, p.138 - 147, 2012.

AHMED, S.; SARKER, N.; KHAIRUDDIN, A.; GHANI, M.; AHMAD, H. A scheme for controlled islanding to prevent subsequent blackout. Power Systems, IEEE Transactions on, [S.1.], v.18, n.1, p.136 - 143, feb 2003.

ARCHER, B.; DAVIES, J. System islanding considerations for improving power system restoration at Manitoba Hydro. In: ELECTRICAL AND COMPUTER ENGINEERING, 2002. IEEE CCECE 2002. CANADIAN CONFERENCE ON, 2002. Anais... [S.l.: s.n.], 2002. v.1, p.60 - 65 vol.1.

BALU, N.; BERTRAM, T.; BOSE, A.; BRANDWAJn, V.; CAUlEY, G.; CURTICE, D.; FOUAD, A.; FINK, L.; LAUBY, M.; WOLLENBERG, B.; WRUBEL, J. On-line power system security analysis. Proceedings of the IEEE, [S.l.], v.80, n.2, p.262 -282 , feb 1992.

BRYANT, R. Graph-Based Algorithms for Boolean Function Manipulation. Computers, IEEE Transactions on, [S.1.], v.C-35, n.8, p.677 -691, aug. 1986.

CHANIOTIS, D.; PAI, M. Model reduction in power systems using Krylov subspace methods. Power Systems, IEEE Transactions on, [S.1.], v.20, n.2, p.888 - 894, may 2005.

CHOW, J. Tim-Scale Modeling of Dynamic Network with Applications to Power Systems. New York: Springer-Verlag, 1982. 
DING, L.; GONZALEZ-LONGATT, F.; WALL, P.; TERZIJA, V. Two-Step Spectral Clustering Controlled Islanding Algorithm. Power Systems, IEEE Transactions on, [S.l.], v.28, n.1, p.75-84, Feb 2013.

GULER, T.; GROSS, G. Detection of Island Formation and Identification of Causal Factors Under Multiple Line Outages. Power Systems, IEEE Transactions on, [S.l.], v.22, n.2, p.505-513, may 2007.

HIYAMA, T. Identification of coherent generators using frequency response. Generation, Transmission and Distribution, IEE Proceedings C, [S.l.], v.128, n.5, p.262 -268, september 1981.

JIN, M.; SIDHU, T.; SUN, K. A new system splitting scheme based on the identification of controlling group. In: FUTURE POWER SYSTEMS, 2005 INTERNATIONAL CONFERENCE ON, 2005. Anais... [S.l.: s.n.], 2005. p.6 pp. -6.

JONSSON, M.; BEGOVIC, M.; DAALDER, J. A new method suitable for real-time generator coherency determination. Power Systems, IEEE Transactions on, [S.l.], v.19, n.3, p.1473 - 1482, aug. 2004.

KOLLURI, S.; MANDAL, S.; GALVAN, F.; THOMAS, M. Island formation in entergy power grid during Hurricane Gustav. In: POWER ENERGY SOCIETY GENERAL MEETING, 2009. PES '09. IEEE, 2009. Anais... [S.1.: s.n.], 2009. p.1 -5.

KUNDUR, P. Power System Stability and Control. New York, NY: McGraw-Hill, 1994. 1176p.

LIU, Y.; LIU, Y. Aspects on Power System Islanding for Preventing Widespread Blackout. In: NETWORKING, SENSING AND CONTROL, 2006. ICNSC '06. PROCEEDINGS OF THE 2006 IEEE INTERNATIONAL CONFERENCE ON, 2006. Anais... [S.l.: s.n.], 2006. p.1090-1095.

LODHA, S.; BHATIA, D. Bipartitioning circuits using TABU search. In: ASIC CONFERENCE 1998. PROCEEDINGS. ELEVENTH ANNUAL IEEE INTERNATIONAL, 1998. Anais. .. [S.l.: s.n.], 1998. p.223 -227. 
LONDON, J.; ALBERTO, L.; BRETAS, N. Analysis of measurement-set qualitative characteristics for state-estimation purposes. Generation, Transmission Distribution, IET, [S.l.], v.1, n.1, p.39-45, january 2007.

MONTICELLI, A. Introdução a sistemas de energia elétrica. Campinas - SP: Editora da UNICAMP, 2003.

NAJAFI, S. Evaluation of interconnected power systems controlled islanding. In: POWERTECH, 2009 IEEE BUCHAREST, 2009. Anais... [S.l.: s.n.], 2009. p.1 -8.

PEIRAVI, A.; ILDARABADI, R. A Fast Algorithm for Intentional Islanding of Power Systems Using the Multilevel Kernel k-Means Approach. Journal of Applied Sciences, [S.l.], v.12, n.9, p.2247-2255, 2009.

SAVULESCU, S. C. Grafos, dígrafos e redes elétricas : aplicações na pesquisa operacional. São Paulo, SP: Instituto Brasileiro de Edições Cientificas, 1980.

SENROY, N. Generator Coherency Using the Hilbert-Huang Transform. Power Systems, IEEE Transactions on, [S.1.], v.23, n.4, p.1701 -1708, nov. 2008.

SOUZA, E. Pires de; SILVA, A. Leite da. An efficient methodology for coherency-based dynamic equivalents [power system analysis]. Generation, Transmission and Distribution, IEE Proceedings C, [S.l.], v.139, n.5, p.371 -382, sep 1992.

SUN, K.; ZHENG, D.-Z.; LU, Q. Splitting strategies for islanding operation of large-scale power systems using OBDD-based methods. Power Systems, IEEE Transactions on, [S.l.], v.18, n.2, p.912 - 923, may 2003.

SUN, K.; ZHENG, D.-Z.; LU, Q. A simulation study of OBDD-based proper splitting strategies for power systems under consideration of transient stability. Power Systems, IEEE Transactions on, [S.l.], v.20, n.1, p.389 - 399, feb. 2005.

SUN, K.; ZHENG, D.-Z.; LU, Q. Searching for feasible splitting strategies of controlled system islanding. Generation, Transmission and Distribution, IEE Proceedings-, [S.1.], v.153, n.1, p.89 - 98, jan. 2006. 
TAYLOR, C.; ERICKSON, D. Recording and analyzing the July 2 cascading outage [Western USA power system]. Computer Applications in Power, IEEE, [S.l.], v.10, n.1, p.26-30, jan 1997.

THADEN, M. Analysis of a major load island outage on the Potomac Electric Power Company system. Power Systems, IEEE Transactions on, [S.l.], v.14, n.1, p.306 -311 , feb 1999.

ThEODORO, E. A. R.; BEnEDito, R. A. S.; LONDON, J. B. A.; AlBERTO, L. F. C. Algebraic-graph method for identification of islanding in power system grids. International Journal of Electrical Power \& Energy Systems, [S.1.], v.35, n.1, p.171 - 179, feb. 2012.

THEODORO, E.; BENEDITO, R.; ALBERTO, L. A fast method for islanding analysis in power system grids. In: CIRCUITS AND SYSTEMS (ISCAS), 2011 IEEE INTERNATIONAL SYMPOSIUM ON, 2011. Anais... [S.l.: s.n.], 2011. p.1856 -1859.

TINNEY, W.; BRANDWAJN, V.; CHAN, S. Sparse Vector Methods. Power Apparatus and Systems, IEEE Transactions on, [S.l.], v.PAS-104, n.2, p.295 -301, feb. 1985.

TSAI, M.-S. Development of islanding early warning mechanism for power systems. In: POWER ENGINEERING SOCIETY SUMMER MEETING, 2000. IEEE, 2000. Anais... [S.l.: s.n.], 2000. v.1, p.22 -26 vol. 1.

VITTAL, V.; HEYDT, G. The problem of initiating controlled islanding of a large interconnected power system solved as a Pareto optimization. In: POWER SYSTEMS CONFERENCE AND EXPOSITION, 2009. PSCE '09. IEEE/PES, 2009. Anais... [S.l.: s.n.], 2009. p.1 -7 .

WANG, X.; VITTAL, V. System islanding using minimal cutsets with minimum net flow. In: POWER SYSTEMS CONFERENCE AND EXPOSITION, 2004. IEEE PES, 2004. Anais... [S.l.: s.n.], 2004. p.379 - 384 vol.1.

YOU, H.; VITTAL, V.; WANG, X. Slow coherency-based islanding. Power Systems, IEEE Transactions on, [S.l.], v.19, n.1, p.483 - 491, feb. 2004. 
ZHANG, Y.; TINNEY, W. Partial refactorization with unrestricted topology changes. Power Systems, IEEE Transactions on, [S.l.], v.10, n.3, p.1361 -1368, aug 1995.

ZHAO, Q.; SUN, K.; ZHENG, D.-Z.; MA, J.; LU, Q. A study of system splitting strategies for island operation of power system: a two-phase method based on obdds. Power Systems, IEEE Transactions on, [S.l.], v.18, n.4, p.1556 - 1565, nov. 2003. 


\section{Apêndice A}

\section{Dados do SEP Estudado}

O dados de linha e os dados de barra do Sistema Sul Brasileiro Equivalente reduzido da fig. (5.14), composto por 10 geradores, 17 transformadores e 40 linhas de transmissão, usado no Capitulo 5 para exemplificar a aplicação do método para projeto de ilhamento controlado são apresentado na tabelas (A.1) e (A.2). A potência base utilizada é de 100 MVA.

\begin{tabular}{|c|c|c|c|c|c|c|c|c|c|}
\hline \multirow{2}{*}{ Barra } & \multirow{2}{*}{ Tipo } & \multirow{2}{*}{$\begin{array}{c}\text { Tensão } \\
(p . u .)\end{array}$} & \multirow{2}{*}{$\begin{array}{c}\text { Ângulo } \\
\left({ }^{\circ}\right)\end{array}$} & \multirow{2}{*}{$\begin{array}{c}\text { Pot. Mec. } \\
\text { Injetada (MW) }\end{array}$} & \multicolumn{2}{|c|}{ Carga } & \multirow{2}{*}{$\begin{array}{l}\text { Shunt } \\
(\text { p.u. })\end{array}$} & \multirow{2}{*}{$\begin{array}{c}\text { Reat. } \\
\text { Trans. } \\
\text { (p.u.) } \\
\end{array}$} & \multirow{2}{*}{$\begin{array}{l}\text { Constante } \\
\text { de Inercia } \\
\left(\mathrm{s}^{2}\right)\end{array}$} \\
\hline & & & & & MW & MVAr & & & \\
\hline 1 & Carga & 1,034 & $-6,9$ & 0 & 0 & 0 & $-2,5$ & 0 & 0 \\
\hline 2 & Carga & 1,025 & $-9,3$ & 0 & 0 & 0 & 0 & 0 & 0 \\
\hline 3 & Gerador & 1,02 & $-6,7$ & 650 & 0 & 0 & 0 & 0,0457 & 0,198 \\
\hline 4 & Carga & 0,974 & -32 & 0 & 177 & 68 & 0 & 0 & 0 \\
\hline 5 & Carga & 1,02 & -34 & 0 & 191 & 42 & 0 & 0 & 0 \\
\hline 6 & Gerador & 1,04 & -14 & 215 & 0 & 0 & 0 & 0,0985 & 0,0599 \\
\hline 7 & Carga & 1,022 & -19 & 0 & 171 & 18,5 & 0 & 0 & 0 \\
\hline 8 & Carga & 0,999 & -16 & 0 & 126 & 47 & 0 & 0 & 0 \\
\hline 9 & Carga & 0,997 & -10 & 0 & 46 & 14,7 & 0 & 0 & 0 \\
\hline 10 & Gerador & 1,02 & 3,07 & 895 & 0 & 0 & 0 & 0,03 & 0,2094 \\
\hline 11 & Carga & 1,015 & $-2,6$ & 0 & 281 & 56,5 & 0 & 0 & 0 \\
\hline
\end{tabular}




\begin{tabular}{|c|c|c|c|c|c|c|c|c|c|}
\hline 12 & Carga & 1,016 & -11 & 0 & 279 & 60,7 & 0 & 0 & 0 \\
\hline 13 & Carga & 1,014 & -21 & 0 & 130 & 29,4 & 0 & 0 & 0 \\
\hline 14 & Carga & 1,026 & -21 & 0 & 427 & -25 & 0 & 0 & 0 \\
\hline 15 & Carga & 0,972 & -27 & 0 & 310 & 141 & 0 & 0 & 0 \\
\hline 16 & Carga & 1,002 & -26 & 0 & 424 & 90,6 & 0 & 0 & 0 \\
\hline 17 & Carga & 0,993 & -28 & 0 & 117 & 53,1 & 0 & 0 & 0 \\
\hline 18 & Slack & 1,022 & 0 & 1530 & 0 & 0 & 0 & 0,018 & 0,3947 \\
\hline 19 & Carga & 1,035 & $-5,6$ & 0 & 0 & 0 & 0 & 0 & 0 \\
\hline 20 & Carga & 1,029 & -19 & 0 & 0 & 0 & $-0,6$ & 0 & 0 \\
\hline 21 & Carga & 1,033 & -17 & 0 & 368 & 59,6 & 0 & 0 & 0 \\
\hline 22 & Carga & 1,011 & -24 & 0 & 0 & 0 & 0 & 0 & 0 \\
\hline 23 & Carga & 1,029 & -11 & 0 & 174 & -8 & -1 & 0 & 0 \\
\hline 24 & Carga & 1,026 & -29 & 0 & 0 & 0 & $-1,5$ & 0 & 0 \\
\hline 25 & Carga & 1,027 & -23 & 0 & 0 & 0 & $-1,5$ & 0 & 0 \\
\hline 26 & Carga & 1,032 & $-9,7$ & 0 & 0 & 0 & $-1,7$ & 0 & 0 \\
\hline 27 & Gerador & 1,018 & 6,93 & 1325 & 0 & 0 & 0 & 0,0215 & 0,3039 \\
\hline 28 & Carga & 1,035 & $-1,3$ & 0 & 0 & 0 & 0 & 0 & 0 \\
\hline 29 & Gerador & 1,03 & -24 & 90 & 0 & 0 & 0 & 0,135 & 0,0189 \\
\hline 30 & Carga & 1 & -28 & 0 & 125 & 39,8 & 0 & 0 & 0 \\
\hline 31 & Gerador & 1,03 & -23 & 120 & 0 & 0 & 0 & 0,1535 & 0,0268 \\
\hline 32 & Gerador & 1,03 & -21 & 241 & 0 & 0 & 0 & 0,1007 & 0,0514 \\
\hline 33 & Carga & 1,005 & -27 & 0 & 0 & 0 & 0 & 0 & 0 \\
\hline 34 & Gerador & 1,02 & 2,72 & 1100 & 0 & 0 & 0 & 0,0184 & 0,2739 \\
\hline 35 & Carga & 1,032 & $-1,4$ & 0 & 0 & 0 & 0 & 0 & 0 \\
\hline 36 & Carga & 1,029 & -33 & 0 & 813 & 110 & 0 & 0 & 0 \\
\hline 37 & Carga & 1,039 & -32 & 0 & 612 & -455 & 0 & 0 & 0 \\
\hline 38 & Gerador & 1,02 & -14 & 460 & 0 & 0 & 0 & 0,055 & 0,1079 \\
\hline 39 & Carga & 1,002 & -20 & 0 & 404 & 135 & 0 & 0 & 0 \\
\hline 40 & Carga & 1,033 & -25 & 0 & 393 & -111 & 0 & 0 & 0 \\
\hline 41 & Carga & 0,992 & -15 & 0 & 262 & 13,2 & 0 & 0 & 0 \\
\hline 42 & Carga & 1,01 & -11 & 0 & 229 & 183 & 0 & 0 & 0 \\
\hline 43 & Carga & 0,982 & -15 & 0 & 184 & 60,2 & 0 & 0 & 0 \\
\hline 44 & Carga & 0,979 & -13 & 0 & 139 & 53,7 & 0 & 0 & 0 \\
\hline 45 & Carga & 0,972 & -32 & 0 & 90,1 & 55,3 & 0 & 0 & 0 \\
\hline
\end{tabular}

Tabela A.1: Dados de barra Pré-Falta. 


\begin{tabular}{|c|c|c|c|c|c|}
\hline Linha & Barra Origem & Barra Destino & $\begin{array}{l}\text { Resist. } \\
\text { (p.u.) }\end{array}$ & $\begin{array}{l}\text { Reat. } \\
(p . u .)\end{array}$ & $\begin{array}{l}\text { Suscept. } \\
\quad \text { (p.u.) }\end{array}$ \\
\hline 1 & 1 & 2 & 0.0003 & 0.00725 & 3.322 \\
\hline 2 & 1 & 19 & 0.0018 & 0.0227 & 2.2721 \\
\hline 3 & 1 & 28 & 0.0014 & 0.0204 & 2.4475 \\
\hline 4 & 2 & 42 & 0 & 0.0063 & 0 \\
\hline 5 & 3 & 23 & 0 & 0.0135 & 0 \\
\hline 6 & 4 & 5 & 0.0386 & 0.1985 & 0.34 \\
\hline 7 & 4 & 33 & 0.0096 & 0.0491 & 0.0842 \\
\hline 8 & 4 & 45 & 0.0033 & 0.0167 & 0.2859 \\
\hline 9 & 5 & 7 & 0.02315 & 0.1689 & 0.8168 \\
\hline 10 & 5 & 36 & 0.0059 & 0.03033 & 0.4755 \\
\hline 11 & 6 & 7 & 0 & 0.046 & 0 \\
\hline 12 & 7 & 8 & 0.00815 & 0.04175 & 0.288 \\
\hline 13 & 7 & 39 & 0.025 & 0.1648 & 0.469 \\
\hline 14 & 8 & 9 & 0.0163 & 0.0835 & 0.144 \\
\hline 15 & 8 & 11 & 0.0316 & 0.1621 & 0.2784 \\
\hline 16 & 9 & 11 & 0.0153 & 0.0861 & 0.1344 \\
\hline 17 & 10 & 11 & 0 & 0.0114 & 0 \\
\hline 18 & 11 & 12 & 0.0306 & 0.1523 & 0.2702 \\
\hline 19 & 11 & 44 & 0.0172 & 0.088 & 0.608 \\
\hline 20 & 12 & 13 & 0.0245 & 0.1256 & 0.2041 \\
\hline 21 & 12 & 19 & 0 & 0.03 & 0 \\
\hline 22 & 13 & 14 & 0.0088 & 0.0415 & 0.5211 \\
\hline 23 & 14 & 15 & 0.0091 & 0.04675 & 0.319 \\
\hline 24 & 14 & 20 & 0 & 0.0062 & 0 \\
\hline 25 & 15 & 16 & 0.0077 & 0.0388 & 0.27 \\
\hline 26 & 16 & 17 & 0.0108 & 0.05525 & 0.3726 \\
\hline 27 & 16 & 22 & 0 & 0.0062 & 0 \\
\hline 28 & 17 & 33 & 0.009 & 0.046 & 0.3106 \\
\hline 29 & 18 & 19 & 0 & 0.0067 & 0 \\
\hline 30 & 19 & 20 & 0.0019 & 0.028 & 3.3576 \\
\hline 31 & 19 & 21 & 0.0019 & 0.0274 & 3.2867 \\
\hline 32 & 19 & 23 & 0.0014 & 0.0195 & 2.3968 \\
\hline
\end{tabular}




\begin{tabular}{|c|c|c|c|c|c|}
\hline 33 & 19 & 35 & 0.0005 & 0.007 & 0.8392 \\
\hline 34 & 20 & 21 & 0.0005 & 0.0069 & 0.8215 \\
\hline 35 & 20 & 22 & 0.0012 & 0.0175 & 2.097 \\
\hline 36 & 23 & 24 & 0.0021 & 0.0309 & 3.7183 \\
\hline 37 & 24 & 37 & 0 & 0.0062 & 0 \\
\hline 38 & 25 & 26 & 0.0022 & 0.03 & 3.83 \\
\hline 39 & 25 & 40 & 0 & 0.062 & 0 \\
\hline 40 & 26 & 28 & 0.0014 & 0.0195 & 2.397 \\
\hline 41 & 27 & 28 & 0 & 0.0114 & 0 \\
\hline 42 & 28 & 35 & 0.0005 & 0.007 & 0.8392 \\
\hline 43 & 29 & 30 & 0 & 0.0871 & 0 \\
\hline 44 & 30 & 33 & 0 & 0.059 & 0 \\
\hline 45 & 31 & 33 & 0 & 0.0701 & 0 \\
\hline 46 & 32 & 33 & 0 & 0.045 & 0 \\
\hline 47 & 33 & 45 & 0.0129 & 0.0657 & 0.1128 \\
\hline 48 & 34 & 35 & 0 & 0.0068 & 0 \\
\hline 49 & 36 & 37 & 0.0007 & 0.00358 & 0.0668 \\
\hline 50 & 36 & 40 & 0.00613 & 0.03162 & 0 \\
\hline 51 & 38 & 39 & 0 & 0.0236 & 0 \\
\hline 52 & 39 & 40 & 0.0202 & 0.1129 & 0.2062 \\
\hline 53 & 41 & 42 & 0.00528 & 0.02979 & 0.1905 \\
\hline 54 & 41 & 43 & 0.011 & 0.1184 & 0.2027 \\
\hline 55 & 41 & 44 & 0.0229 & 0.1174 & 0.2027 \\
\hline 56 & 42 & 43 & 0.0086 & 0.0442 & 0.2868 \\
\hline 57 & 43 & 44 & 0.0181 & 0.0929 & 0.1607 \\
\hline
\end{tabular}

Tabela A.2: Dados de Linha. 